\title{
Vessel Relocation Strategy for Multiple Steel Catenary Riser Fatigue Damage Mitigation
}

\author{
Achoyamen Michael Ogbeifun*a, Selda Oterkus ${ }^{a}$, Julia Race ${ }^{a}$, Harit Naik ${ }^{b}$, Dakshina Moorthyc, \\ Subrata Bhowmik ${ }^{\mathrm{b}}$, Julie Ingram ${ }^{\mathrm{c}}$.
}

aDepartment of Naval Architecture, Ocean and Marine Engineering, University of Strathclyde, 100 Montrose Street, Glasgow, G4 0LZ, UK; ${ }^{b}$ McDermott International, 40 Eastbourne Terrace, Paddington, London, W2 6LG, UK; ' McDermott International, 757 N. Eldridge Parkway, Houston, TX 77079, USA.

*corresponding author; e-mail: achoyamen.ogbeifun@strath.ac.uk, phone: +44 7414517860

\begin{abstract}
In previous work, the vessel relocation methodology for a single steel catenary riser (SCR) was developed to extend the fatigue life of the SCR touchdown zone (TDZ). The method was developed considering symmetrical vessel relocation programs, where the vessel offsets about the nominal station in all directions is equal. However, in actual field applications, the production platform hosts multiple SCRs of different azimuth, cross-section geometry and global configurations. Also, the symmetrical relocation consideration eliminates the potentials of exploring non-symmetrical relocation patterns that may be suitable candidate solutions. These considerations add complexity to the problem since, for example, each of the SCR may have unique optimum relocation programs (ideal solutions), but one global optimum solution is required. In this work, we extend the symmetrical relocation method and apply the index matching technique to solve the multi-objective optimization problem. The non-symmetrical relocation of this methodology for multiple SCRs is demonstrated by comparing the global optimum solutions with those of the no-relocation case. The developed approach can be applied to new and existing SCRs for life extension purposes.
\end{abstract}

Keywords: Steel catenary riser, Touch-down zone, Vessel relocation, fatigue damage, fatigue damage spreading, relocation program

\section{INTRODUCTION}

Steel catenary riser (SCR) systems are used to transport hydrocarbon production-related materials between the seabed and the host floating platform. SCRs are the most attractive riser solution likely because of their simplicity, robustness, and lower procurement costs [1-6]. A significant challenge with SCR application is the high stress and fatigue damage incurred around its critical sections: the hang off (HO) and the TDZ [5, 7-9], which are depicted in Figure 1. The high fatigue response in the SCR HO region is relatively easier to control than those occurring at the TDZ. At the HO region, suitable high strength materials can be employed to reduce the high stress and fatigue damage experienced. However, at the touchdown zone, a more extended section of the SCR interacts in a complex way with the seabed, resulting in high and intricate fatigue response patterns that pose significant challenges to manage. Relevant research institutions and offshore industries have committed several efforts to increase the application of SCRs for deepwater hydrocarbon extraction by developing new solutions to address the SCR challenges. These solutions include the SCR configuration change, alternative riser pipe material application, increased understanding of riser soil interactions, decoupled SCRs, upset pipe end, hydrodynamic dampers, vessel relocation, etc. 


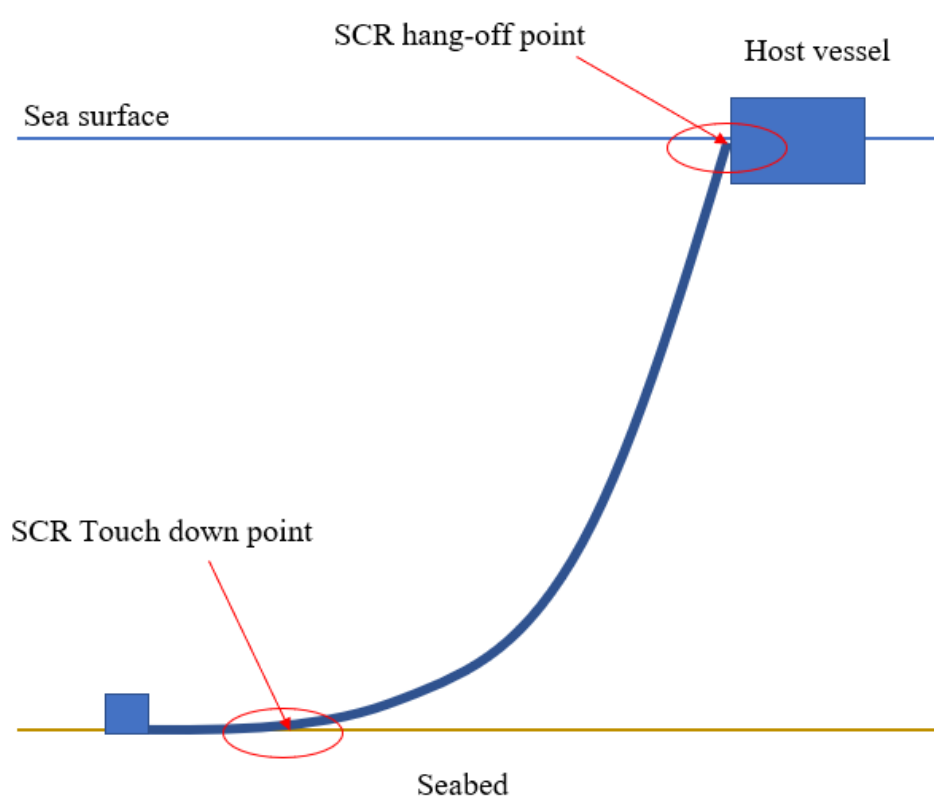

Figure 1. Steel catenary riser schematic showing critical sections where stress and fatigue damage responses are higher.

SCR configuration can be changed to obtain steel lazy wave risers (SLWR) and shaped risers [10-15]. This will require the installation of buoyancy modules on the section of the SCR. The buoyancy modules provide an uplifted section on the SCR, making it more compliant to external forces, reducing stresses and fatigue damage. Hydrodynamic dampers can also be installed on the SCR to enhance its ability to dampen out stress waves propagated from vessel motion to the SCR TDZ [16]. The application of alternative materials for SCR pipes can provide increased strength and resistance to corrosion. An example of such material is titanium [2, 17-20], which can significantly improve the SCR ability to accommodate considerable stress and fatigue damage considering its high flexural rigidity. Many advancements have been made in riser soil interaction modelling, such as developing non-linear riser soil interaction models [21-23]. With these models, better understandings of the complex interactions between the SCR TDZ are being acquired and explored more accurately. Also, new SCR concepts are developed where the SCRs are not directly tied to the floating vessel but through flexible pipe jumpers. An example is the uncoupled steel catenary riser systems [24, 25]. Decoupling the SCR from the vessel motion reduces the dynamic top tension, TDZ stress, and fatigue damage. The use of upset pipe end (thicker pipe sections at welded joints) and titanium welding connection for deepwater SCR are now being explored to improve the fatigue life of the riser at critical joints $[19,26]$. Vessel relocation involves the movement of the riser host platform from one location or station to another to enhance the fatigue damage spreading over a longer section of the SCR TDZ[27-30]. Fatigue damage reduction can be achieved in this case compared with the case where the vessel has no relocation. The spreading of the fatigue damage is based on reduction of the exposure time of the TDZ to the fatugue load effect.

The vessel relocation solution for fatigue mitigation in the SCR TDZ has been referenced in literature and have been implemented in real-life projects [27-30]. However, a formal methodology for assessing the optimum vessel relocation program is still absent from open literature. In the context of this work, this vessel movement is required to enhance the spread of the SCR TDZ fatigue damage over a more extended section of the SCR TDZ, resulting in an effective reduction of the damage when compared with those of the SCRs that are not involved in vessel relocation. The SCR TDZ fatigue damage is affected by the fatigue load 
exposure time and the variation in the riser configuration during the application of the fatigue load. While the movement and direction of movement of the vessel affect the SCR TDZ configuration, the number of relocation stations affects the exposure time to the fatigue load. The wider the variation or spread in the location of the fatigue hot spot of the SCR TDZ, the lower the resulting fatigue exposure time and a consequent increase in the reduction of the SCR TDZ fatigue damage. However, the vessel movements during the relocation activities are limited by the design storm responses of the SCRs, which imposes constraints on the optimisation problem.

This study is the sequel to previous work on symmetrical vessel relocation methodology for a single SCR (see Figure 2 (a)) [31]. In that work, the relocation optimisation methodology was developed based on three primary design variables, which are the axis of relocation $(\alpha)$, the span radius of relocation $(R)$ and the number of relocation stations $(p)$. The optimum combination of these variables was obtained through the optimisation solution process, where the effective fatigue damage $\left(D_{e f f}\right)$ was the objective function and the SCR design storm responses (stress utilization around TDZ $(U)$, top tension $\left(T_{\text {top }}\right)$ and TDZ compression $\left(T_{T D Z}\right)$ ) were the constraint functions. The index matching optimisation technique was applied to solve the optimization problem, and the following deductions were made from the single SCR symmetrical vessel relocation analysis example:

- For a given $p$, the exposure time over the design life of the riser does not change irrespective of the $\alpha$ and the $R$. However, both $\alpha$ and $R$ affect the configuration of the risers, which in turn impacts the fatigue damage.

- The number of cycles of relocations $(N)$ over the design life of the riser $\left(T_{D}\right)$ does not affect the cumulated fatigue exposure time of the SCR TDZ across the relocation stations. Hence, increasing $N$ will not positively impact the riser fatigue life but can, however, increase the cost associated with the relocation operation.

- Considering the constraint functions imposed by the riser storm responses, the optimum $\alpha$ may not be the riser azimuth direction or riser plane as is generally believed. The decision to obtain optimum $\alpha$ is sensitive to the constraint functions and the fluctuating bending stress of the SCR across the stations in that direction.

- Increasing $R$ will result in increased variation in the SCR TDZ hot spots, which will enhance the fatigue damage spreading and reduction in $D_{\text {eff }}$. However, $R$ is significantly limited by the constraint functions, which are the design storm responses of the SCR. Higher $R$ values can cause large compression, stress utilization and fatigue damage in the SCR TDZ when the vessel is relocated to stations on the extreme near side of the riser.

- The reduction in the SCR TDZ fatigue damage increases with increasing $p$. However, the higher the value of $p$, the higher will be the number of relocations $(n)$ of the vessel over the riser design life, and hence the increased cost of the relocation program. Therefore, a practical $p$ value should be selected with relocation program cost consideration.

A real scenario involves relocating a floating platform hosting several riser systems, like the vessel-SCR layout in Figure 2 (b), causing complex SCR TDZ offsets. To demonstrate this, we monitor the SCR TDP as the vessel is relocated from the nominal station to stations at distances of $7 \%$ of the water depth, along the six relocation axes shown in Figure 2 (b). The resulting TDPs locations due to the vessel offset are compared with the TDPs when no vessel relocation is applied. The 7\% vessel offset selected here is for demonstration purposes. As will be seen in 
the main analysis part of this study, the vessel offset values are limited or decided by the constraint function defined by the SCR TDZ stress utilisation, compression, and top tension. In this demonstration, the risers have the same cross-section properties and hang off angles $\left(12^{\circ}\right)$ and are hosted by the vessel in a water depth of $1500 \mathrm{~m}$. The numerical analyses in this demonstration and other parts of this study are conducted using the OrcaFlex software, with modelling and post-processing often automated using MATLAB scripts. As a result of the vessel movement, the active seabed sections of the six SCRs will experience different degrees of spatial variation compared to the nominal configuration. The six SCR TDP offsets from their nominal position when the vessel is relocated towards the vessel portside for relocation axes $(1,2,3,5,6)$ and towards the stern (axis 4 ) are presented in Figure 3 (a). Similarly, the six SCR TDP offsets from their nominal position when the vessel is relocated towards the vessel starboard for relocation axes $(1,2,3,5,6)$ and towards the bow (axis 4$)$ are presented in Figure 3 (b). For both sets of vessel relocation directions, it is observed that if the axis of relocation relative to a given riser is in the riser far direction, a longer section of the riser will be hanging, meaning the TDP arc length position will be longer than the nominal TDP arc length. For this condition, the TDP offsets $\left(L_{T D P}-L_{n o m}\right)$ will be positive. This is observed for SCR-4,5,6 for vessel offset towards the vessel port side and SCR 1, 2, 3 for vessel offset towards the starboard side. The converse is the case when the vessel is relocated in the near direction of the risers, where more sections of the riser will rest on the seabed with a resulting shorter TDP arclength compared with the nominal. For this case, $\left(L_{T D P}-L_{n o m}\right)$ will be negative as observed for SCR-1,2,3 for vessel relocation towards the portside, and SCR-4,5,6 for vessel relocation towards the starboard. It is also observed that for vessel relocations in the riser far direction, $\left|L_{T D P}-L_{n o m}\right|$ values are higher than $\left|L_{n o m}-L_{T D P}\right|$ for vessel offsets in the risers near direction. Also, if the relocation axis is close to or out of the riser plane direction, there is insignificant variation in the TDP location compared with the nominal TDP. This is observed for SCR-4 for relocations along the $60^{\circ}$ axis, SCR-2 for relocations along the $90^{\circ}$ axis and SCR3 for relocations along the $120^{\circ}$ relocation axis. The overall variation in the TDP location $(\triangle T D P)$ caused by the vessel offset in both the far and near directions of the risers are presented in Figure 4 (a) - (d). One could see, in general, that while the TDP variation for the SCR is maximum for some relocation axis, it can even be zero for another axis. For example, SCR-2, SCR-3 and SCR-4 experience maximum variations in TDP location for relocation axis-1 $\left(0^{0}\right)$, axis-2 $\left(30^{\circ}\right)$, and axis-6 $\left(150^{\circ}\right)$ respectively, but each experience no variation of TDP for vessel relocation along axis-4 $\left(90^{\circ}\right)$, axis-5 $\left(120^{\circ}\right)$ and axis-3 $\left(60^{\circ}\right)$ respectively. This implies that for a given relocation axis, while some risers enjoy the maximum variation in TDZ fatigue hot spot, other risers may benefit very little in TDZ hots spot variation. It is, therefore, obvious that the influence on SCR TDZ fatigue hots spot spreading for this simple demonstrated relocation pattern is not directly apparent. 
(a)

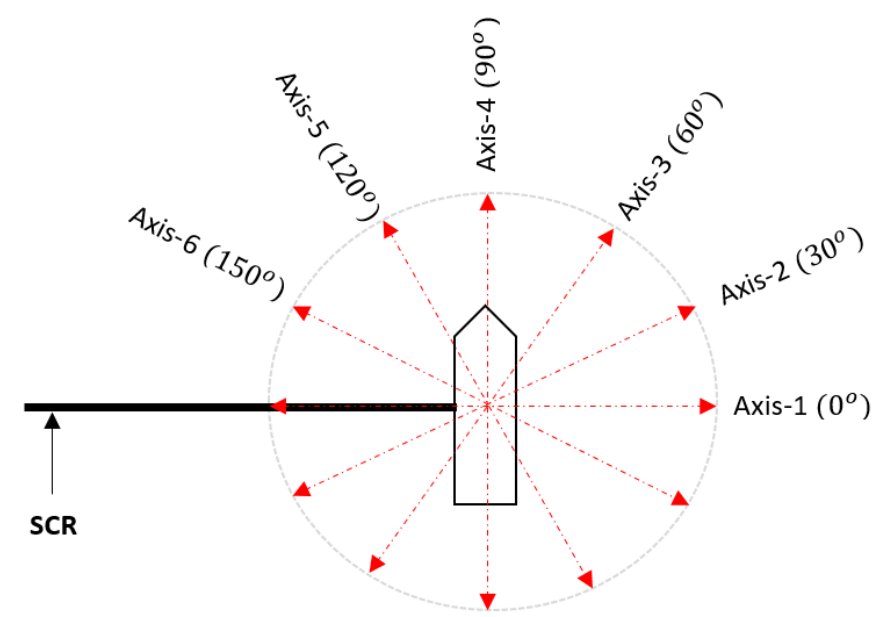

(b)

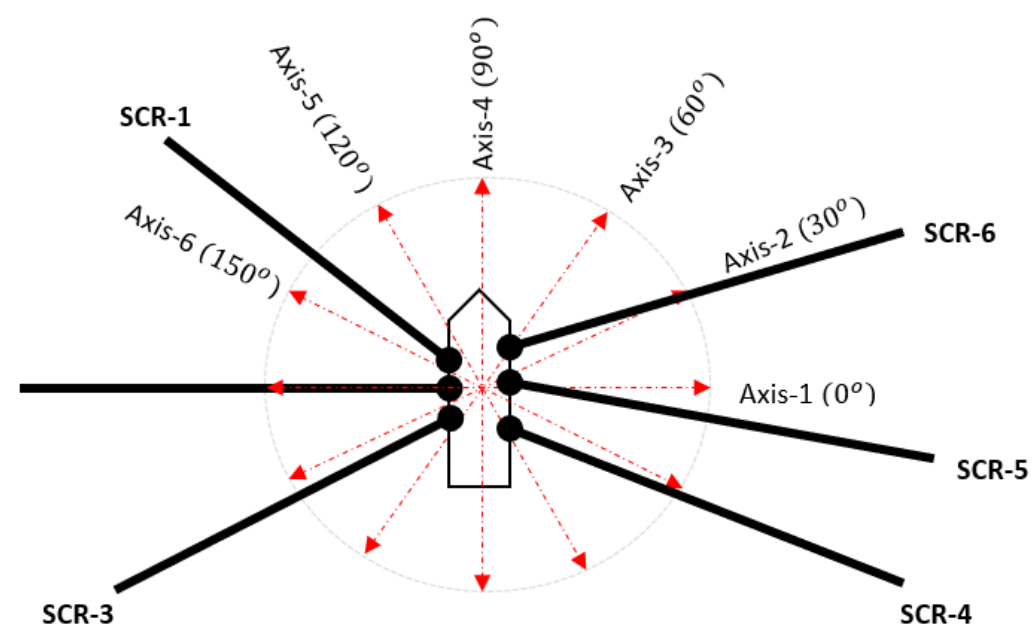

Figure 2. (a) Vessel relocation axes for (a) single SCR system, (b) Multiple SCR systems. 
(a)

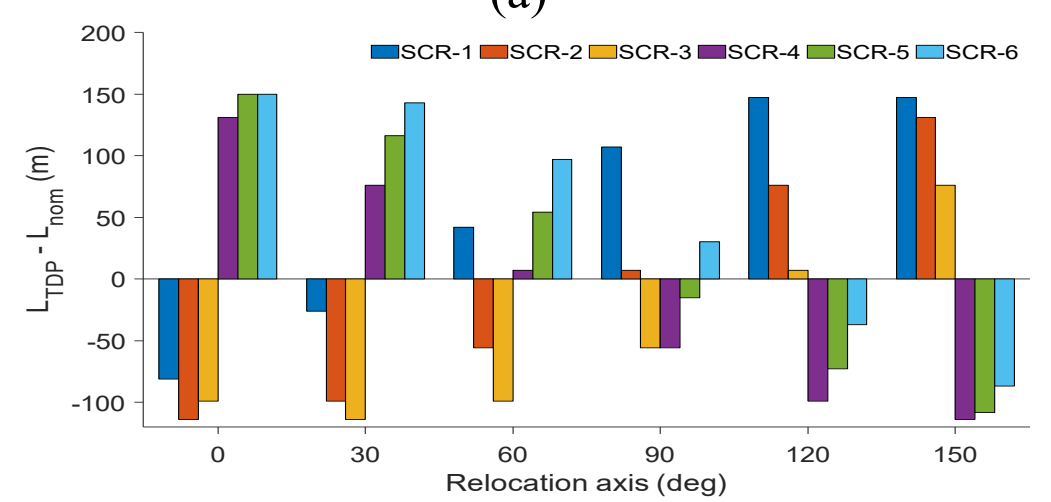

(b)

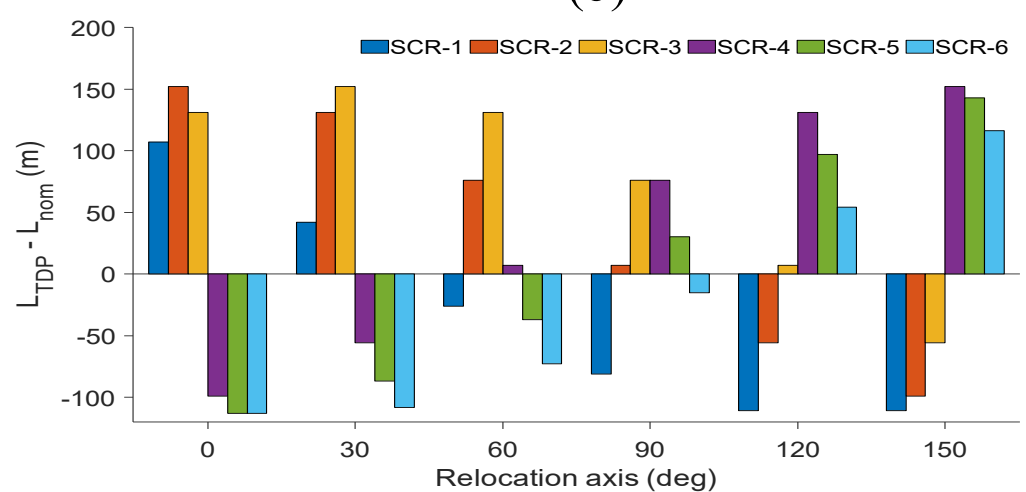

Figure 3. SCR TDP offsets from their nominal position for 7\% vessel offset (a) towards the portside (along axes-1,2,3,5,6), and stern (along axis-4); (b) towards the starboard (along axes-1,2,3,5,6, and bow (along axis-4).

(a)
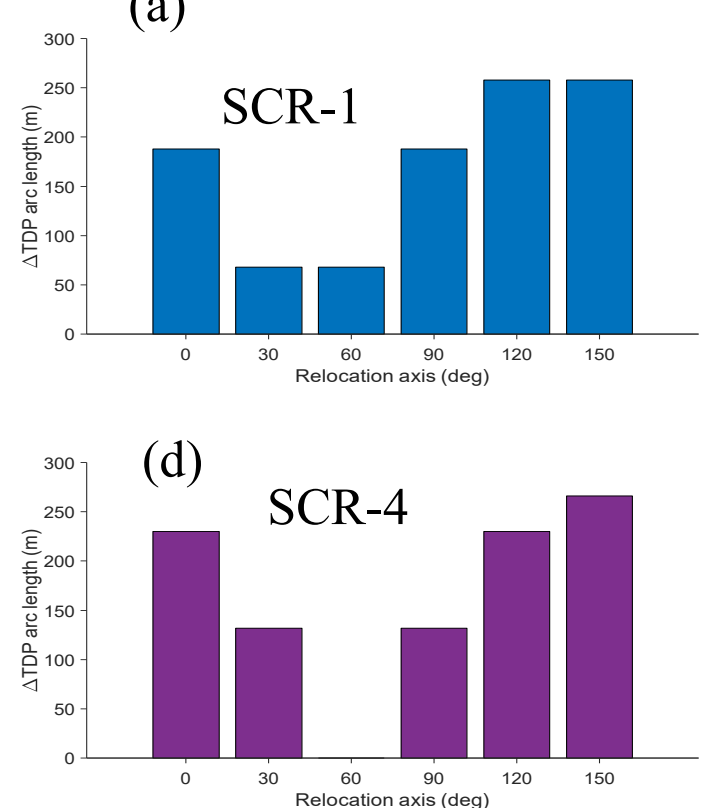

(b)

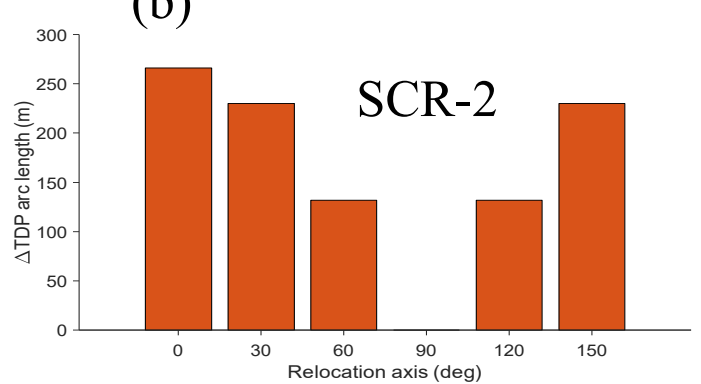

${ }^{300} 7(\mathrm{e})$

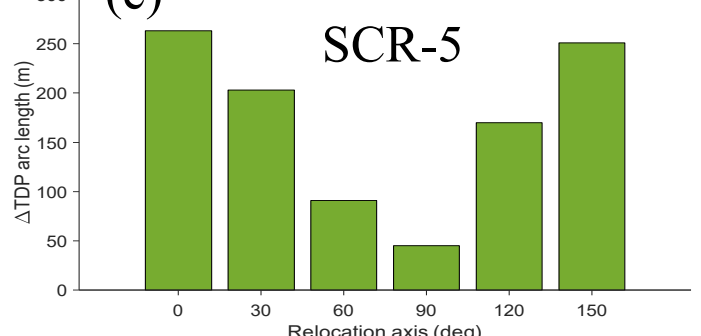

(c)

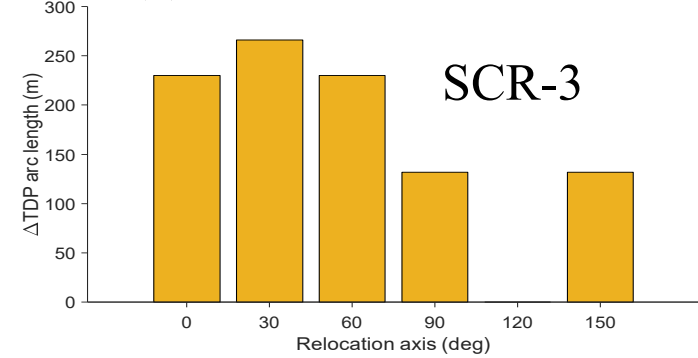

(f)

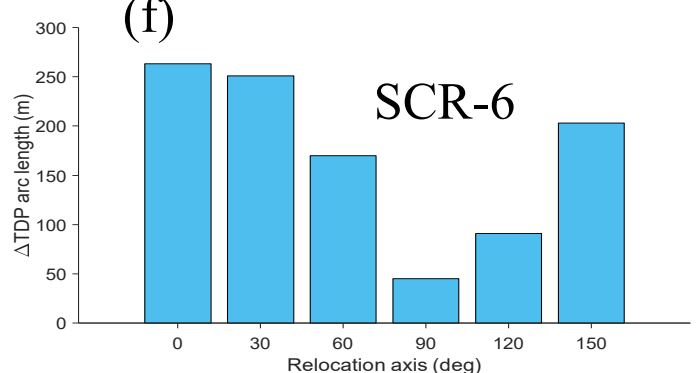

Figure 4. Resulting overall change in SCRs' TDP between vessel far and near offsets for (a) SCR-1, (b) SCR-2, (c) SCR-3, (d) SCR-4, (e) SCR-5, (f) SCR-6. 
Considering risers with different hang off angles, different azimuths, and vessel offsets patterns, it becomes clear that determining the best relocation program will not be an easy task. However, this study addresses this challenge by providing a methodology to assess a group of optimum relocations programs from which all risers benefit best in terms of the SCR TDZ fatigue damage reduction. For such a scenario, the objective and constraint functions are multiples of the number of risers. Hence, there will not be a unique relocation program or combination of $(\alpha, R, p)$ that will be the optimal solution, but a family of optimum relocation programs, which will best satisfy the objective function for all the risers.

\section{VESSEL RELOCATION STRATEGY}

\subsection{Definition of terms relevant to the modelling of vessel relocation programs}

\subsubsection{Relocation program}

A relocation program in the context of this study is the combination of vessel relocation variables, namely: the axis of relocation $(\alpha)$, the relocation span radii $\left(R: R_{1}, R_{2}\right)$ and the number of relocation stations $(p)$. The relocation programs can also be referred to as the design points in the optimisation design space for the problem. The number of numerical models representing the design points simulated to evaluate the objective and constraint functions will depend on the size and the discretisation of the optimisation design space.

\subsubsection{Vessel relocation axis}

In this work, we consider vessel relocation programs in straight lines known as the relocation axes. A relocation axis is characterised by angle $\alpha$ measured from a suitable referenced line, as shown in Figure 5. The axis extends from one limit to another on the respective sides of the vessel.

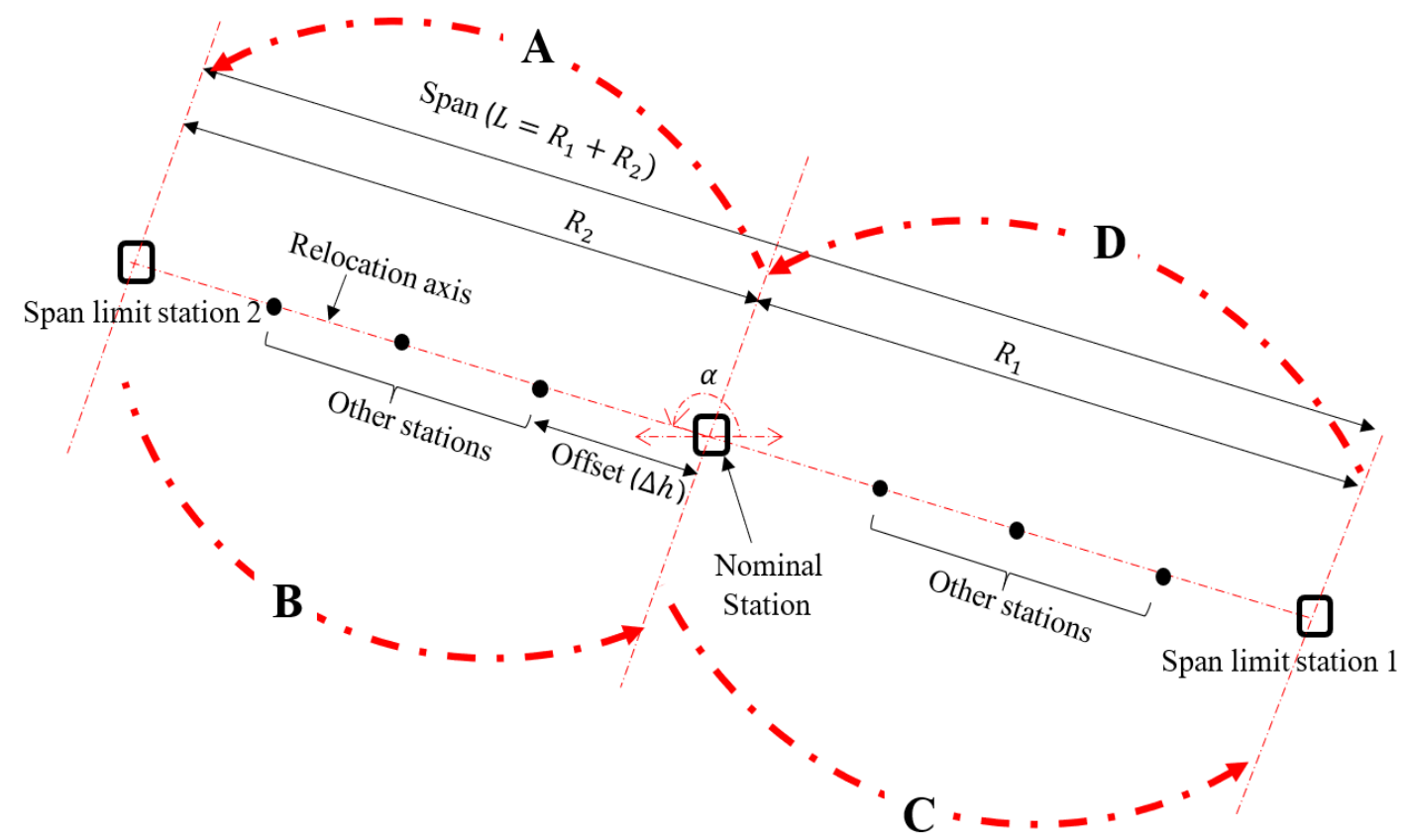

Figure 5. A vessel relocation program layout, depicting $p$ relocation stations along a relocation axis, $\alpha$, with span limit stations (extreme stations) positioned at $R_{1}$ and $R_{2}$ from the nominal station. 


\subsubsection{Relocation span limits and span radius}

The limit on the extent to which the vessel can be moved on either side of the nominal station, along the relocation axis, is constrained by factors including the TDZ stress utilisation, the top tension, and the TDZ compression of the SCR. The span of relocation $\left(L=R_{1}+R_{2}\right)$ is the distance between both span limit stations. For symmetric relocation patterns, the distance of the two-span limit stations from the nominal station are equal, $R_{1}=R_{2}=L / 2$. For nonsymmetric relocation patterns, $R_{1} \neq R_{2}$.

\subsubsection{Relocation stations}

In any relocation program, the vessel is moved intermittently from one position to another, starting from the nominal position, which is the mean or nominal station. These vessel positions are referred to as relocation stations. Each relocation program contains $p$ number of relocation stations. Examples of symmetric station patterns for relocation programs with $p=3,5,7,9$ etc., are presented in Table 1. For $p=1$, the vessel is in its nominal station, meaning there is no vessel relocation. Consider a relocation program with $p=9$, one cycle of the relocation will require the following sequence of vessel movement:

$$
1 \text { relocation cycle }=\left\{\begin{array}{l}
\boldsymbol{A}: 1 \rightarrow 2 \rightarrow 3 \rightarrow 4 \rightarrow 5 . \\
\boldsymbol{B}: 5 \rightarrow 4 \rightarrow 3 \rightarrow 2 \rightarrow 1 \\
\boldsymbol{C}: 1 \rightarrow 6 \rightarrow 7 \rightarrow 8 \rightarrow 9 \\
\boldsymbol{D}: 9 \rightarrow 8 \rightarrow 7 \rightarrow 6 \rightarrow 1
\end{array}\right.
$$

Table 1. Examples of symmetric vessel relocation patterns.

\begin{tabular}{|c|c|c|c|c|c|c|c|c|c|c|c|c|c|}
\hline \multirow{2}{*}{$\begin{array}{c}\text { No of stations } \\
(p)\end{array}$} & \multicolumn{13}{|c|}{ Station index $(m)$} \\
\hline & & Por & & & & & Nominal & & & Star & ard & & \\
\hline No relocation & & & & & & & 1 & & & & & & \\
\hline 3 & & & & & & 2 & 1 & 3 & & & & & \\
\hline 5 & & & & & 3 & 2 & 1 & 4 & 5 & & & & \\
\hline 7 & & & & 4 & 3 & 2 & 1 & 5 & 6 & 7 & & & \\
\hline 9 & & & 5 & 4 & 3 & 2 & 1 & 6 & 7 & 8 & 9 & & \\
\hline$\ldots$ & & $\cdots$ & $\ldots$ & $\cdots$ & $\cdots$ & $\cdots$ & $\ldots$ & $\cdots$ & $\cdots$ & $\ldots$ & $\ldots$ & $\ldots$ & \\
\hline$k$ & $(k+1) / 2$ & $\cdots$ & 5 & 4 & 3 & 2 & 1 & 6 & 7 & 8 & 9 & $\cdots$ & $k$ \\
\hline
\end{tabular}

\subsubsection{Relocation offsets}

The direct distance between two neighbouring stations is referred to as the relocation offset $(\Delta h)$ (see Figure 5). For equally spaced relocation stations, the relocation offsets can be obtained from the relocation span, $L$, and the number of relocation stations, $p$, as expressed in equation (2). However, equal distance between stations cannot be guaranteed for nonsymmetric relocation patterns if the nominal station's location is fixed.

$$
\Delta h=\frac{L}{p-1}=\frac{R_{1}+R_{2}}{p-1}
$$




\subsubsection{Fatigue damage fraction}

This is the factor by which the fatigue damage in the SCR is reduced when the vessel is at a relocation station. The fatigue damage fraction at each station, $f_{m}$ (where $m=1$ to $p$ ) is expressed in equation (3) [31].

$$
f_{m}= \begin{cases}\frac{3}{(2 p-1)} & m=\text { nominal station. } \\ \frac{1}{(2 p-1)} & m=\text { span limit } 1 \text { station } \\ \frac{1}{(2 p-1)} & m=\text { span limit2 station } \\ \frac{2}{(2 p-1)} & m=\text { other }(p-3) \text { stations }\end{cases}
$$

where:

$$
\sum_{m=1}^{p} f_{m}=1
$$

\subsubsection{Effective fatigue damage}

The effective (resulting) fatigue damage $\left(D_{\text {eff }}\right)$ in the SCR TDZ for a relocation program is expressed in equation (5).

where:

$$
D_{\text {eff }}=\sum_{m=1}^{p} f_{m} D_{m}
$$

$D_{m}=$ fatigue damage around the SCR TDZ at station $m$.

$p=$ number of relocation stations for the program.

$m=$ relocation station counter from 1 to $p$.

For an existing field (brownfield) SCR, if the remaining or residue fatigue life of the SCR is $T_{\text {rem }}$, then the life extension, $T_{\text {ext }}$, of the SCR is expressed in equation (6).

$$
T_{\text {ext }}=\frac{1}{D_{\text {eff }}}-T_{\text {rem }}
$$

\subsubsection{Station coordinates}

The initial configurations of all SCRs are calculated for the vessel positioned at the nominal station, with coordinate $(0,0)$. The risers' configurations will change from the nominal configurations as the vessel moves from one station to another. The relocation programs are 
defined by a given combination of $\alpha, R_{1}, R_{2}, p$, bounded by a pair of span limit stations at $R_{1}$ and $R_{2}$ from the nominal station, as seen in Figure 5. Consider a symmetric relocation program's span limit stations with coordinates $\left(x_{1}, y_{1}\right)$ and $\left(x_{2}, y_{2}\right)$ along a given relocation axis. The coordinates of $p$ equidistant stations (within and including the span limits stations) can be expressed as:

$$
(x, y)=\left(x_{1}+r\left(x_{2}-x_{1}\right), y_{1}+r\left(y_{2}-y_{1}\right)\right)
$$

where $r$ is the fractional part of each division within the span limit stations, which can be expressed in terms of the relocation offsets $(\Delta h)$ and a station counter $(i)$, where $i=0$ to $p-1$ as shown in equation (8).

$$
r=\frac{i \Delta h}{R_{1}+R_{2}}=\frac{i}{p-1}
$$

\section{ANALYSIS DATA AND METHODOLOGY}

\subsection{Analysis data}

Riser data: The SCRs used in this study are made of X70 steel grade material. The risers are hosted by a generic floating production, storage, and offloading (FPSO) unit at different azimuths (riser planes) shown in Figure 6. The cross-section dimensions of the SCRs, their hang off angles (HO) measure relative with the downward vertical, and their azimuth angles measure relative to the vessel heading (AZ) are presented in Table 2. The SCRs (WT) minimum wall thicknesses are calculated based on the burst and collapse pressure resistance criteria in DNV-OS-F201 [32]. Other common data applied to the SCRs, including the optimisation design variables for the vessel relocation programs, are presented in Table 3 . Note that the vessel relocation axes (red dotted lines) are measured from the positive vessel x-axis.

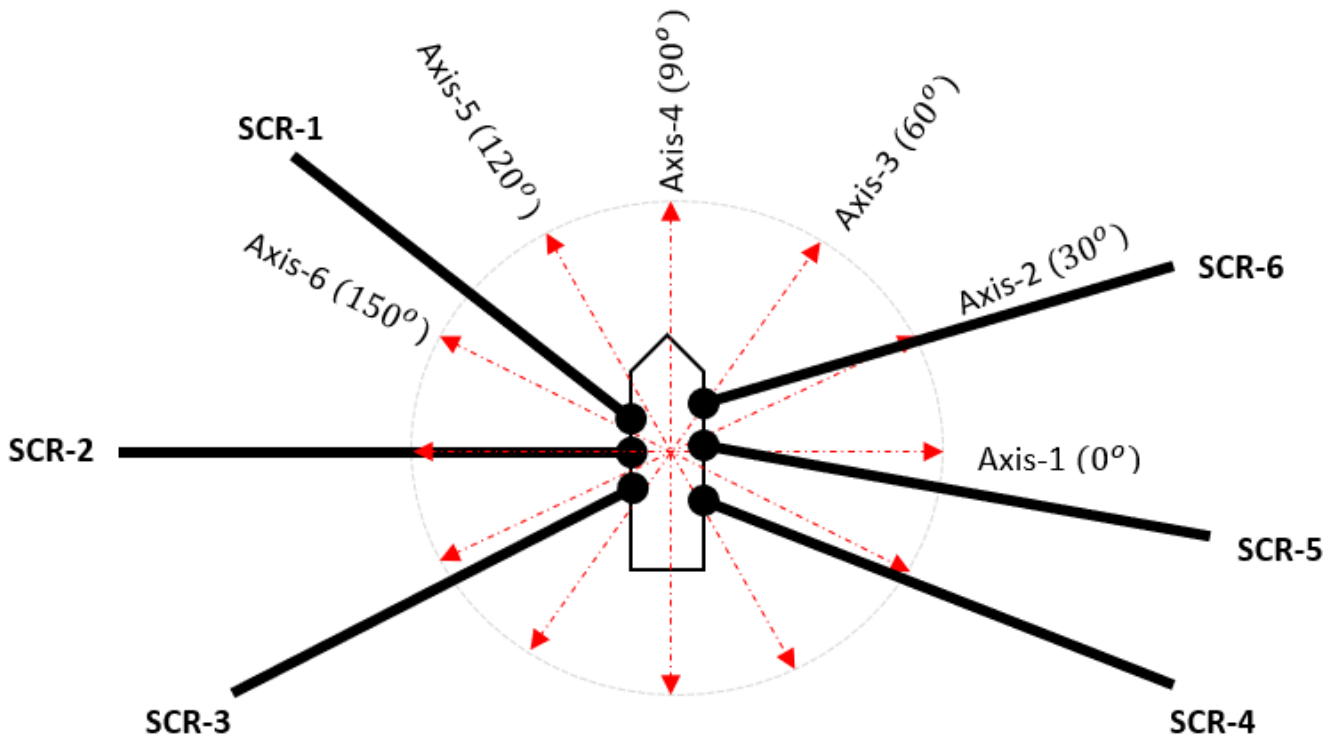

Figure 6. The layout of the vessel relocation axes. 
Table 2. SCRs' cross-section geometry and configuration data.

\begin{tabular}{ccccc}
\hline SCR ID & $\begin{array}{c}\text { HO angle } \\
\text { (deg) }\end{array}$ & $\begin{array}{c}\text { AZ } \\
(\mathbf{d e g})\end{array}$ & $\begin{array}{c}\text { OD } \\
(\mathbf{m})\end{array}$ & $\begin{array}{c}\text { WT } \\
(\mathbf{m})\end{array}$ \\
\hline SCR-1 & 12 & 65 & 0.2540 & 0.0212 \\
SCR-2 & 15 & 90 & 0.3556 & 0.0297 \\
SCR-3 & 14 & 100 & 0.3048 & 0.0254 \\
SCR-4 & 15 & 240 & 0.3556 & 0.0297 \\
SCR-5 & 12 & 260 & 0.2540 & 0.0212 \\
SCR-6 & 14 & 280 & 0.3048 & 0.0254 \\
\hline
\end{tabular}

Table 3. Operational data for the SCRs.

\begin{tabular}{ll}
\hline \multicolumn{1}{c}{ SCR data } & \multicolumn{1}{c}{ Values } \\
\hline Internal Design pressure & $10 \mathrm{ksi}$ \\
SMTS & $565 \mathrm{MPa}$ \\
Content density & $600 \mathrm{~kg} / \mathrm{m}^{3}$ \\
Hang off rotational stiffness (linear) & $12 \mathrm{kN} \cdot \mathrm{m} / \mathrm{deg}$ \\
Water depth & $1500 \mathrm{~m}$ \\
S-N curve (seawater plus cathodic protection) & D-Curve $[33]$ \\
Riser design life $\left(T_{D}\right)$ (greenfield) & 30 years \\
Relocation axis $(\alpha)$ & {$[0,30,60,90,120,150]$ deg } \\
Span radii $\left(R: R_{1}, R_{2}\right)(\%$ water depth) & $\left\{R_{1}: 1 \leq R \leq 20\right\},\left\{R_{2}: 1 \leq R \leq 20\right\}$ \\
Number of station $(p)$ & $\{p: 3 \leq p \leq 9\}$ \\
\hline
\end{tabular}

The optimisation design variables are the axes of relocation $(\alpha)$, the span radii $(R)$ and the number of relocation stations $(p)$. The ranges of values for these variables have been presented in Table 3.

- The axes of relocation $(\boldsymbol{\alpha})$ - The relocation axes are at $30^{\circ}$ from each other, resulting in 6 discrete values for the $360^{\circ}$ coverage. Five out of the six axes extend from one side (portside) to the other side (starboard). The axis-4 aligns with the heading of the vessel.

- The span radius $\left(\boldsymbol{R}: \boldsymbol{R}_{\mathbf{1}}, \boldsymbol{R}_{\mathbf{2}}\right)$ - The span radii (measured from the nominal station) are expressed in percentage of the water depths and are discretized at $1 \%$ interval, resulting in 20 discrete values for $\mathrm{R}$.

- The number of relocation stations $(\boldsymbol{p})$ - The number of relocation stations ranges from 3 to 9 at intervals of 2 , resulting in 4 discrete values of $p$. For symmetric relocation programs, the station patterns are obtained by expanding values of $p$ as shown in Figure 7 , where " 1 " is the nominal station. However, for non-symmetrical relocation programs, the patterns will be skewed about the nominal station.

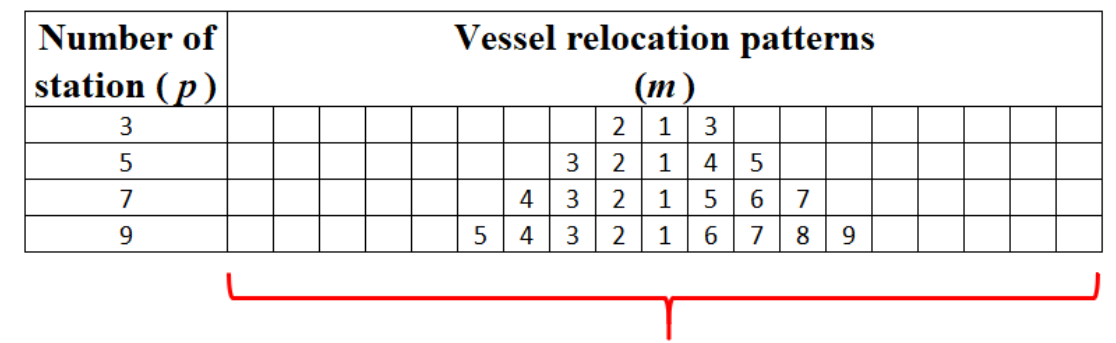

Station ID

Figure 7. Station arrangement in symmetric relocation programs. 
In previous work for symmetric relocation optimisation for single SCR [31], it was found that the optimum relocation program $(\alpha, R, p)$ was $(30 \mathrm{deg}, 5 \%, 19)$. A further investigation of this relocation program showed that although 19 stations gave the least effective fatigue damage, the number of stations beyond $p=9$ along $\alpha=30 \mathrm{deg}$, for $R=5 \%$ contributed very little reduction to the effective damage of the SCR TDZ as shown in Table 4 and Figure 8. Hence, we can generalise that increasing the number of stations beyond a certain number of $p$ will only increase the associated operating cost for the relocation program, with minimal reduction to the effective damage. Although we cannot yet generalise this behaviour for multiple SCR vessel relocation optimisations, considering the required computational resource requirements, it is only rational to consider a maximum of nine (9) relocation stations for this study. The suitability of $p=9$, wil be discussed in the result section.

Table 4. Order of performance of relocation programs with varying number of relocation stations, $p$ [31].

\begin{tabular}{ccccc}
\hline Index & $\begin{array}{c}\text { Order of } \\
\text { Performance* }\end{array}$ & $R(\%)$ & $\alpha(\mathrm{deg})$ & $p$ \\
\hline No relocation & - & - & - & 1 \\
217 & 311 & 5 & 30 & 3 \\
218 & 195 & 5 & 30 & 5 \\
219 & 122 & 5 & 30 & 7 \\
220 & 43 & 5 & 30 & 9 \\
221 & 15 & 5 & 30 & 11 \\
222 & 9 & 5 & 30 & 13 \\
223 & 4 & 5 & 30 & 15 \\
224 & 2 & 5 & 30 & 17 \\
225 & 1 & 5 & 30 & 19 \\
\hline
\end{tabular}

*The order of performance is the relocation program's serial number $(\mathrm{S} / \mathrm{N})$ position in the design optimisation space for the problem [31].

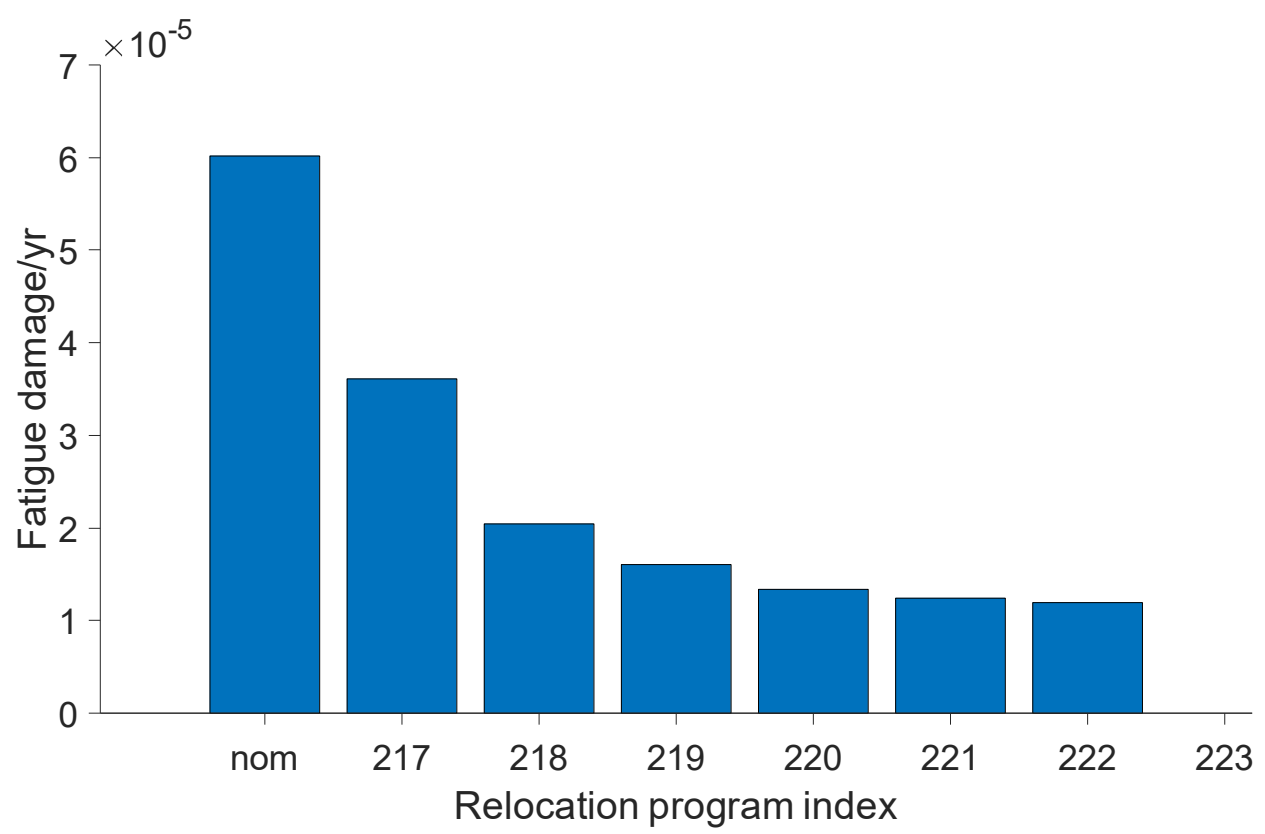

Figure 8. Fatigue damage variation with an increasing number of relocation station $p$, for single SCR symmetric relocation program [31]. 
Environmental data: To demonstrate the vessel relocation strategy for multiple SCRs, one regular wave load is considered for the storm (constraint function evaluation) and fatigue (objective function evaluation) analyses, as presented in Table 5. This means the probability of occurrence for the single fatigue sea state is $100 \%$. The wave loads are considered Beam Seas (perpendicular to vessel heading) to impact the largest combined roll and heave FPSO motions on the risers.

Table 5. Wave load data representative of fatigue and design storm sea state conditions.

\begin{tabular}{llcl}
\hline \multicolumn{1}{c}{ Analyses } & Wave type & Data & Values \\
\hline \multirow{2}{*}{ Extreme } & \multirow{2}{*}{ Regular } & $H$ & $8 \mathrm{~m}$ \\
\multirow{2}{*}{ Fatigue } & & $T$ & $12 \mathrm{sec}$ \\
& \multirow{2}{*}{ Regular } & $H$ & $4.5 \mathrm{~m}$ \\
& & $T$ & $9.5 \mathrm{sec}$ \\
\hline
\end{tabular}

The vessel's response amplitude operators are symmetrical about the longitudinal vessel axis. Since Beam Seas are applied, the most relevant vessel response amplitude operators (RAOs), the heave and roll RAOs, are presented in Figure 9. The non-linear hysteretic seabed model for catenary pipeline contact is implemented to model the SCR TDZ soil interactions. The soil model data used are presented in Table 6 .

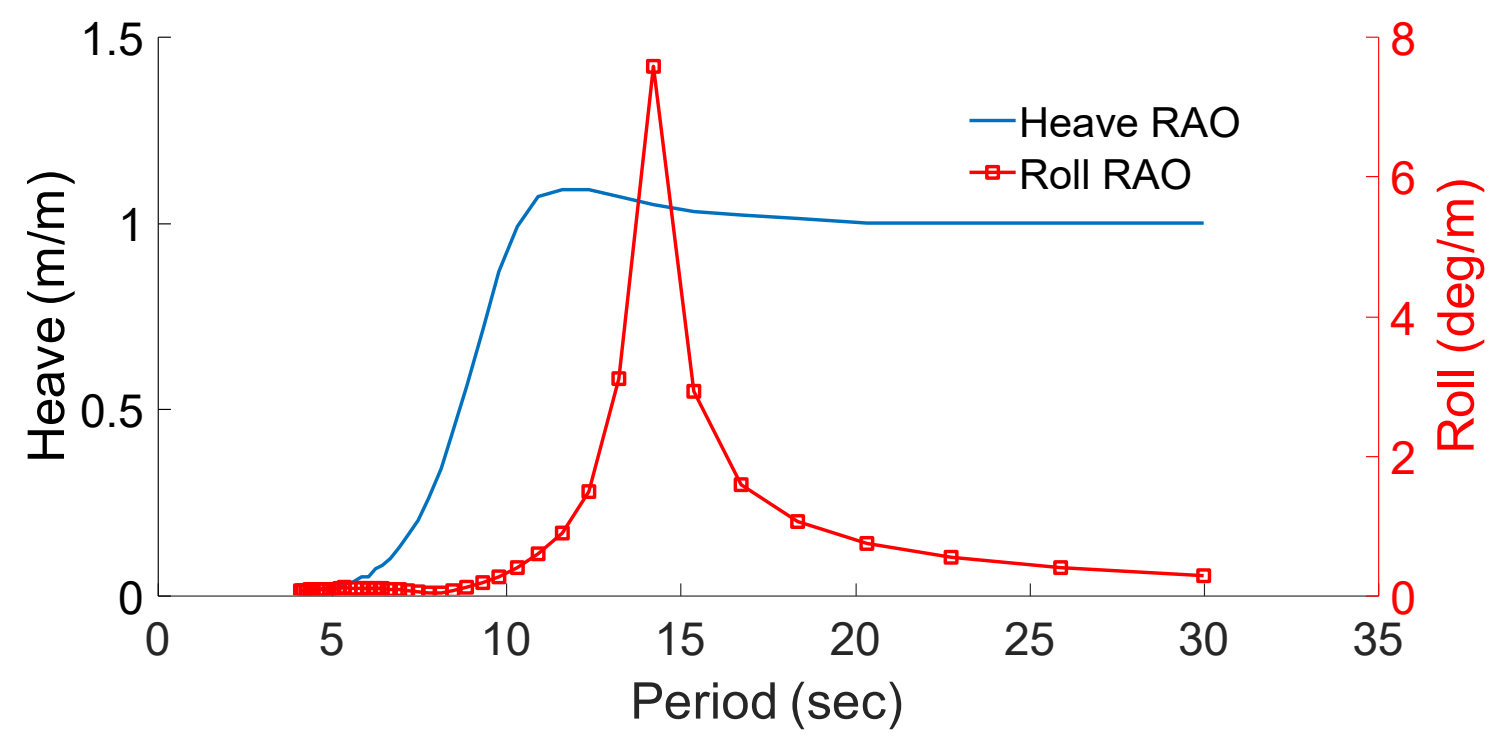

Figure 9. Vessel heave and roll RAOs to wave load in the Beam Sea direction $\left(90^{\circ}\right.$ and $\left.270^{\circ}\right)$

Table 6. Non-linear catenary pipeline soil interaction model data [21].

\begin{tabular}{lll}
\hline Parameter & Symbol & Value \\
\hline Mudline shear strength & $s_{u 0}$ & $5 \mathrm{kPa}$ \\
Shear strength gradient & $\rho$ & $1.5 \mathrm{kPa} / \mathrm{m}$ \\
Power law parameter & {$[a, b]$} & {$[6,0.25]$} \\
Normalised maximum stiffness & $K_{\text {max }}$ & 200 \\
Suction ratio & $f_{\text {suc }}$ & 0.6 \\
Suction decay parameter & $\lambda_{\text {suc }}$ & 0.4 \\
Repenetration parameter & $\lambda_{\text {rep }}$ & 0.2 \\
\hline
\end{tabular}

\subsection{Vessel relocation optimization}

The objective of the vessel relocation optimisation analysis is to determine optimum combinations of the design variables, $\alpha, R$ and $p$, which result in the least effective fatigue damage in the SCR TDZ. The optimum relocation programs must satisfy constraint functions, Page | 13 
which are the design limit set for the SCR design storm responses. The vessel relocation optimization problem can be expressed as follows:

$$
\text { find } \mathbf{X}=\left\{\begin{array}{l}
\alpha \\
R \\
p
\end{array}\right\} \text { which minimizes } D_{e f f}
$$

Subject to the following constraints, $\mathbf{g}$ :

where:

$$
\mathbf{g}=\left\{\begin{array}{c}
U_{T D Z}<1 \\
T_{t o p}<T_{y} \\
T_{T D Z}>T_{\min }
\end{array}\right.
$$

$\alpha=$ Relocation axis measured from a reference axis.

$R: \quad=$ Span radii $\left(R_{1}, R_{2}\right)$.

$p \quad=$ Number of relocation stations.

$D_{\text {eff }}=$ Effective fatigue damage per relocation program.

$U_{T D Z}=$ Stress utilization in the SCR TDZ.

$T_{\text {top }}=$ Maximum effective tension at the riser top.

$T_{T D Z}=$ Minimum effective tension around the riser TDZ.

$T_{y}=$ Yield tension of the riser pipe $=0.9 S A$.

$S \quad=$ Specified minimum yield strength.

$A \quad=$ SCR pipe cross-section area.

$T_{\min }=$ Minimum allowable effective tension $\left(T_{\min }=85 \mathrm{kN}\right.$ in this work $)$.

The above optimisation model is applied for each of the six SCRs hosted by the vessel. This implies that there will be six objective functions, $\left(D_{e f f}\right)$, where $j=1$ to 6 and eighteen $(3 \times 6$ $=18$ ) constraints functions to be evaluated for the problem. In section 3.4, two approaches are presented to organise these objective functions and conduct the optimization step. Any suitable optimization technique can be applied to solve the problem. However, the index matching optimization technique is used in this study. Details of the index matching technique are provided in the following section.

\subsection{Index matching optimization technique.}

The index matching optimisation technique [31] is applied to solve the vessel relocation optimisation problem. Given a multi-objective optimization problem:

$$
\text { Minimize: } f(\mathbf{X})=\left\{\begin{array}{c}
f_{1}(\mathbf{X}) \\
f_{2}(\mathbf{X}) \\
\cdot \\
\cdot \\
\cdot \\
f_{n}(\mathbf{X})
\end{array}\right\}
$$

subject to the following constraints:

where:

$$
\mathrm{g}_{\mathrm{j}}(\mathbf{X}) \leq \mathbf{b}_{\mathbf{j}}, \quad j=1,2,3 \ldots, t
$$




$$
\mathbf{X}=\left\{\mathbf{x}_{1}, \mathbf{x}_{2}, \mathbf{x}_{3}, \ldots, \mathbf{x}_{\mathbf{p}}\right\}^{\mathbf{T}}
$$

where:

$f(\boldsymbol{X})=$ Collection of objective functions to be optimised.

$\mathrm{g}_{\mathrm{j}}(\mathbf{X})=$ Collection of constraint functions.

$\mathbf{X}=$ Collection of the design variable vectors.

The optimization design space is defined by a unique combination of elements from each vector in $\mathbf{X}$. For $k$ such design points at which the objective and the constraint functions are evaluated, there will be $k$ corresponding elements in each objective function. Let the Collection of index vectors, I, each containing $k$ indices represent the index position of the $k$ elements in each objective function as depicted in Figure 10, where $\mathbf{I}$ is expressed as:

$$
I=\left\{\begin{array}{c}
I_{1} \\
I_{2} \\
\cdot \\
\cdot \\
\cdot \\
I_{n}
\end{array}\right\}
$$

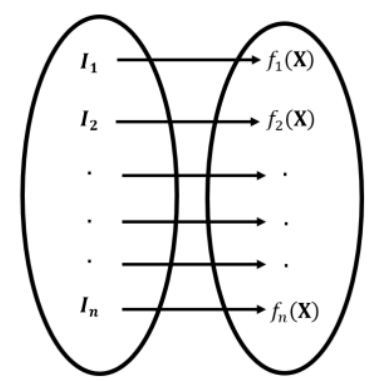

Figure 10. Index system of vectors representing objective functions.

The feasible design space, $\mathbf{X}_{\mathbf{F D S}}$, is the region of the design space where the constraint functions are satisfied. The objective function values at the feasible design points can be obtained by evaluating them at $\mathbf{X}_{\mathbf{F D S}}$ as shown in equation (13). The corresponding feasible set of index systems, $\mathbf{I}_{\mathbf{F D S}}$, which is a subset of $\mathbf{I}$ is expressed in equation (14).

$$
\begin{gathered}
\mathbf{Y}=\left\{f\left(\mathbf{X}_{\mathbf{F D S}}\right)\right\}=\left\{\begin{array}{c}
f_{1}\left(\mathbf{X}_{\mathbf{F D S}}\right) \\
f_{2}\left(\mathbf{X}_{\mathbf{F D S}}\right) \\
\cdot \\
\cdot \\
\cdot \\
f_{n}\left(\mathbf{X}_{\mathbf{F D S}}\right)
\end{array}\right\} \\
\mathbf{I}_{\mathbf{F D S}}=\left\{\mathbf{I}\left(\mathbf{X}_{\mathbf{F D S}}\right)\right\}=\left\{\begin{array}{c}
\boldsymbol{I}_{1}\left(\mathbf{X}_{\mathbf{F D S}}\right) \\
\boldsymbol{I}_{2}\left(\mathbf{X}_{\mathbf{F D S}}\right) \\
\cdot \\
\cdot \\
\cdot \\
\boldsymbol{I}_{\boldsymbol{n}}\left(\mathbf{X}_{\mathbf{F D S}}\right)
\end{array}\right\}
\end{gathered}
$$


If the columns of $\mathbf{Y}^{\mathbf{T}}$ are sorted in ascending order (for minimization) problem or descending order for maximization problem, we will have $\mathbf{Y}^{\prime}$ as presented in equation (15). We can then rearrange indices in the vectors of $\mathbf{I}_{\mathbf{F D S}}$ such that their positions match the current posts of the element they represent in vectors of $\mathbf{Y}$ before they were sorted. The re-ordered $\mathbf{I}_{\mathbf{F D S}}$ is expressed in equation (16).

$$
\begin{gathered}
\mathbf{Y}^{\prime}=\operatorname{sort}\left\{\mathbf{Y}^{\mathrm{T}}\right\} \\
\mathbf{I}^{\prime}=\left(\mathbf{I}_{\text {FDS }}\right)_{\text {reordered }}=\left\{\begin{array}{c}
\boldsymbol{I}^{\prime}{ }_{\mathbf{1}} \\
\boldsymbol{I}^{\prime}{ }_{\mathbf{2}} \\
\cdot \\
\cdot \\
\vdots \\
\boldsymbol{I}^{\prime}{ }_{\boldsymbol{n}}
\end{array}\right\}
\end{gathered}
$$

The intersection of the indices in the first $q$ rows and across all columns of $\left(\mathbf{I}^{\prime}\right)^{\mathbf{T}}$ gives a family of index numbers that represent or point to the sets of optimum design points, i.e.:

$$
\mathbf{I}_{\text {opt }}=\bigcap_{1}^{q}\left\{\left(\mathbf{I}^{\prime}\right)^{\mathrm{T}}\right\}
$$

The family of optimum design variables, $\mathbf{X}_{\mathbf{o p t}}$, and the corresponding optimum values of the objective functions, $\mathbf{Y}_{\mathbf{o p t}}$, can then be obtained through the following matching:

$$
\begin{aligned}
& \mathbf{X}_{\text {opt }}=\mathbf{X}\left(\mathbf{I}_{\text {opt }}\right) \\
& \mathbf{Y}_{\text {opt }}=\mathbf{Y}\left(\mathbf{I}_{\text {opt }}\right)
\end{aligned}
$$

The flow chart for the index matching optimization process is presented in Figure 11 and summarised as follows:

- Assemble all possible combinations of the design variables.

- Run numerical analyses (for each combination) to determine the values of the constraint functions.

- Run numerical analyses (for each combination) to determine the values of the objective function.

- Eliminate the combinations that do not satisfy the constraints.

- Order the remaining combinations in ascending order of the objective function to find the combination that minimises the objective function while satisfying the constraints.

For the vessel relocation example in this study, the six objective functions are the effective fatigue damage in the TDZ of the six SCR. These objective functions are evaluated within the feasible constraint region for the 18 constraint functions. 


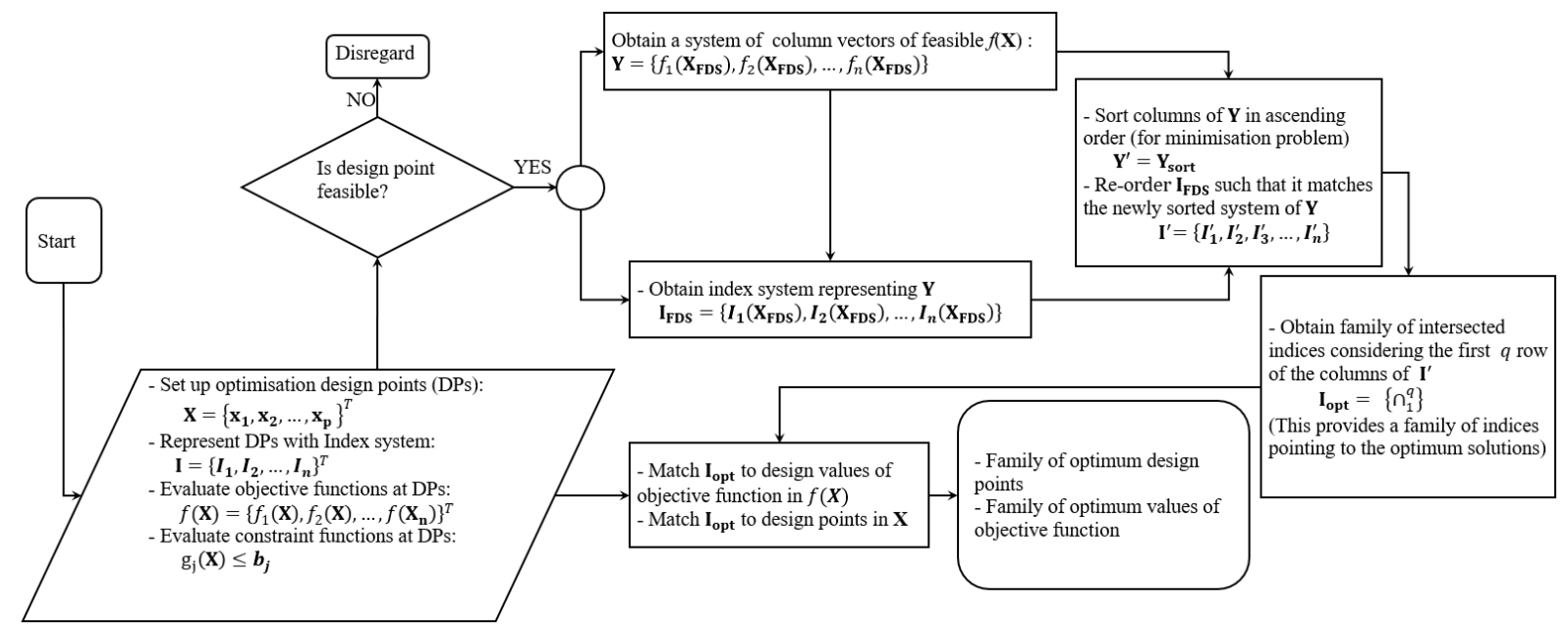

Figure 11. Index matching optimization technique flowchart.

\subsection{Procedure to obtain global fatigue damage function.}

There is a need to determine the optimal global solutions to provide optimum $D_{\text {eff }}$ for the six SCRs. There are two methods applied in this study, both based on the index matching technique but applied differently. Results comparison for both methods will be discussed in the results section.

\subsubsection{Method 1 - Constructing a global objective function}

The global objective function, $F$, is created through a linear combination of the six objective functions, weighted by their contributions to $F$. This is expressed in equation (20).

$$
F=\sum_{j=1}^{6} a_{j}\left(D_{e f f}\right)_{j}
$$

where $j$ is the number of SCRs, which in this analysis example ranges from 1 to 6 . Although the components of $F$ have the same unit $\left(\mathrm{yr}^{-1}\right)$, the six SCR configurations are different. This implies differences in the fatigue damage scale. Hence, there is the need to standardise or normalize the effective damage, $D_{e f f}$, of each of the SCRs before computing their linear sum, to obtain the normalised joint objective function, $F^{\text {nom }}$. The following are steps taken to obtain $F^{\text {nom }}$ :

- Evaluate $D_{\text {eff }}$ in the six SCRs for the feasible relocation programs using equation (5).

- For each program, obtain the maximum and minimum $D_{\text {eff }}$ in the six SCR TDZs. These are $\left(D_{e f f}\right)_{j}^{\max }$ and $\left(D_{e f f}\right)_{j}^{\min }$ respectively.

- Obtain the normalised or standardized $D_{e f f}$ as expressed in equation (21).

$$
\left(D_{e f f}\right)_{j}^{\text {nom }}=\frac{\left(D_{e f f}\right)_{j}-\left(D_{e f f}\right)_{j}^{\min }}{\left(D_{e f f}\right)_{j}^{\text {max }}-\left(D_{e f f}\right)_{j}^{\min }}, j=1 \text { to } 6
$$

- Obtain the weight contributions, $a_{j}$, of the $\operatorname{six} \operatorname{SCRs}(j=1$ to 6$)$ based on maximum 
or minimum values of $\left(D_{e f f}\right)_{j}$. This means the higher the maximum effective damage for a given SCR, the higher will be its weight contributions to the global fatigue damage function, and the less favourable its contributions will be to the minimisation of the global fatigue damage function. The weight calculations options are presented in equations (22) and (23).

$$
\begin{aligned}
& a_{j}=a_{j}^{\text {max }}=\frac{\left(D_{e f f}\right)_{j}^{\text {max }}}{\sum_{j=1}^{6}\left(D_{e f f}\right)_{j}^{\text {max }}} \\
& a_{j}=a_{j}^{\text {min }}=\frac{\left(D_{e f f}\right)_{j}^{\text {min }}}{\sum_{j=1}^{6}\left(D_{e f f}\right)_{j}^{\text {min }}}
\end{aligned}
$$

- The combined normalised $D_{\text {eff }}$ is then obtained using equation (24).

$$
F^{n o m}=\sum_{j=1}^{6} a_{j}\left(D_{e f f}\right)_{j}^{n o m}
$$

The index optimisation technique can then be applied to obtain the optimum solutions for this single global objective function.

\subsubsection{Method 2 - Intersection of the index systems of the Ideal solutions}

The individual ideal solutions are the family of optimum relocation programs obtained considering each objective function exclusively. This means, within the feasible design space, the best family of optimum relocation programs are obtained for each SCR without considering the influence of the other SCRs objective functions. Recall from equation (16) that the reordered index system representing each of the objective functions can be written as:

$$
\mathbf{I}^{\prime}=\left(\mathbf{I}_{\mathrm{FDS}}\right)_{\text {reordered }}=\left\{\boldsymbol{I}_{1}^{\prime}, \mathbf{I}_{2}^{\prime}, \ldots, \mathbf{I}_{\mathbf{6}}^{\prime}\right\}^{\mathrm{T}}
$$

A direct intersection of the columns of $\mathbf{I}^{\prime}$, taken $q$ rows at a time, provides the family of joint optimum solutions for the six SCRs. Figure 12 (a) shows a common region where the family of global optimum solutions lie, while Figure 12 (b) demonstrates the intersection operation process for the columns of $\mathbf{I}^{\prime}$ taken $q$ rows at a time. As will be seen later in the result section, the first values of $q$, may yield no intersected indices, resulting in an empty set. However, as $q$ increases i.e., as we go further down the columns, the number intersected indices increase. The maximum value of $q$, denoted as $Q$ in Figure $12(\mathrm{~b})$, is the number of feasible design points or relocation program within the optimisation designs space. 
Indices of the family of global optimum relocation programs

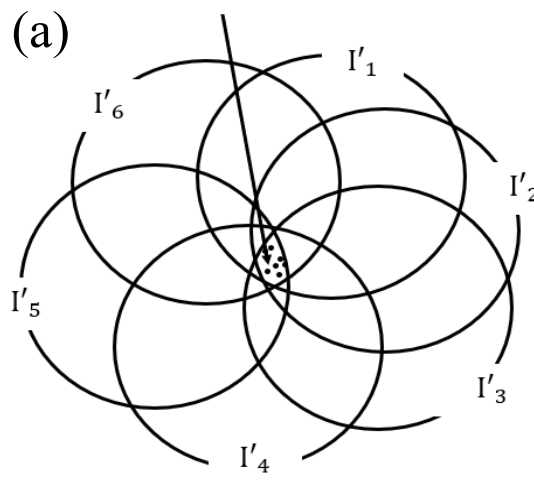

(b)

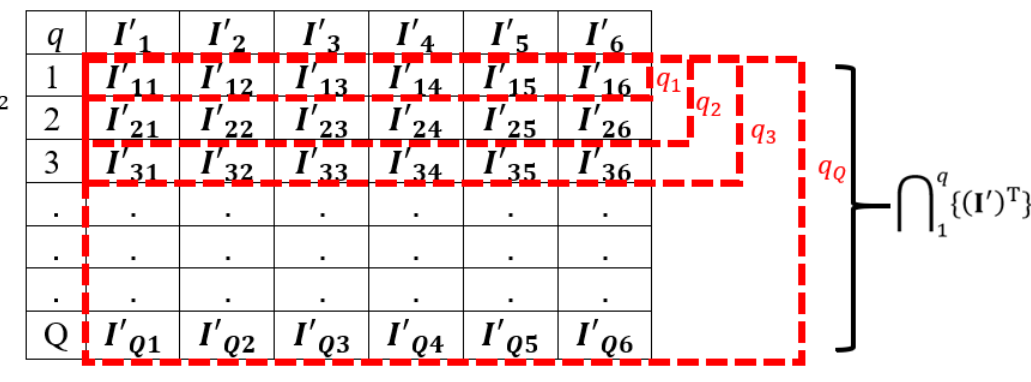

Figure 12. (a) Intersection region containing the family of global optimum relocation programs, (b) Conducting intersection operation on the index columns of the ideal solutions, $q$ row at a time.

\subsection{Screening methodology based on SCR storm constraint analysis}

This section provides a screening analysis methodology to help reduce the computational resource requirements by identifying and eliminating unfeasible relocation stations during the storm and fatigue analysis. The constraint function defined in equation (10) is imposed on the vessel optimisation relocation problem to determine feasible span limits for all relocation programs. Constraint function evaluation requires numerical modelling and simulations of all constituent stations of every candidate relocation program. There are three constraints inequalities for any of the six SCRs $(j=1$ to 6$)$. This result in 18 constraints to be evaluated for each constituent station of any relocation program. Conducting the full constraint function evaluation (storm response analysis) and objective function evaluation (fatigue analysis) at every station (both feasible and non-feasible) of every candidate relocation program can be very expensive computationally. If any of the 18 SCRs' constraint functions is violated in any station of a relocation program, that relocation program becomes unfeasible and should be eliminated from the process. Hence, it is expected that no fatigue analysis should be conducted for that program. However, instead of eliminating an unfeasible initially considered symmetric relocation program, the program can degenerate to a non-symmetrical feasible program. Hence, the screening exercise removes the need for unnecessary simulation and expands the optimisation design space within which good non-symmetrical relocation programs can be captured. The screening procedure is as follows:

- Make an initial consideration of symmetric pattern for the relocation programs, with the span limits equidistant from the nominal station $\left(R=R_{1}=R_{2}\right)$.

- Conduct numerical modelling and analysis of the SCRs and evaluate the constraint functions at the span limits stations to determine their feasibilities. This means that if the span limit stations are feasible, the remaining $p-2$ relocation stations in between the span limit stations will also be feasible and fall within the feasible region depicted in Figure 13. Hence, no need to conduct storm responses for all $p$ stations between these limits. This implies a huge computation saving. 


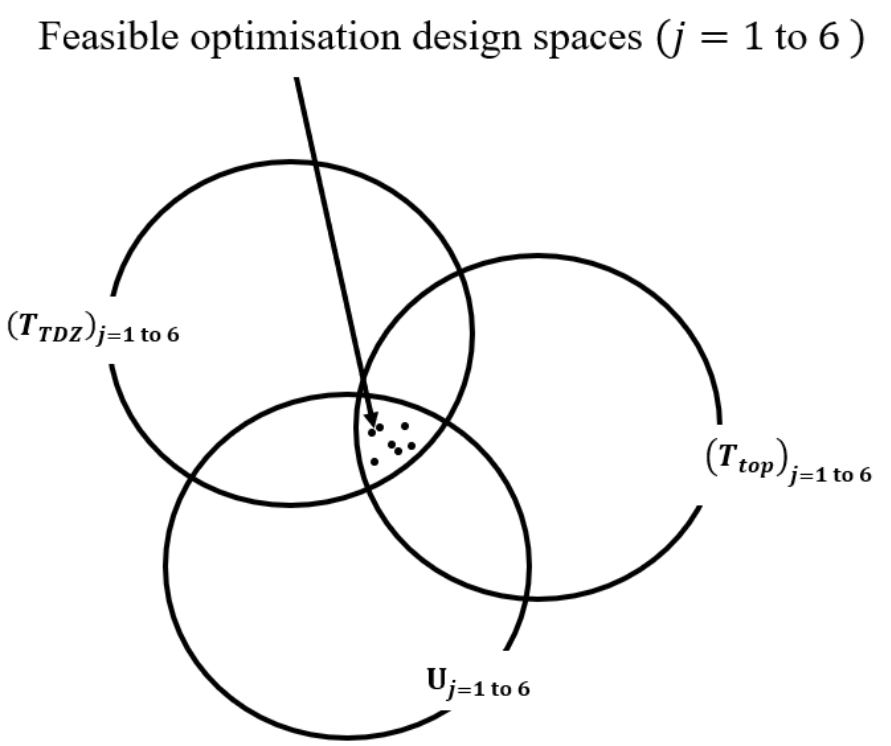

Figure 13. Feasible region for relocation programs.

- If the span limit stations for a relocation program is feasible, then the relocation program will stay symmetrical, as depicted in Figure 14 (a). We calculate $r$ using equation (8) and then calculate the coordinates of the $p$ stations using equation (7).

- Suppose any or both span limit stations of the relocation program are not feasible. In that case, the relocation pattern can degenerate to the next lower feasible span limit(s), which may be non-symmetrical, as depicted in Figure 14 (b). For this scenario, we calculate $r$ using $p^{\prime}$ in place of $p$ in equation (8), where $p^{\prime}=p-1$, to remove the nominal station coordinate $(0,0)$ from the list of the equidistant station coordinates. The stations' coordinates are then calculated using equation (7). The resulting coordinate list is then modified by inserting the nominal station coordinate $(0,0)$ at the appropriate location (transition from one side of the relocation axis to the other side). In this case, the distance between the nominal station and its nearest neighbours will not have equal distance, $\Delta h$, like other stations, but $\Delta h / 2$.

- Calculate the fatigue damage fraction, $f$, for the stations in the relocation programs using equation (3).

- Conduct numerical modelling and fatigue analysis for the feasible relocation programs to evaluate the objective function, $D_{e f f}$, using equation (5). 

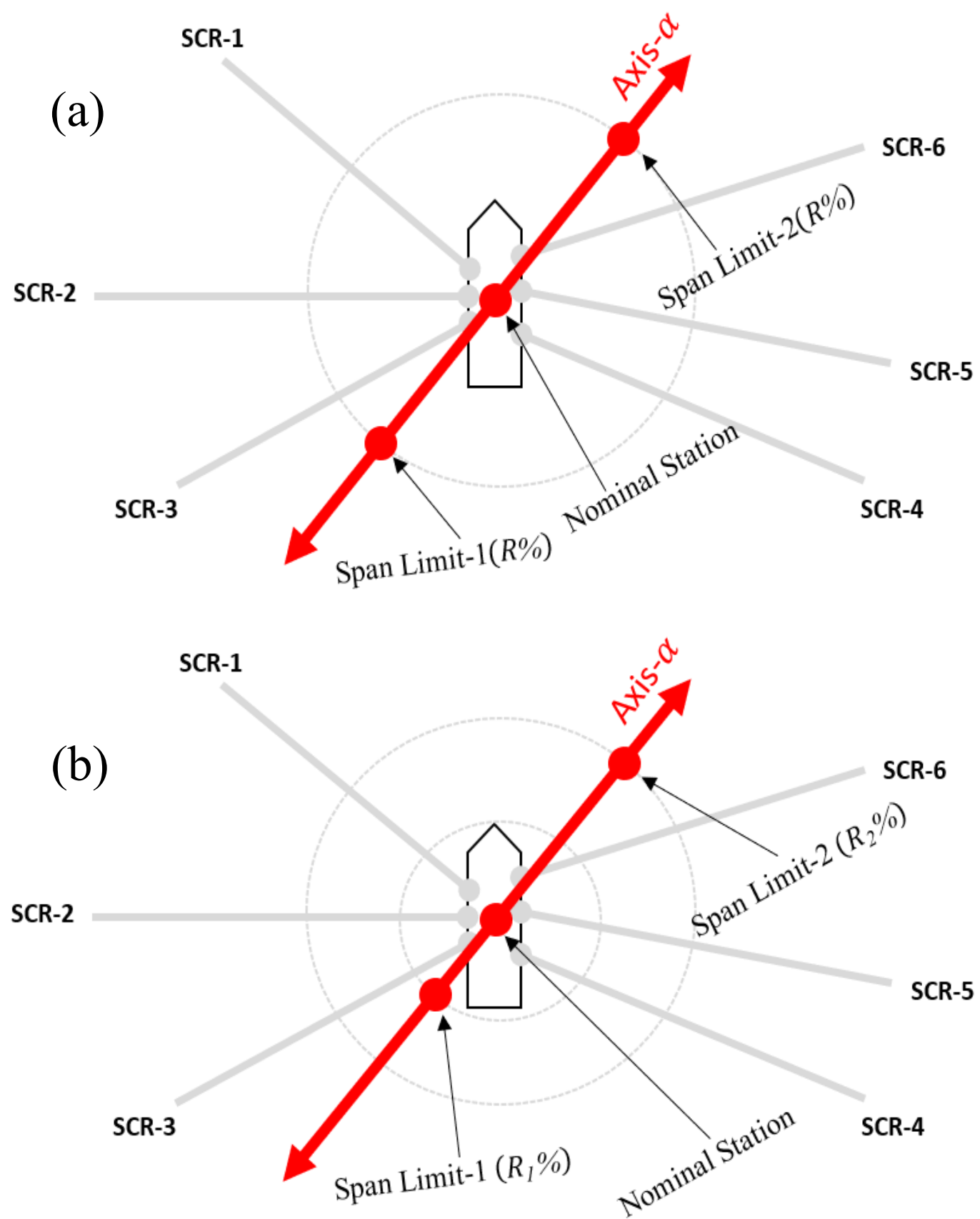

Figure 14. Depiction of the span limits and nominal stations in (a) a symmetric vessel relocation program layout, (b) a non-symmetrical vessel relocation program layout.

The key consideration during the screening analysis, as mentioned in the second bullet point, is that if the span limit stations are feasible, the remaining $p-2$ relocation stations in between the span limit stations will also be feasible and fall within the feasible region the design optimisation space. This consideration is correct as long at there is no incidence at any of the stations, and no resonance occurring for any of the risers during the vessel relocations. To demonstrate this, Consider the example of the 6 SCRs hosted by the vessel in section 1 . The span limit stations are considered symmetrical and at radii of $7 \%$ of the water depth $(105 \mathrm{~m})$ from the nominal station, as depicted in Figure 15 (a). The relocation axes for this example are axis-1 $\left(0^{\circ}\right)$, axis-2 $\left(45^{\circ}\right)$, axis-3 $\left(90^{\circ}\right)$, and axis-4 $\left(135^{\circ}\right)$. There are five relocation stations $(1,2,3,4,5)$, including the span limit stations ( 1 and 5) along each relocation axis. Hence, there are 20 relocation stations for this example. All stations along each relocation axes are equidistant from each other. For the visual understanding of this example set up and interpretation of results, Figure 14 (a), which depicted a generic symmetrical relocation pattern, 
is put side by side with Figure 15 (a) as Figure 15 (b). With the orientations of the SCRs in Figure 15 (b), one would be able to match the riser responses to the sense of their locations and configurations during the vessel relocations along any of the four axes and across the relocation stations. The Beam Sea regular storm wave load in Table 5 is applied on the vessel-riser systems at each relocation station.

The constraint functions which are the stress utilization at the SCRs' TDZ $\left(U_{T D Z}\right)$, the minimum effective tension representative of SCRs' TDZ compression $\left(T_{T D Z}\right)$ and the maximum top tensions for the SCRs at each of the relocation stations along each relocation axis are postprocessed from the simulations and presented in Table 7 . The highest and lowest values of these responses within the SCR region of interest for the relocation station per relocation axes are highlighted in Table 7. One could observe that for all the axis of relocation, the worst value occurs at the span limit stations ( 1 and 5), while the response at stations in between the span limits station falls within the response value obtained for the SCR at the span limit stations. An exception is only observed for SCR-2 for the relocation program along the $90^{\circ}$ axis. Recall from Figure 15 (b) that SCR-2 is at an azimuth of $90^{\circ}$ and that the relocation of the vessel along the vessel heading, which is perpendicular to the azimuth of SCR-2, will induce small SCR TDZ offsets on the SCR-2 TDZ, as seen in the results presented in Figure 3 and Figure 4. This is not a problem to achieving the optimum relocation program in the primary analyses of the study since relocation along $90^{\circ}$ provides the least TDZ spreading. Without detailed optimisation of the relocation program, it is evident from perceived and a physical sense that this axis will give negligible fatigue damage spreading and will not even appear among the optimum solutions. However, as will be seen in the detailed optimisation analysis in this study, we included relocation along this axis in the design optimisation space for the sake of completeness. We can conclude from these results that the extreme responses of the SCRs will most likely be at the extreme station (span limit-1 and 2) unless resonance or an incidence occurs. This is the basis for the screening exercise, based on the vessel-SCRs systems at span limits-1 and 2. If the SCRs failed the constrained function at any of these span limit stations, that symmetric relocation program is unfeasible and would need to be modified or degenerated to a feasible nonsymmetrical relocation program. With this approach, there is no need to conduct simulations in the stations that lie between the span limit stations for the evaluation of the objective function. However, for any feasible relocation program determined based on the feasibility of the span limit station, all relocation stations between the span limit stations must be included in the fatigue calculations during the evaluation of the objective functions $\left(D_{e f f}\right)$ for the problem. 
(a)

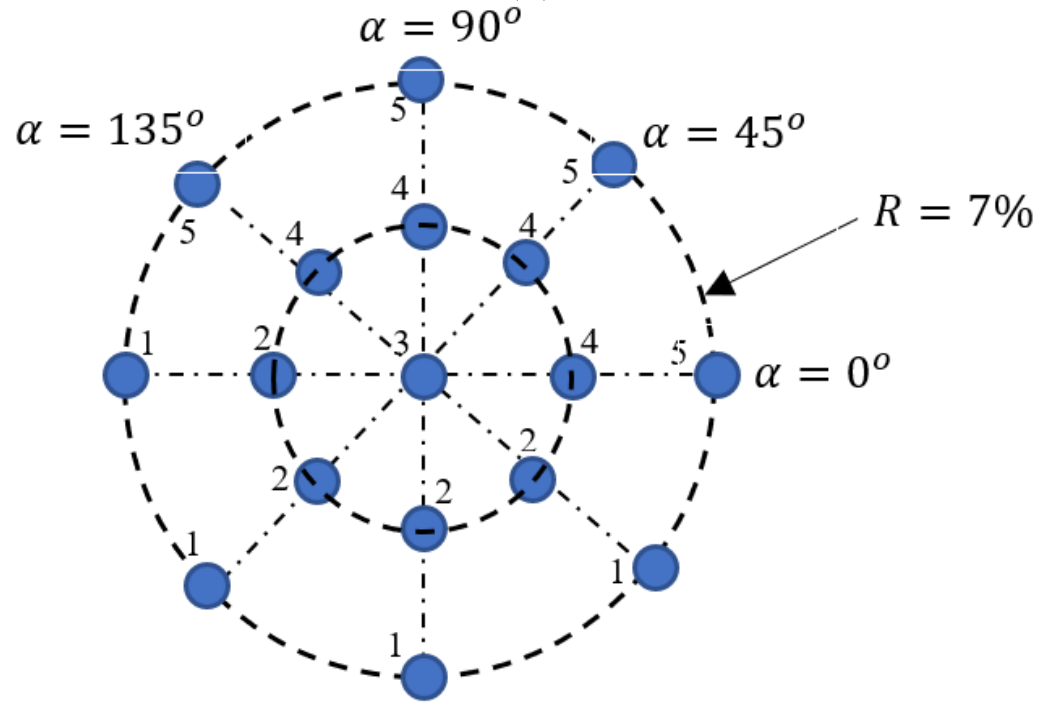

(b)

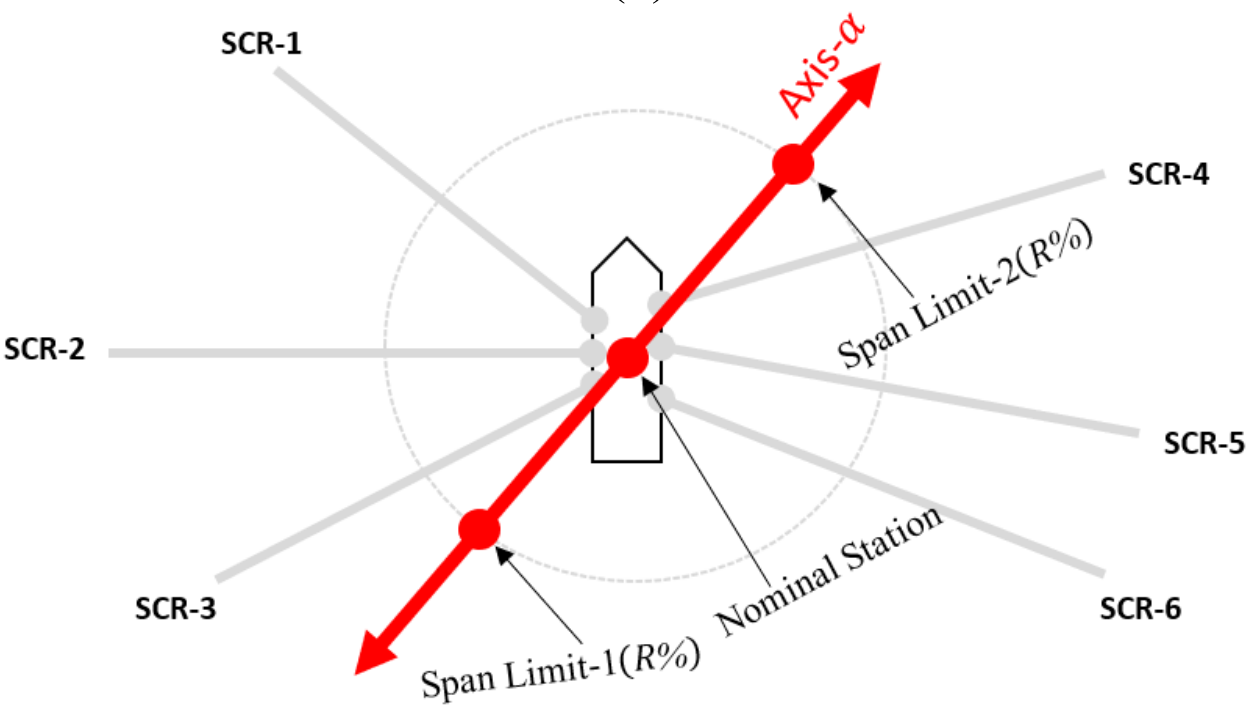

Figure 15. (a) - Layout of vessel relocation stations showing both span limit stations $(1$ and 5$)$ with three intermediate stations $(2,3,4)$ for each of the four relocation axes $(b)$ A generic symmetric vessel relocation layout showing the directions or azimuth of the six SCRs

Table 7. Table of constraint functions' values showing maximum and minimum values occur at span limit stations.

\begin{tabular}{|c|c|c|c|c|c|c|c|c|c|c|c|c|c|c|c|c|c|c|c|c|c|}
\hline \multirow{3}{*}{$\begin{array}{c}\text { SCR } \\
\text { Responses }\end{array}$} & \multirow{3}{*}{ SCR } & \multirow{2}{*}{\multicolumn{5}{|c|}{$\begin{array}{c}\text { Axis - } 1\left(0^{\circ}\right) \\
\text { Stations }\end{array}$}} & \multirow{2}{*}{\multicolumn{5}{|c|}{$\begin{array}{c}\text { Axis - } 2\left(45^{\circ}\right) \\
\text { Stations }\end{array}$}} & \multirow{2}{*}{\multicolumn{5}{|c|}{$\begin{array}{c}\text { Axis - } 3\left(90^{\circ}\right) \\
\text { Stations }\end{array}$}} & \multirow{2}{*}{\multicolumn{5}{|c|}{$\begin{array}{l}\text { Axis - } 4\left(135^{\circ}\right) \\
\text { Stations }\end{array}$}} \\
\hline & & & & & & & & & & & & & & & & & & & & & \\
\hline & & 1 & 2 & 3 & 4 & 5 & 1 & 2 & 3 & 4 & . & 1 & 2 & 3 & 4 & . & 1 & 2 & & 4 & 5 \\
\hline \multirow{6}{*}{$U_{T D Z}$} & SCR-1 & 0.81 & 0.77 & 0.74 & 0.71 & 0.68 & 0.76 & 0.75 & 0.74 & 0.73 & 0.71 & 0.71 & 0.72 & 0.74 & 0.75 & 0.77 & 0.68 & 0.71 & 0.74 & 0.77 & 0.82 \\
\hline & SCR-2 & 0.70 & 0.67 & 0.63 & 0.61 & 0.60 & 0.68 & 0.66 & 0.63 & 0.62 & 0.60 & 0.63 & 0.63 & 0.63 & 0.63 & 0.63 & 0.60 & 0.62 & 0.63 & 0.65 & 0.68 \\
\hline & SCR-3 & 0.73 & 0.69 & 0.66 & 0.64 & 0.61 & 0.72 & 0.69 & 0.66 & 0.64 & 0.62 & 0.67 & 0.67 & 0.66 & 0.66 & 0.65 & 0.63 & 0.65 & 0.66 & 0.68 & 0.70 \\
\hline & SCR-4 & 0.68 & 0.71 & 0.74 & 0.77 & 0.81 & 0.72 & 0.73 & 0.74 & 0.75 & 0.76 & 0.78 & 0.76 & 0.74 & 0.72 & 0.70 & 0.82 & 0.78 & 0.74 & 0.71 & 0.68 \\
\hline & SCR-5 & 0.59 & 0.61 & 0.63 & 0.66 & 0.70 & 0.60 & 0.62 & 0.63 & 0.65 & 0.67 & 0.64 & 0.64 & 0.63 & 0.63 & 0.62 & 0.69 & 0.66 & 0.63 & 0.61 & 0.59 \\
\hline & SCR-6 & 0.59 & 0.60 & 0.63 & 0.66 & 0.70 & 0.59 & 0.61 & 0.63 & 0.65 & 0.68 & 0.62 & 0.62 & 0.63 & 0.63 & 0.64 & 0.66 & 0.64 & 0.63 & 0.61 & 0.60 \\
\hline \multirow{6}{*}{$T_{T D Z}$} & SCR-1 & 75.31 & 96.38 & 121.07 & 149.21 & 180.97 & 106.05 & 112.79 & 121.07 & 131.38 & 142.52 & 151.33 & 135.57 & 121.07 & 108.93 & 98.88 & 185.79 & 151.01 & 121.07 & 94.97 & 72.71 \\
\hline & SCR-2 & 187.87 & 312.82 & 515.37 & 762.63 & 1008.27 & 295.63 & 381.51 & 515.37 & 706.62 & 903.57 & 607.68 & 547.02 & 515.37 & 547.80 & 608.63 & 901.86 & 705.98 & 515.37 & 381.85 & 295.38 \\
\hline & SCR-3 & 124.07 & 218.94 & 352.43 & 428.49 & 517.98 & 169.72 & 241.58 & 352.43 & 417.34 & 492.39 & 329.09 & 339.26 & 352.43 & 368.73 & 388.40 & 441.53 & 394.13 & 352.43 & 281.05 & 238.20 \\
\hline & SCR-4 & 536.93 & 439.37 & 361.14 & 295.59 & 239.22 & 410.21 & 382.53 & 361.14 & 342.48 & 327.86 & 285.83 & 320.79 & 361.14 & 407.44 & 463.77 & 224.47 & 287.28 & 361.14 & 451.54 & 567.94 \\
\hline & SCR-5 & 364.46 & 297.00 & 239.67 & 192.86 & 152.44 & 310.75 & 273.16 & 239.67 & 212.83 & 189.48 & 226.99 & 231.75 & 239.67 & 251.04 & 265.24 & 167.13 & 200.44 & 239.67 & 287.36 & 342.55 \\
\hline & SCR-6 & 648.12 & 530.35 & 432.98 & 351.20 & 282.18 & 611.42 & 514.54 & 432.98 & 363.84 & 305.24 & 476.65 & 452.70 & 432.98 & 418.29 & 408.63 & 346.26 & 385.94 & 432.98 & 487.80 & 551.78 \\
\hline \multirow{6}{*}{$T_{\text {top }}$} & SCR-1 & 1991.84 & 2070.90 & 2163.45 & 2271.80 & 2399.93 & 2097.51 & 2127.56 & 2163.45 & 2206.47 & 2254.93 & 2265.38 & 2211.72 & 2163.45 & 2122.97 & 2088.55 & 2404.72 & 2274.17 & 2163.45 & 2068.94 & 1988.41 \\
\hline & SCR-2 & 3633.24 & 3809.38 & 4019.38 & 4271.88 & 4584.36 & 3743.17 & 3870.57 & 4019.38 & 4194.88 & 4402.46 & 4041.09 & 4026.39 & 4019.38 & 4024.37 & 4037.90 & 4405.09 & 4196.35 & 4019.38 & 3869.61 & 3740.88 \\
\hline & SCR-3 & 2764.22 & 2890.84 & 3043.20 & 3228.01 & 3449.86 & 2814.55 & 2918.34 & 3043.20 & 3192.93 & 3367.57 & 3010.35 & 3023.01 & 3043.20 & 3072.83 & 3113.81 & 3280.79 & 3151.70 & 3043.20 & 2950.58 & 2873.32 \\
\hline & SCR-4 & 5074.90 & 4792.20 & 4549.81 & 4344.20 & 4171.05 & 4713.24 & 4624.28 & 4549.81 & 4484.30 & 4439.03 & 4336.30 & 4431.47 & 4549.81 & 4684.16 & 4834.28 & 4133.56 & 4322.89 & 4549.81 & 4818.17 & 5131.78 \\
\hline & SCR-5 & 2147.22 & 2031.86 & 1935.93 & 1855.26 & 1786.62 & 2057.98 & 1991.63 & 1935.93 & 1888.94 & 1849.13 & 1915.18 & 1923.88 & 1935.93 & 1954.23 & 1976.69 & 1811.49 & 1868.75 & 1935.93 & 2015.13 & 2109.73 \\
\hline & SCR-6 & 3279.64 & 3072.90 & 2904.82 & 2764.63 & 2647.70 & 3205.38 & 3041.60 & 2904.82 & 2789.27 & 2692.46 & 2969.62 & 2933.66 & 2904.82 & 2884.50 & 2871.53 & 2749.87 & 2821.09 & 2904.82 & 3003.40 & 3117.70 \\
\hline
\end{tabular}

Page | 23 


\subsection{Numerical modelling and analysis procedure}

The OrcaFlex numerical software package is used to conduct the analyses for this study. The analysis simulations are performed in the time domain, applying the implicit integration scheme in the numerical solution process. The pre-processing, modelling, simulations and postprocessing are automated using MATLAB programs integrated with the OrcaFlex programming interface, OrcFxAPI [34]. The developed MATLAB program pre-processes analysis data and computes additional data required for the numerical modelling in OrcaFlex. The program then generates OrcaFlex models for the relocation programs. The regular design storm and fatigue wave loads are modelled with the Dean Stream theory. The stress utilisation is post-processed using the DNV-OS-F201 combined load (bending, tension, and pressure) resistance factor design criteria [35]. For the fatigue calculation, the S-N D-curve in seawater with cathodic protection is used [33]. The Rain flow counting technique [36] expresses the varying SCR TDZ stress spectrum as a histogram of stress reversals. Miner's rule is then applied to cumulate the fatigue damage for the SCR. The flow chart for the analysis is summarised in Figure 16.

It is mentioned in section 3.1 that the wave loads are considered Beam Seas (perpendicular to the vessel heading) to impact the largest combined roll and heave FPSO motions on the risers. The two directions for the beam sea are $0^{\circ}$ and $180^{\circ}$ along the global $\mathrm{X}$-axis, considering a vessel heading of $90^{\circ}$. Although the vessel response is symmetric about its longitudinal axis, wave application in these two directions will not result in the same responses in the 6 SCRs. This is because the SCRs configuration and orientations are different, with different hydrodynamic loads for the two wave directions. As a result, the storm and fatigue wave loads are applied in both the screening analysis and optimisation simulation stages. Our interest in these two directional wave applications is to capture the extreme values of the storm responses and the worse fatigue damage for each of the 6 SCRs. Any of the worst storm responses, $R_{\text {extreme }}$, can be obtained using equation (26). The combined fatigue damage, $D_{\text {combined }}$, in each of the SCR can be obtained using equation (27), assuming a probability of occurrence of $50 \%$ for each of the two wave directions. The $D_{\text {combined }}$ across the relocation stations of a relocation program can then be factored by the corresponding set of the fatigue damage fraction, $f$, to obtain $D_{e f f}$ (see equation (5)).

$$
\begin{gathered}
R_{\text {extreme }}=\max \left(R_{\text {waveDir }=0^{\circ}}, R_{\text {waveDir }=180^{\circ}}\right), R=\left\{U_{T D Z}, T_{T D Z}, T_{\text {top }}\right\} \\
D_{\text {combined }}=\frac{D_{\text {waveDir }=0^{\circ}}+D_{\text {waveDir }=180^{\circ}}}{2}
\end{gathered}
$$

The span limit station conventions are presented in Figure 17. The conventions will be helpful to visualise the positions of these limit stations relative to the nominal station. They will also help to understand the expected strength and fatigue behaviours of the SCRs at these stations. 


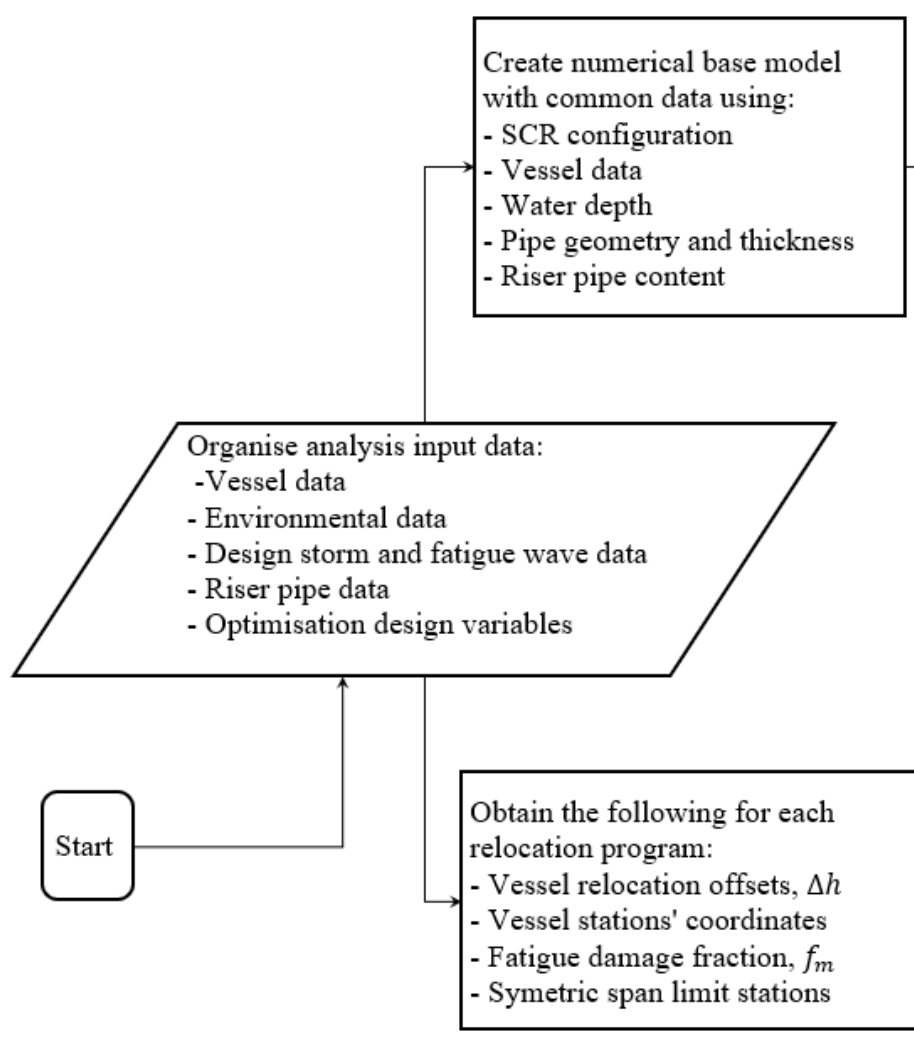

Create numerical base mode

Pipe geometry and thicknes

Riser pipe content

Fatigue damage fraction, $f_{m}$
Symetric span limit stations

Figure 16. Analysis flow chart.
Apply index matching optimisation technique

Conduct feasibility analysis of span limit stations - Generate and simulate numerical models for span limit stations of all relocation programs

- Evaluate constraint functions at span limit

tations

- Check constraint inequalities for feasibility

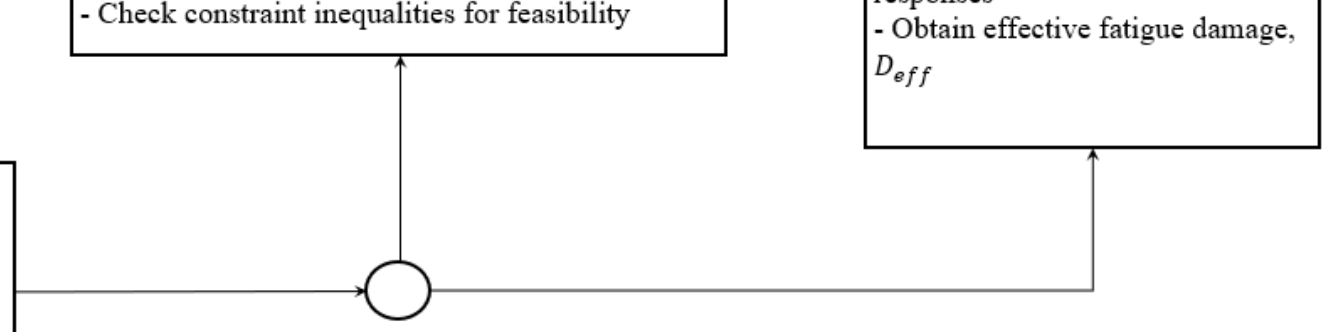

objective function for all feasible relocation programs

- Conduct simulation with fatigue

wave data

- Post process fatigue damage

responses

- Obtain effective fatigue damage,

- Obtain family of optimum

design points

- Obtain optimum values of

the objective function, $D_{e f f}$

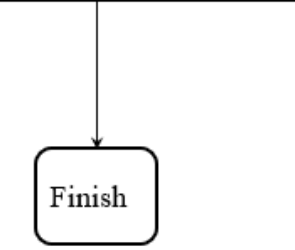



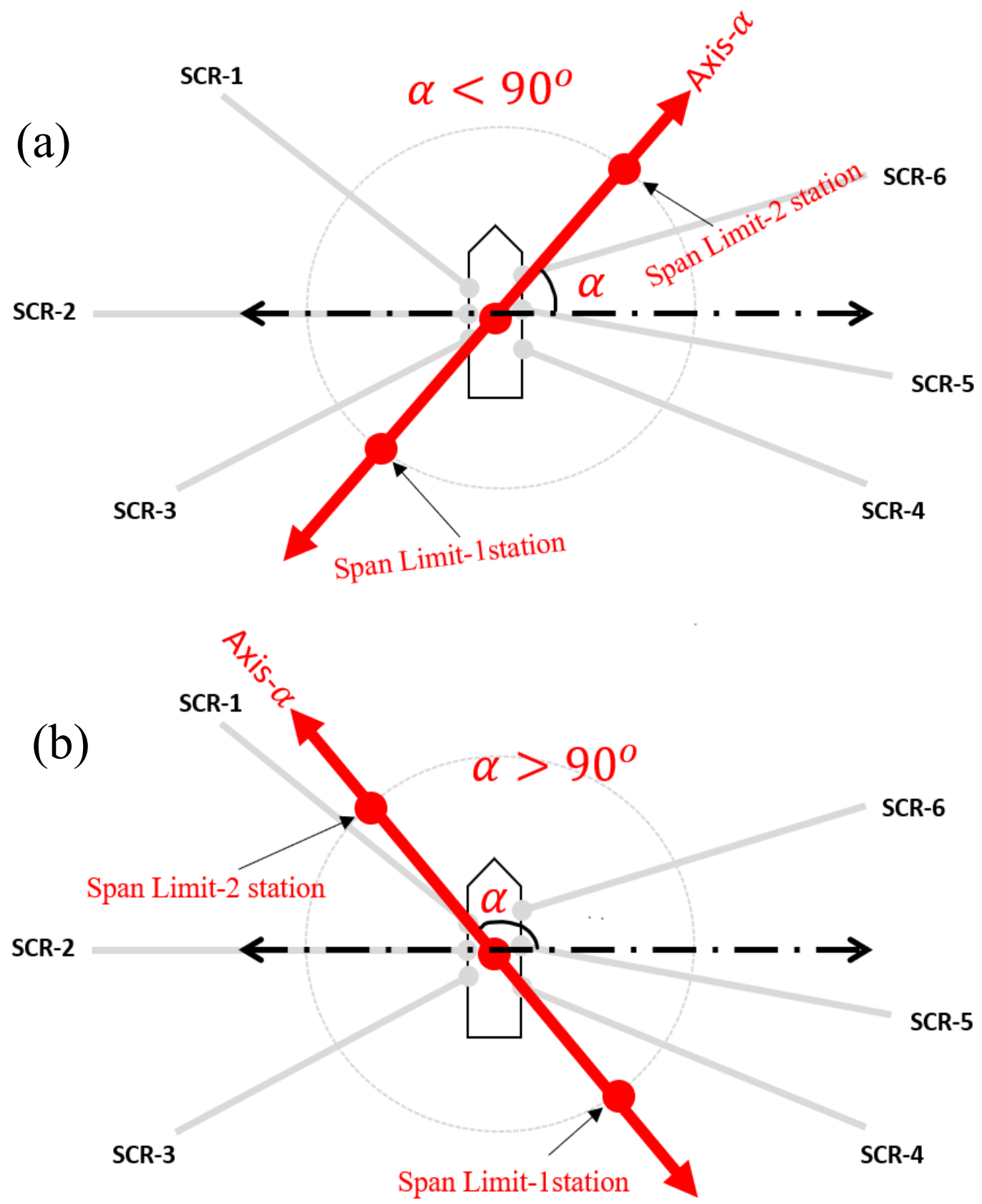

Figure 17. Span limit station convention: (a) span limit station-1 on the portside and span limit station-2 on the starboard side for $\alpha<90$, (b) span limit station-1 on the starboard side and span limit station- 2 on the portside for $\alpha>90$; for $\alpha=90^{\circ}$, span limit station-1 on the aft side, span limit station- 2 on the forward side.

\section{ANALYSES, RESULTS AND DISCUSSIONS.}

\subsection{Screening (storm constraint analysis) results}

Referring to the screening procedure outlined in section 3.5 , we initially consider symmetric vessel relocation patterns on which the relocation programs will be developed. Recall that we have 6 discrete points for $\alpha$, and 20 discrete points each for $R_{1}$ and $R_{2}$. The coordinate sets of the span limit stations calculated based on the combination of $\alpha$ and $R_{1}$ and $\alpha$ and $R_{2}$ on both Page | 26 
sides of the nominal relocation station are respectively presented in Table 8 (a) and Table 8 (b). For brevity, the decimal parts of the coordinates have been truncated. Each table has 120 elements, which should not be taken as equal to the number of relocation programs since varying the value of $p$ for the same pair of span limits stations results in different relocation programs. A combination of corresponding coordinates from the two tables provides the span limit station pairs (\{span limit-1 station, span limit-2 station $\}$ ) as have been demonstrated in Figure 14 (a). So, if we assign the same integer ID (from 1 to 120) as shown in Table 8 (c) to corresponding stations on Table 8 (a) and Table 8 (b), we will obtain the span limit ID pairs as presented in Table $8(d)$.

Following the steps in section 3.5, the screening analysis is conducted for each of these symmetric span limit station pairs, i.e., two numerical models are built to represent each span limit station in a pair. Storm response analyses are conducted for these pairs and the constraint function in equation (10) is evaluated for the six SCRs. It should be noted that each SCR has three constraint functions to be satisfied, meaning that 18 constraint functions must be satisfied at both stations of each span limit pair for that relocation pattern to be feasible (see Figure 13). When a relocation pattern is unfeasible, all dependent relocation programs will also be unfeasible. The resulting feasibility matrices for the sets of the span limit stations for $\left(R_{1}, \alpha\right)$ and $\left(R_{2}, \alpha\right)$ are presented in Table 9 (a) and Table 9 (b) respectively. Any of the 6 SCRs at any of the span limit stations having a zero (0) implies that SCR failed or violated at least one of the storm response constraints in equation (10). If we combine the feasibility matrix in Table 9 (a) and Table 9 (b) and express the outcome in terms of the span limit pair IDs, we will obtain Table 9 (c), which demonstrate the feasibility and unfeasibility of the symmetrical relocation patterns shaded in green and red respectively. For example, consider the span limit station pair ID $\{95,95\}$ in Table 9 (c) characterised by $\alpha=120^{\circ}, R_{1}=16 \%$ and $R_{2}=16 \%$. Although all the SCRs passed the constraint test for span limit-1 station i.e. $[1,1,1,1,1,1]$ in Table 9 (a), ID $\{95,95\}$ is unfeasible because SCR-1 failed to satisfy at least one of the 3 constraint functions at span limit-2 station i.e. $[0,1,1,1,1,1]$ in Table 9 (b). This is no surprise since the relocation axis, $\alpha=120^{\circ}$ falls within the azimuth sector of SCR-1 as depicted in Figure 17, and the vessel at span limit-2 position will induce significant compression on SCR1. For demonstration purposes, the 6 SCRs' range graph maximums for the three constraint functions and their corresponding bar chart of peak values when the vessel is at the span limit stations pair ID $\{95,95\}$ are presented in Figure 18, Figure 19 and Figure 20:

- Figure 18 (a) and (b) show the graph of the TDZ stress utilization response at span limit-1 and span limit-2 stations. Figure 18 (c) and (d) are the bar chart representation of the maximum value of the stress utilisation around the SCR TDZ.

- Figure 19 (a) and (b) show the range graph compression $\left(T_{T D Z}\right)$ around the 6 SCR TDZ for the vessel positioned at span limit-1 and span limit -2 stations. Figure 19 (c) and (d) present bar charts of the highest compressions around the SCR TDZ.

- Figure 20 (a) and (b) shows the range graph maximums of the 6 SCR top tensions $\left(T_{\text {top }}\right)$ at span limit-1 and span limit-2 station. Figure 20 (c) and (d) are bar chart representations of the maximum value of the SCRs $T_{\text {top }}$.

It could be observed that all constraint functions are satisfied except the compression limit for SCR-1 at span limit-2 station as shown in Figure 19 (b) and (d), where the $T_{T D Z}$ in the SCR-1 TDZ was less than $85 \mathrm{kN}$. $T_{T D Z} \geq 0 \mathrm{kN}$ can be specified as the compression limit around the SCR TDZ, but to allow for safety margins, we have set this limit to $T_{T D Z} \geq 85 \mathrm{kN}$. Once the results have been post-processed, the index matching technique (applied for the optimisation 
process) provides the flexibility to the user or the design engineer to reset these constraint limits based on design standards and client specifications, without the need for re-simulation.

The relocation programs dependent on the unfeasible symmetric relocation patterns (shaded red) are supposed to be eliminated from the solution process if only symmetric relocation patterns were to be considered for the problem. However, in this screening analysis, we explore the opportunity to identify the infeasible symmetric relocation patterns and modify their span limits, thereby converting or degenerating them to non-symmetric but feasible relocation patterns. This increases the potential of obtaining non-symmetric relocation programs that could be a good solution to the problem. To conduct this conversion process, if any symmetric span limit station pair is unfeasible, the next possible lower span limit pair are considered. For example, consider the unfeasible symmetric span limit pair ID $\{95,95\}$ in Table 9 (c); this pair being feasible at span limit-1, will retain its ID $\{95, \ldots\}$. However, because it is unfeasible at span limit 2, the ID $\{\ldots, 95\}$ will be degenerated to the next lower feasible span radius along the same relocation axis $\left(\alpha=120^{\circ}\right)$, which in this case is ID $\{\ldots, 29\}$. Hence the unfeasible symmetric span limit pair ID $\{95,95\}$ is now converted to a feasible non-symmetric span limit pair ID $\{95,29\}$, which corresponds to $\alpha=120^{\circ}, R_{1}=16 \%, R_{2}=5 \%$. The same modification is applied for all unfeasible span limit pairs to derive the feasible span limit pair matrix presented in Table 9 (d). It is observed from Table 9 (d) that after the reduction process, some span limit station pairs are repeated (see the 16 cells shaded grey). Hence, we remove these duplicates from the design space to avoid repetition of simulation of relocation programs developed from them in the fatigue analysis stage.

The cells in Table 9 (d) (excluding the greyed cells) define the feasible span limit pairs for which the vessel relocation programs are generated, and optimisation simulations are conducted. The screening analysis removes the need to include the storm simulation during the optimisation process, where all candidate stations of all relocation programs are supposed to be simulated. Instead, with the feasible relocation patterns obtained from the screening process, only fatigue calculation (evaluation of the objective function) will be conducted. Recall from Figure 7, that for each span limit pair, there are four dependent relocation programs $(p=3,5,7,9)$, with a total of 24 stations. By conducting the storm response analysis only for the span limit stations and removing 16 duplicated limit pairs after the modification, we eliminate the need to simulate (16 span limit pair duplications $\times 24$ stations $\times 2$ wave directions $=768)$ numerical fatigue models. Also, instead of the $(120$ span limits pairs $\times 24$ stations $\times 2$ wave directions $=5760$ ) numerical storm models that would have been simulated during the optimisation simulation stage, only $(2 \times 120$ span limit pairs $\times 2$ storm wave direction $=480$ ) numerical storm models are simulated at the screening stage. Hence, the screening exercise provides the opportunity to enlarge the optimisation space by including nonsymmetric relocation programs and provide up to $47.5 \%$ reduction in the computation resource required for the vessel relocation optimisation problem. 
Table 8. Coordinates and station IDs for symmetric relocation patterns: (a) Set of span limit-1 coordinates, (b) Set of span limit-2 coordinates, (c) integer ID representation for both sets of span limit-1 and span limit-2 stations, (d) ID pairs for span limit-1 and span limit-2 stations ((span limit-1, span limit-2))

(a)

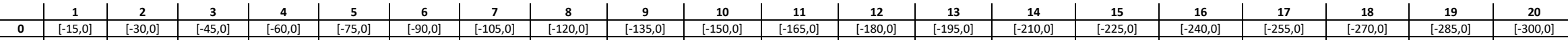

Axis (deg)

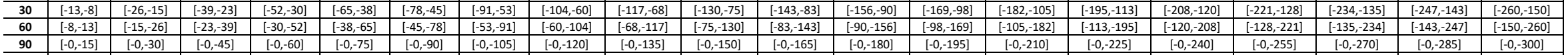

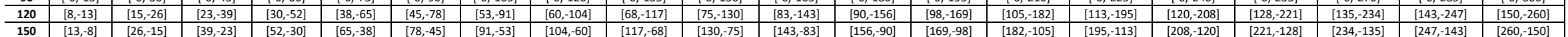

(b)

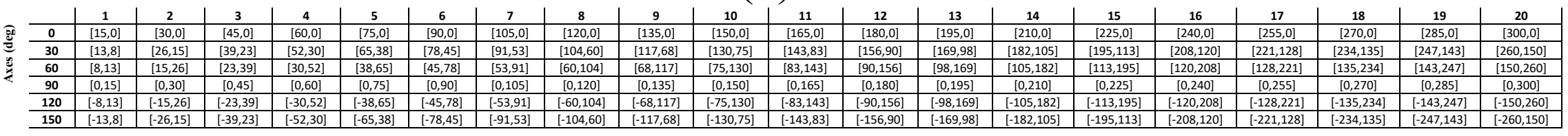

(c)

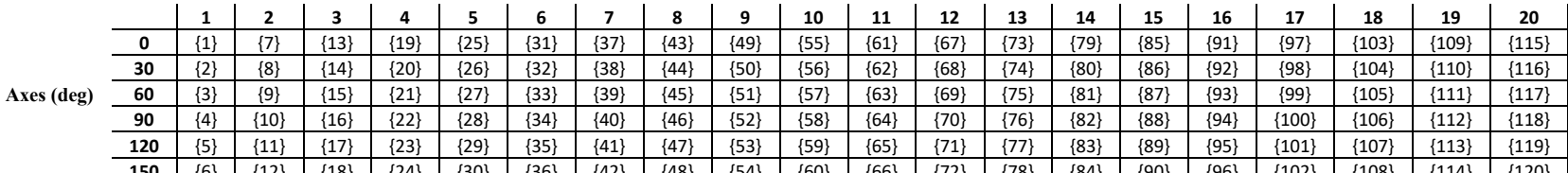

(d)

\begin{tabular}{|c|c|c|c|c|c|c|c|c|c|c|c|c|c|c|c|c|c|c|c|c|c|}
\hline \multirow{7}{*}{ (deg) } & & 1 & 2 & 3 & 4 & 5 & 6 & 7 & 8 & 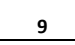 & 10 & 11 & 12 & 13 & 14 & 15 & 16 & 17 & 18 & 19 & 20 \\
\hline & 0 & $\{1,1\}$ & $\{7,7\}$ & $\{13,13\}$ & $\{19,19\}$ & $\{25,25\}$ & $\{31,31\}$ & $\{37,37\}$ & $\{43,43\}$ & $\{49,49\}$ & $\{55,55\}$ & $\{61,61\}$ & $\{67,67\}$ & $\{73,73\}$ & $\{79,79\}$ & $\{85,85\}$ & $\begin{array}{l}\{1,91\} \\
\end{array}$ & $\{97,97\}$ & $\{103,103\}$ & $\{109,109\}$ & $\{115,115\}$ \\
\hline & 30 & $\{2,2\}$ & $\{8,8\}$ & $\{14,14\}$ & $\{20,20\}$ & $\{26,26\}$ & $\{32,32\}$ & $\{38,38\}$ & $\{44,44\}$ & $\{50,50\}$ & $\{56,56\}$ & $\{62,62\}$ & $\{68,68\}$ & $\{74,74\}$ & $\{80,80\}$ & $\{86,86\}$ & $\{92,92\}$ & $\{98,98\}$ & $\{104,104\}$ & $\{110,110\}$ & $\{116,116\}$ \\
\hline & 60 & $\{3,3\}$ & $\{9,9\}$ & $\{15,15\}$ & $\{21,21\}$ & $\{27,27\}$ & $\{33,33\}$ & $\{39,39\}$ & $\{45,45\}$ & $\{51,51\}$ & $\{57,57\}$ & $\{63,63\}$ & $\{69,69\}$ & $\{75,75\}$ & $\{81,81\}$ & $\{87,87\}$ & $\{93,93\}$ & $\{99,99\}$ & $\{105,105\}$ & $\{111,111\}$ & $\{117,117\}$ \\
\hline & 90 & $\{4,4\}$ & $\{10,10\}$ & $\{16,16\}$ & $\{22,22\}$ & $\begin{array}{l}\{28,28\} \\
\end{array}$ & $\begin{array}{l}\{34,34\} \\
\end{array}$ & $\{40,40\}$ & $\{46,46\}$ & $\{52,52\}$ & $\{58,58\}$ & $\{64,64\}$ & $\{70,70\}$ & $\{76,76\}$ & $\begin{array}{l}82,82\} \\
\end{array}$ & $\begin{array}{l}\{88,88\} \\
\end{array}$ & $\{94,94\}$ & $\{100,100\}$ & $\{106,106\}$ & $\{1112,112\}$ & $\{118,118\}$ \\
\hline & 120 & $\{5,5\}$ & $\{11,11\}$ & $\{17,17\}$ & $\{23,23\}$ & $\{29,29\}$ & $\{35,35\}$ & $\{41,41\}$ & $\{47,47\}$ & $\{\{33,53\}$ & $\{59,59\}$ & $\{65,65\}$ & $\{71,71\}$ & $\{77,77\}$ & $\{83,83\}$ & $\{89,89\}$ & $\{95,95\}$ & $\{101,101\}$ & $\{107,107\}$ & $\{113,113\}$ & $\{119,119\}$ \\
\hline & 150 & $\{6,6\}$ & $\{12,12\}$ & $\{18,18\}$ & $\{24,24\}$ & $\{30,30\}$ & $\{36,36\}$ & $\{42,42\}$ & $\{48,48\}$ & $\{54,54\}$ & $\{60,60\}$ & $\{66,66\}$ & $\{72,72\}$ & $\{78,78\}$ & $\{84,84\}$ & $\{90,90\}$ & $\{96,96\}$ & $\{102,102\}$ & $\{108,108\}$ & $\{114,114\}$ & $\{120,120\}$ \\
\hline
\end{tabular}

Table 9. Relocation pattern feasibility matrices: (a)Feasibility matrix for the 6 SCRs at span limit-1 stations, (b) Feasibility matrix for the 6 SCRs at span limit-2 stations, (c) Span limit ID pair feasibility matrix for symmetric relocation patterns, (d) Modified symmetric span limit ID pair now containing non-symmetric relocation patterns. 
(a)

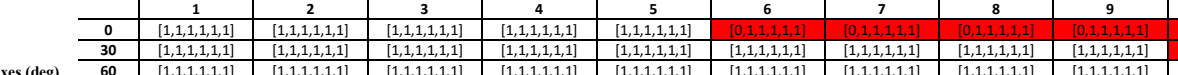

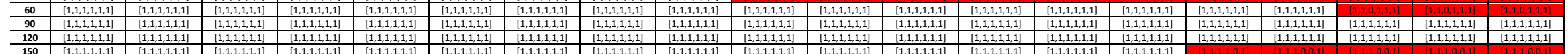

(b)

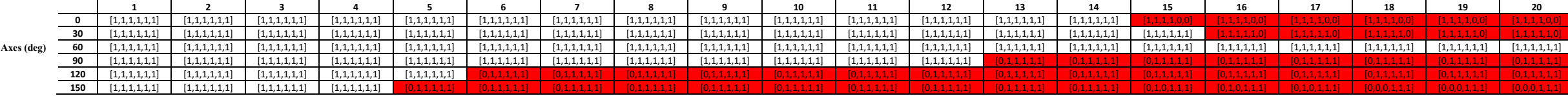

(c)

Axes (deg)

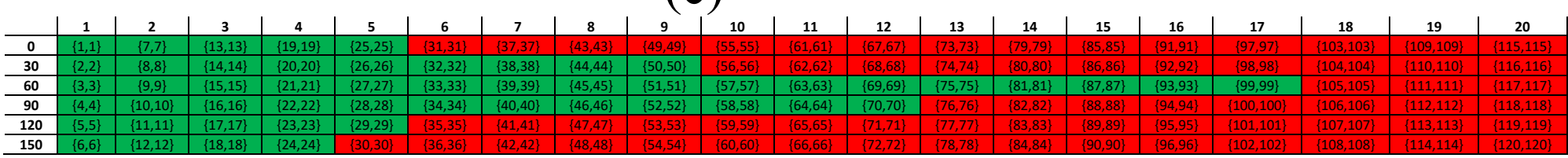

(d)

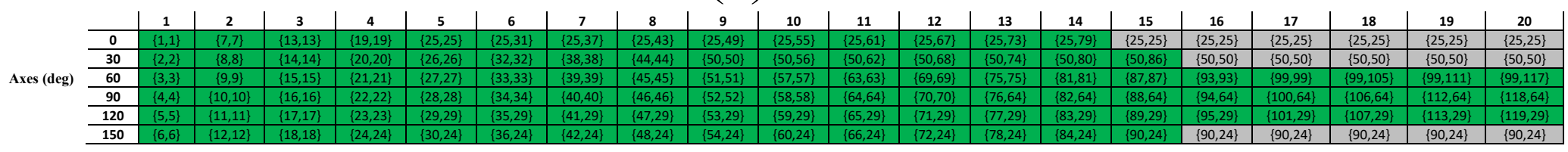



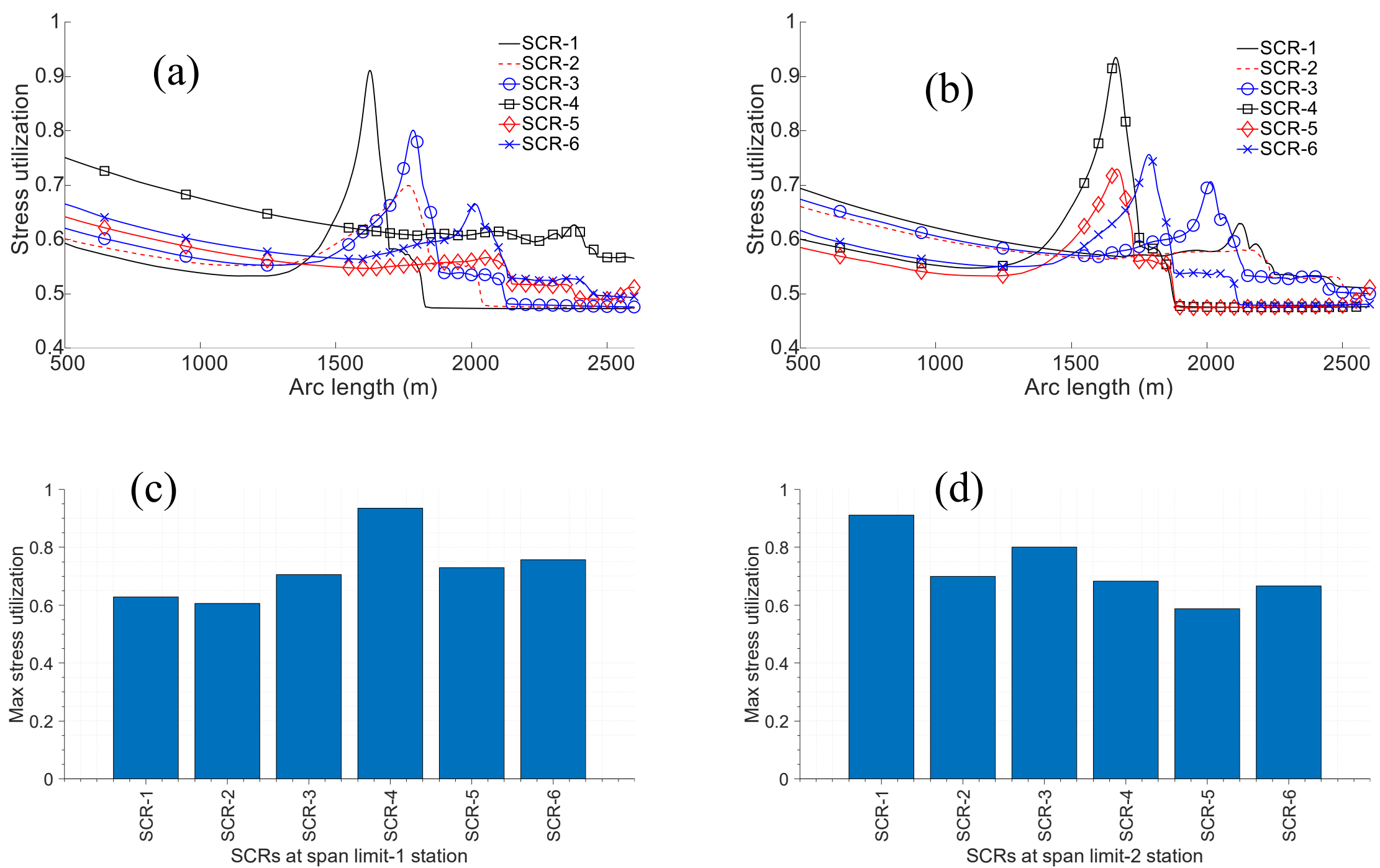

Figure 18. TDZ stress utilization at span limit station pair (station pair ID \{95,95\}): (a) range graph maximum at span limit-1 station, (b) range graph maximum at span limit-2 station, (c) Maximum values at span limit-1 station, (d) Maximum values at span limit-2 station. 

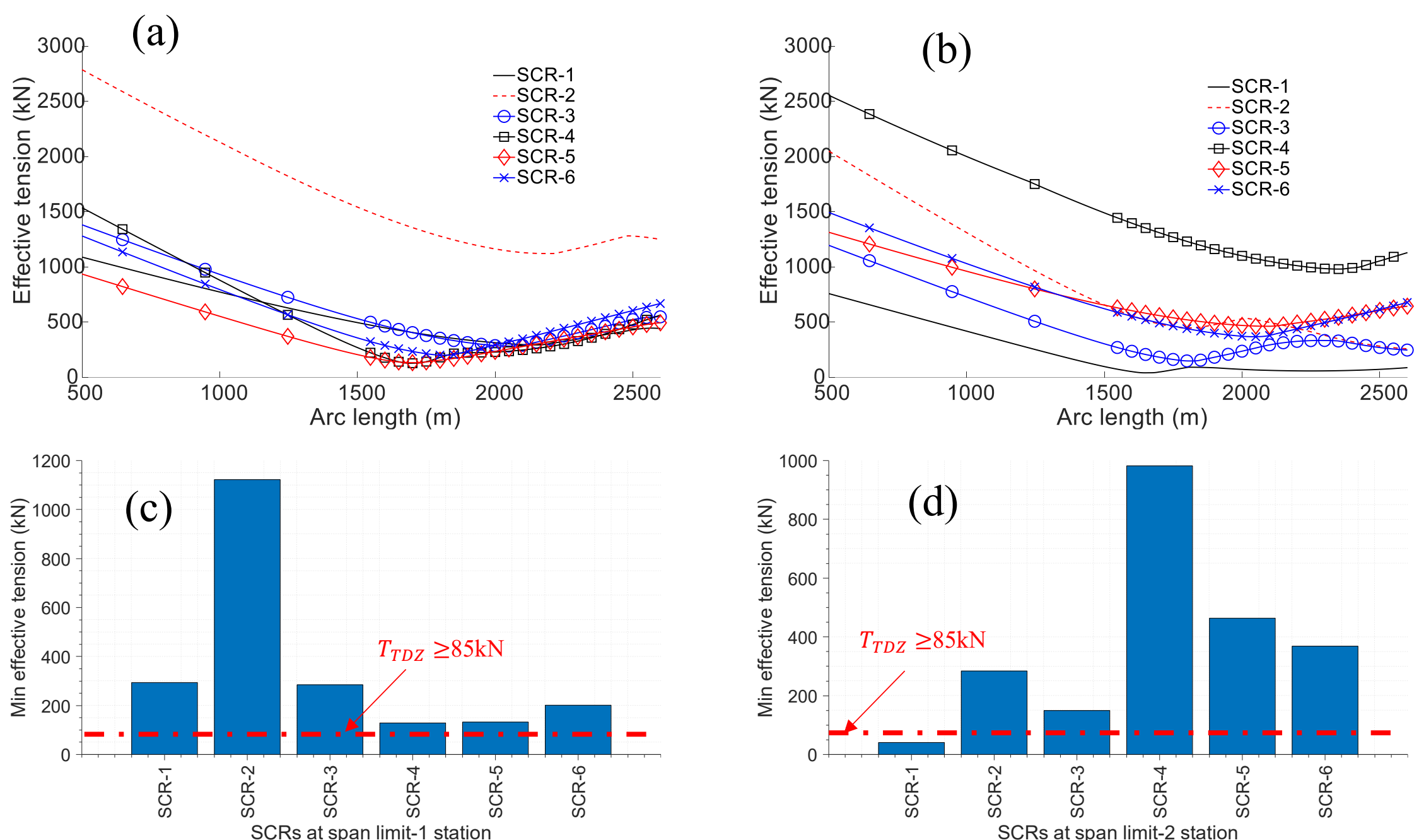

Figure 19. TDZ compression (minimum effective tension) at span limit station pair (station pair ID \{95,95\}): (a) range graph minimum at span limit-1 station, (b) range graph minimum at span limit-2 station, (c) Minimum values at span limit-1 station, (d) Minimum values at span limit-2 station. 
(a)
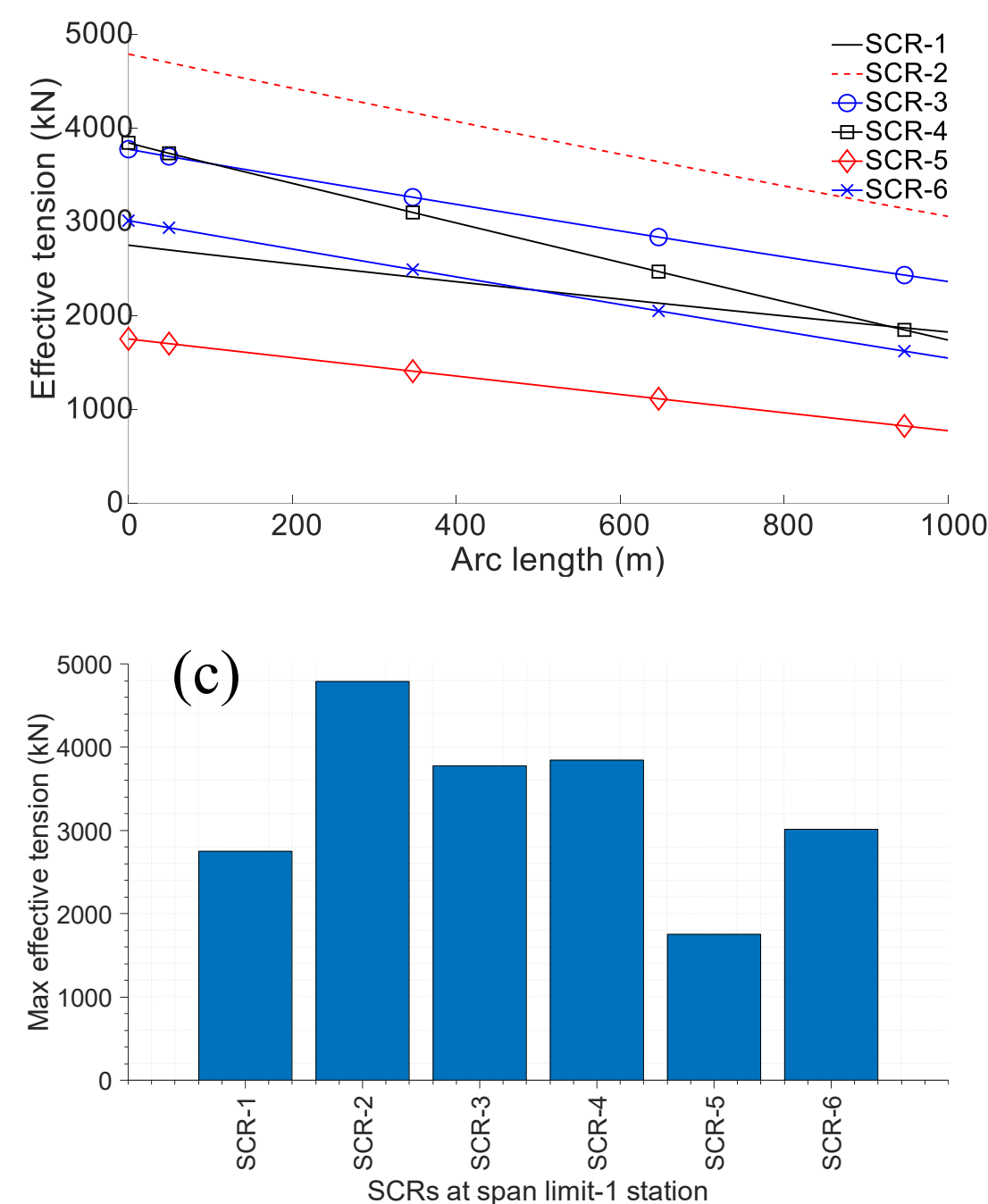

(b)
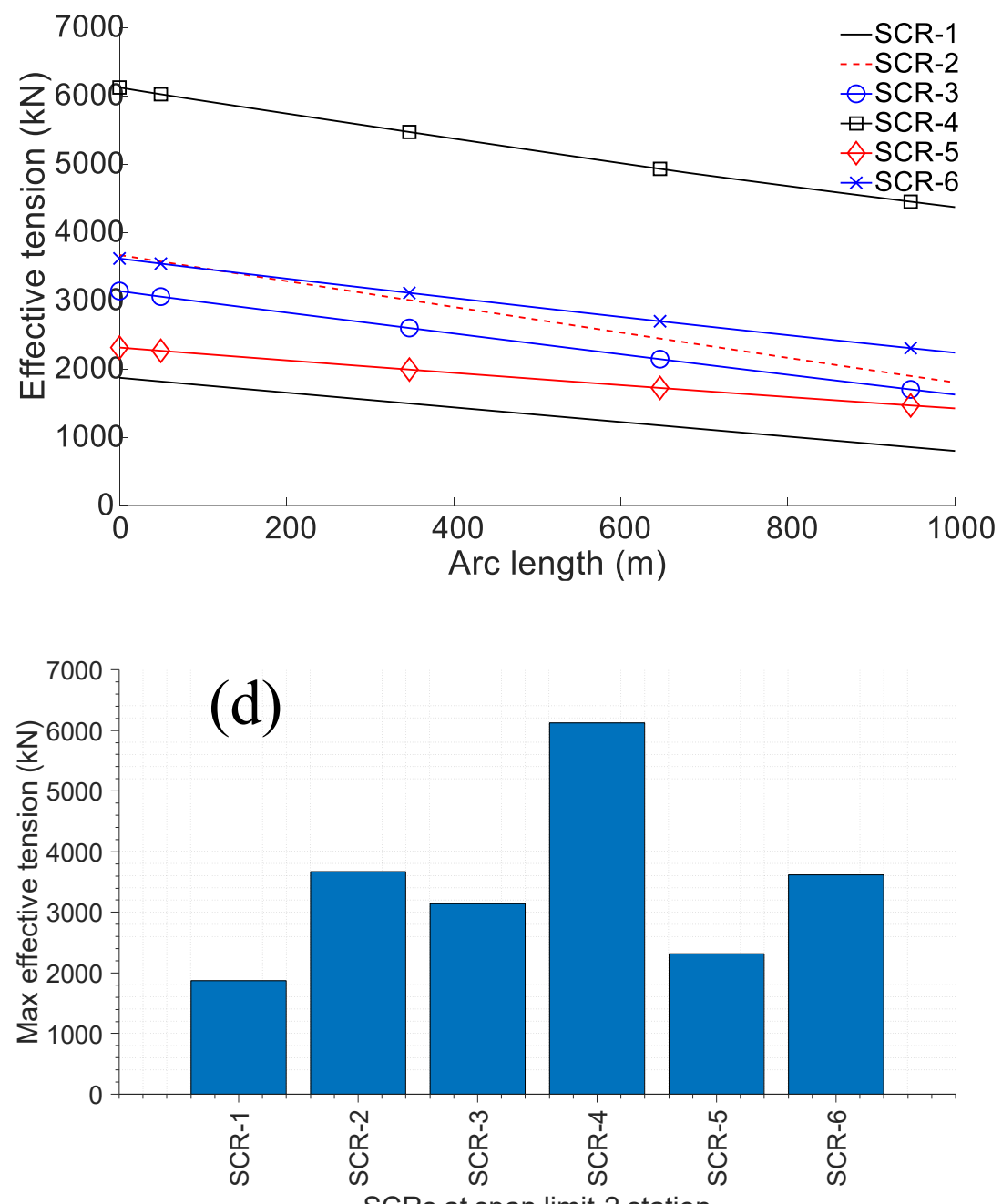

Figure 20. Top tension at span limit station pair (station pair ID $\{95,95\}$ ): (a) range graph maximum at span limit-1 station, (b) range graph maximum at span limit-2 station, (c) Maximum values at span limit-1 station, (d) Maximum values at span limit-2 station.

*Note from equation (10) that the limit on the maximum top tension constraints for the 6 SCRs are $\approx[7883,15450,11351,15450,7883,11351] \mathrm{kN}$ 


\subsection{The global and ideal optimum relocation programs}

In section 3.4, two methods were developed for the index matching optimisation technique to obtain families of optimum relocation programs. The global optimum relocation programs presented in this section are computed based on these two methods. Results obtained by the two methods are also compared in this section.

\subsubsection{Method 1 solutions - Construction of a global objective function}

The solution method detailed in section 3.4.1 creates a normalised global objective function $\left(F^{n o m}\right)$, which jointly represents the six SCR objective functions, $\left(D_{e f f}\right)$, where $j=1$ to 6 . The normalised effective fatigue damage, $F^{\text {nom }}$, is only representative of the effective fatigue damage for the SCRs' TDZ. It is used by the index matching optimisation technique to track the optimum relocation programs' indices. From the obtained index set, the actual effective damage response of the 6 SCRs can then be matched and reported. For this study, the parameters required to calculate $F^{\text {nom }}$ are obtained and presented in Table 10.

Table 10. Parameters for calculating the normalised global objective function $\left(F^{\text {nom }}\right)$.

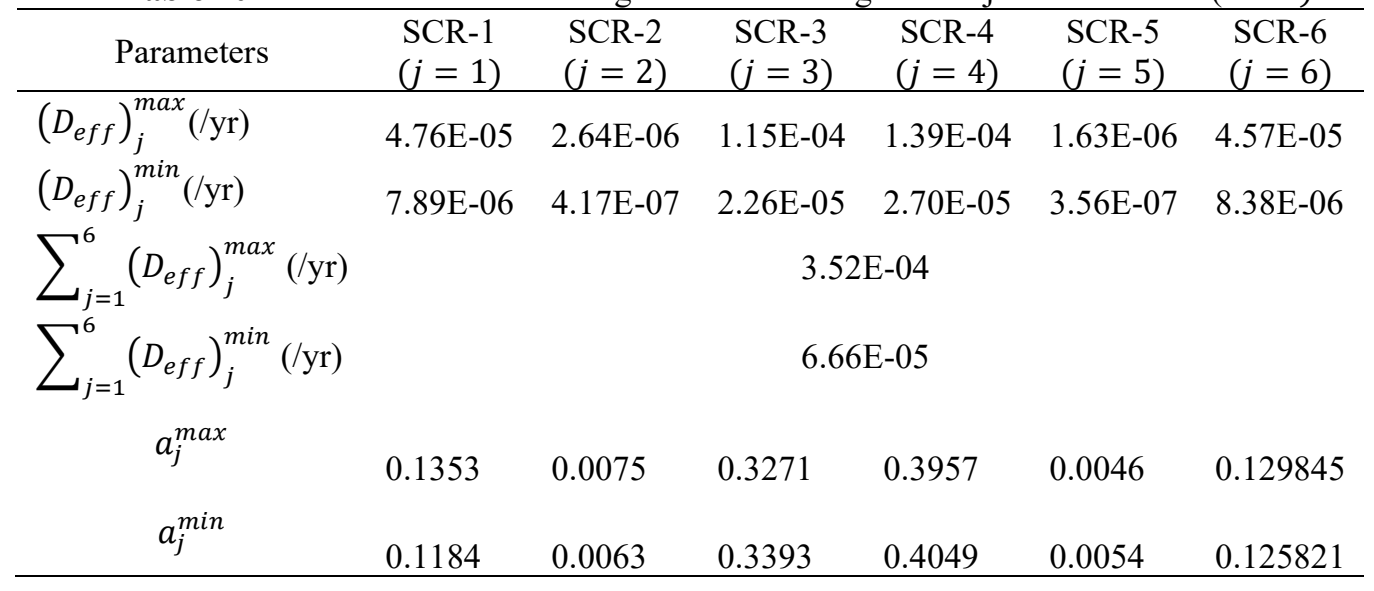

Applying the index matching optimisation technique on the computed $F^{\text {nom }}$ based on the two options of $a_{j}^{\max }$ and $a_{j}^{\min }$, the first 20 global optimum relocation programs are obtained and presented in Table 12. The following are details of the columns of Table 12.

- The "S/N" column indicates the position of each of the relocation programs in decreasing order of performance of the normalised global objective function, $F^{\text {nom }}$.

- The "Index" column is the unique index representation of the relocation programs used to track the family members of the global optimum relocation programs.

- The " $\left[p, R_{1}, R_{2}, \alpha\right]$ " column contains the coordinates or design points of the relocation programs. These are the optimisation design variables for the vessel relocation optimisation analysis. Recall that the span limit of any relocation program is defined by the span radii $R_{1}$ and $R_{2}$ on both sides of the nominal station. For $R_{1}=R_{2}$ the relocation program is symmetrical, i.e., the span limit stations are equidistant from the nominal station. For $R_{1} \neq R_{2}$, the relocation program is non-symmetrical, i.e., the span limit stations for the relocation program are not equidistant from the nominal station.

- The " $F$ nom" column is the normalised joint global objective function. As seen in Table 11 , the values of $F^{\text {nom }}$ appear in increasing order, with the minimum at the top. 
It could be observed that the index representation of the global optimum solutions matches closely for the $F^{\text {nom }}$ calculated based on $a_{j}^{\max }$ and $a_{j}^{\text {min }}$, with a few mismatches as one progresses down the index columns. A more intuitive comparison of $F^{\text {nom }}$ from the two weighting options is presented in Figure 21, where it is seen that the order of index solutions for the first 20 global optimum relocation programs matches, except $\mathrm{S} / \mathrm{N} 4$ and 5 (relocation program index-72 and index-100). From Table 11 and Figure 21, it could be seen that the solutions are less sensitive to which options of $a_{j}^{\text {max }}$ or $a_{j}^{\text {min }}$ is used for the calculation process in method-1. Hence, the $F^{\text {nom }}$ calculated from $a_{j}^{\max }$ will be considered. The effective damage $\left(D_{e f f}\right)_{j}$ of the six SCRs are obtained by matching corresponding indices of $F^{\text {nom }}$ to the effective fatigue damage data. These are presented in Table 12. It could be seen from Table 12 that while the $F^{\text {nom }}$ column contains values in increasing order (the minimum at the top), this is not guaranteed for the $D_{\text {eff }}$ columns of the 6 SCRs. This of course is a peculiar feature of a multi-objective optimisation problem, where a good global solution is likely not to be the best solution across all the objectives but one that assigns weighted consideration to them. However, the performance of these $D_{e f f}$ values compared with the no vessel relocation case will prove the effectiveness of the vessel relocation strategy for multiple SCRs. This will be discussed shortly. The fatigue damage for the 6 SCRs for the no vessel relocation case is presented in Table 13. The "no vessel relocation" is where the vessel is kept at the nominal station without vessel offsets. It represents the traditional way of conducting SCR fatigue analysis.

\subsubsection{Method 2 solutions - Intersection of the index systems of the Ideal solutions}

The results obtain using method-2 is presented in Table 14, which contains the ideal optimum solutions for each of the 6 SCRs with their corresponding design variables, $\left[\alpha, R_{1}, R_{2}, p\right]$ and effective fatigue damage, $D_{\text {eff }}$. The individual ideal solutions are the family of optimum relocation programs obtained considering each objective function, $\left(D_{e f f}\right)_{j}$ exclusively. This means, within the feasible design, a given $\left(D_{e f f}\right)_{j}$ is obtained without considerations of the influence from other objective functions. Technically, this is a single objective optimisation problem for the objective function in question. As such, there will be 6 independent families of ideal solutions for the six SCRs presented in the columns of Table 14. It is observed from Table 14 that the best (top) ideal optimum relocation program for each objective function is different except for SCR- 1 and SCR-3, which have a common best ideal optimum relocation program (index-356) characterised by the design variables, $\left[\alpha, R_{1}, R_{2}, p\right]=\left[150^{\circ}, 15 \%, 4 \%\right.$, 9]. However, as we progress down the columns, order of members of ideal solutions for SCR1 and SCR-3 differs. The family of global optimum relocation programs are obtained by conducting the intersections of the index columns $\left[I_{1}^{\prime}, I_{2}^{\prime}, I_{3}^{\prime}, I_{4}^{\prime}, I_{5}^{\prime}, I_{6}^{\prime}\right], q$ row at a time, as discussed in section 3.4.2 and demonstrated in Figure 12 (b). As one progresses down the columns, there appear not to be any intersection until $q=34$, where index-148 appeared. Going further down the columns result in more intersection of relocation program indices. However, we truncate the table after the first 20 intersections where obtained. Please note that the table's text size has been reduced to fit on one page, and some rows containing repetitions of intersected indices have been removed from the presented $q$ rows for brevity. It is of interest to investigate the performance comparison of the global optimum relocation programs with the ideal optimum relocation program and the "no vessel relocation" case. This will be discussed shortly. 
Table 11. The first 20 family of global optimum relocation programs.

\begin{tabular}{|c|c|c|c|c|c|c|}
\hline & \multicolumn{3}{|c|}{$F^{\text {nom }}$ calculated using $a_{j}^{\text {max }}$} & \multicolumn{3}{c|}{$F^{\text {nom }}$ calculated using $a_{j}^{\text {min }}$} \\
\hline $\mathrm{S} / \mathrm{N}$ & Index & $\begin{array}{c}{\left[\alpha, R_{1}, R_{2}, p\right]} \\
(-),(\%),(\%),(\mathrm{deg})]\end{array}$ & $F^{\text {nom }}(/ \mathrm{yr})$ & Index & $\begin{array}{c}{\left[\alpha, R_{1}, R_{2}, p\right]} \\
{[(-),(\%),(\%),(\mathrm{deg})]}\end{array}$ & $F^{\text {nom }}(/ \mathrm{yr})$ \\
\hline 1 & 76 & {$[0,4,4,9]$} & 0.018362 & 76 & {$[0,4,4,9]$} & 0.018413 \\
\hline 2 & 96 & {$[150,4,4,9]$} & 0.026558 & 96 & {$[150,4,4,9]$} & 0.026776 \\
\hline 3 & 52 & {$[0,3,3,9]$} & 0.036916 & 52 & {$[0,3,3,9]$} & 0.036366 \\
\hline 4 & 100 & {$[0,5,5,9]$} & 0.039671 & 72 & {$[150,3,3,9]$} & 0.039625 \\
\hline 5 & 72 & {$[150,3,3,9]$} & 0.040425 & 100 & {$[0,5,5,9]$} & 0.03989 \\
\hline 6 & 124 & {$[0,5,6,9]$} & 0.04144 & 124 & {$[0,5,6,9]$} & 0.041289 \\
\hline 7 & 104 & {$[30,5,5,9]$} & 0.044943 & 104 & {$[30,5,5,9]$} & 0.044615 \\
\hline 8 & 148 & {$[0,5,7,9]$} & 0.047302 & 148 & {$[0,5,7,9]$} & 0.046814 \\
\hline 9 & 80 & {$[30,4,4,9]$} & 0.048734 & 80 & {$[30,4,4,9]$} & 0.0482 \\
\hline 10 & 128 & {$[30,6,6,9]$} & 0.049725 & 128 & {$[30,6,6,9]$} & 0.049464 \\
\hline 11 & 120 & {$[150,5,4,9]$} & 0.053831 & 120 & {$[150,5,4,9]$} & 0.052608 \\
\hline 12 & 152 & {$[30,7,7,9]$} & 0.064608 & 152 & {$[30,7,7,9]$} & 0.064302 \\
\hline 13 & 116 & {$[120,5,5,9]$} & 0.068294 & 116 & {$[120,5,5,9]$} & 0.067108 \\
\hline 14 & 51 & {$[0,3,3,9]$} & 0.074796 & 51 & {$[0,3,3,7]$} & 0.075049 \\
\hline 15 & 95 & {$[150,4,4,7]$} & 0.078031 & 95 & {$[150,4,4,7]$} & 0.078536 \\
\hline 16 & 75 & {$[0,4,4,7]$} & 0.078471 & 75 & {$[0,4,4,7]$} & 0.078555 \\
\hline 17 & 192 & {$[150,8,4,9]$} & 0.082259 & 192 & {$[150,8,4,9]$} & 0.080732 \\
\hline 18 & 144 & {$[150,6,4,9]$} & 0.082992 & 144 & {$[150,6,4,9]$} & 0.082813 \\
\hline 19 & 147 & {$[0,5,7,7]$} & 0.083254 & 147 & {$[0,5,7,7]$} & 0.083076 \\
\hline 20 & 176 & {$[30,8,8,9]$} & 0.084187 & 176 & {$[30,8,8,9]$} & 0.083529 \\
\hline
\end{tabular}

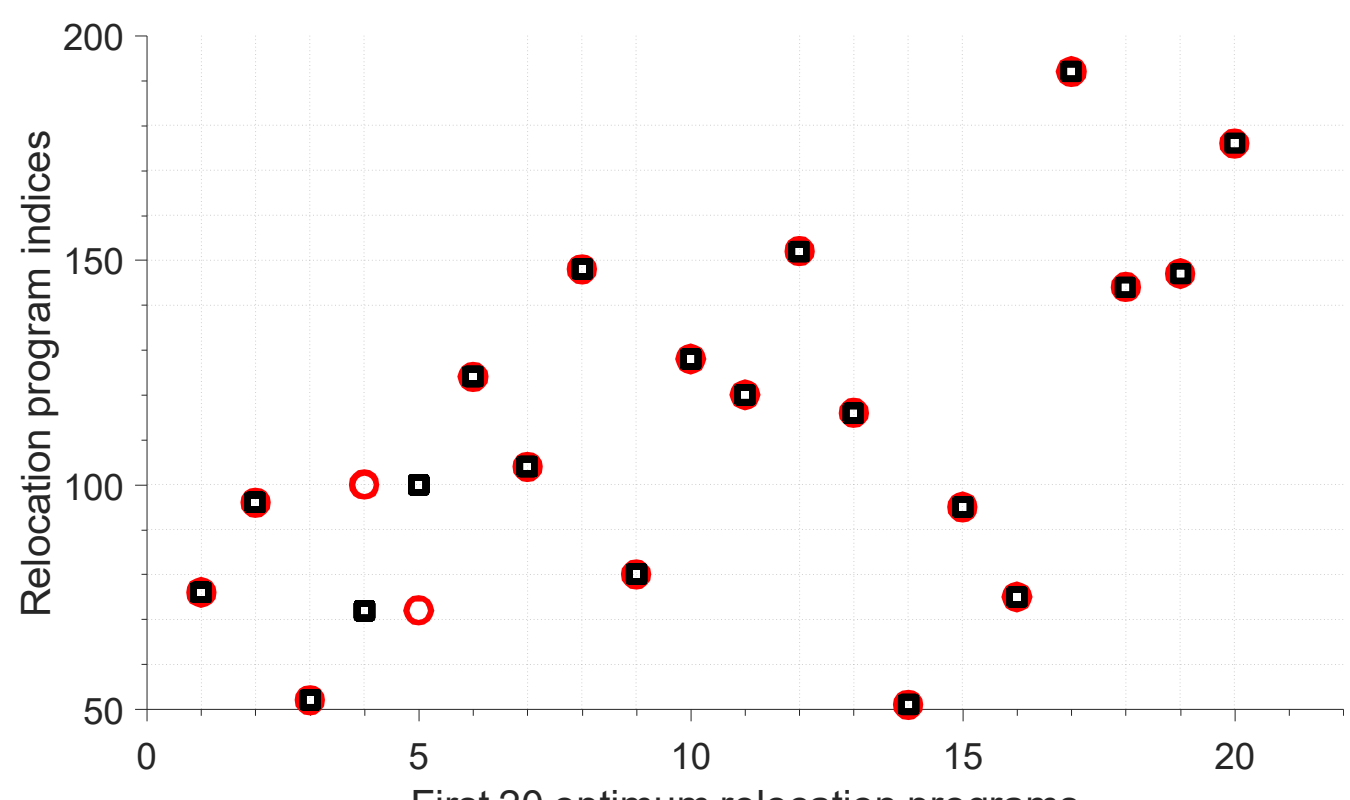

First 20 optimum relocation programs

Figure 21. A matching plot of the first 20 members of the global optimum relocation program calculated based on the two weighting options, $a_{j}^{\max }$ and $a_{j}^{\min }$. 
Table 12. Effective fatigue damage in the 6 SCR TDZ for the first 20 members of the optimum relocation programs (calculated from method 1).

\begin{tabular}{|c|c|c|c|c|c|c|c|c|c|}
\hline \multirow{2}{*}{$\mathrm{S} / \mathrm{N}$} & \multirow{2}{*}{ Index } & \multirow{2}{*}{$\begin{array}{c}{\left[\alpha, R_{1}, R_{2}, p\right]} \\
{[(-),(\%),(\%),(\operatorname{deg})]}\end{array}$} & \multirow{2}{*}{$F^{\text {nom }}(/ \mathrm{yr})$} & \multicolumn{6}{|c|}{ Corresponding $D_{e f f}(/ \mathrm{yr})$ for each SCRs' TDZ } \\
\hline & & & & SCR-1 & SCR-2 & SCR-3 & SCR-4 & SCR-5 & SCR-6 \\
\hline 1 & 76 & {$[0,4,4,9]$} & 0.018362 & $9.01 \mathrm{E}-06$ & $4.66 \mathrm{E}-07$ & $2.62 \mathrm{E}-05$ & $2.70 \mathrm{E}-05$ & 3.99E-07 & $8.81 \mathrm{E}-06$ \\
\hline 2 & 96 & {$[150,4,4,9]$} & 0.026558 & $9.89 \mathrm{E}-06$ & $4.66 \mathrm{E}-07$ & $2.62 \mathrm{E}-05$ & $2.89 \mathrm{E}-05$ & 3.99E-07 & $8.39 \mathrm{E}-06$ \\
\hline 3 & 52 & {$[0,3,3,9]$} & 0.036916 & $8.86 \mathrm{E}-06$ & $4.66 \mathrm{E}-07$ & $2.67 \mathrm{E}-05$ & $3.21 \mathrm{E}-05$ & 3.99E-07 & $8.38 \mathrm{E}-06$ \\
\hline 4 & 100 & {$[0,5,5,9]$} & 0.039671 & $1.02 \mathrm{E}-05$ & $4.66 \mathrm{E}-07$ & $2.87 \mathrm{E}-05$ & $2.84 \mathrm{E}-05$ & $3.99 \mathrm{E}-07$ & $9.87 \mathrm{E}-06$ \\
\hline 5 & 72 & {$[150,3,3,9]$} & 0.040425 & $8.85 \mathrm{E}-06$ & $4.66 \mathrm{E}-07$ & $3.04 \mathrm{E}-05$ & $2.93 \mathrm{E}-05$ & 3.99E-07 & $8.45 \mathrm{E}-06$ \\
\hline 6 & 124 & {$[0,5,6,9]$} & 0.04144 & $9.25 \mathrm{E}-06$ & $4.20 \mathrm{E}-07$ & $2.55 \mathrm{E}-05$ & $3.31 \mathrm{E}-05$ & $3.57 \mathrm{E}-07$ & $9.77 \mathrm{E}-06$ \\
\hline 7 & 104 & {$[30,5,5,9]$} & 0.044943 & $9.01 \mathrm{E}-06$ & $4.66 \mathrm{E}-07$ & $2.64 \mathrm{E}-05$ & $3.29 \mathrm{E}-05$ & $3.99 \mathrm{E}-07$ & $1.01 \mathrm{E}-05$ \\
\hline 8 & 148 & {$[0,5,7,9]$} & 0.047302 & $8.65 \mathrm{E}-06$ & $4.18 \mathrm{E}-07$ & $2.79 \mathrm{E}-05$ & $3.17 \mathrm{E}-05$ & $3.58 \mathrm{E}-07$ & $1.09 \mathrm{E}-05$ \\
\hline 9 & 80 & {$[30,4,4,9]$} & 0.048734 & $8.96 \mathrm{E}-06$ & $4.66 \mathrm{E}-07$ & $2.47 \mathrm{E}-05$ & $3.66 \mathrm{E}-05$ & 3.99E-07 & $9.13 \mathrm{E}-06$ \\
\hline 10 & 128 & {$[30,6,6,9]$} & 0.049725 & $9.21 \mathrm{E}-06$ & $4.66 \mathrm{E}-07$ & $2.93 \mathrm{E}-05$ & $3.00 \mathrm{E}-05$ & $3.99 \mathrm{E}-07$ & $1.13 \mathrm{E}-05$ \\
\hline 11 & 120 & {$[150,5,4,9]$} & 0.053831 & $8.66 \mathrm{E}-06$ & $4.23 \mathrm{E}-07$ & $3.16 \mathrm{E}-05$ & $3.19 \mathrm{E}-05$ & $3.57 \mathrm{E}-07$ & $8.67 \mathrm{E}-06$ \\
\hline 12 & 152 & {$[30,7,7,9]$} & 0.064608 & $9.74 \mathrm{E}-06$ & $4.66 \mathrm{E}-07$ & $3.26 \mathrm{E}-05$ & $2.94 \mathrm{E}-05$ & $3.99 \mathrm{E}-07$ & $1.23 \mathrm{E}-05$ \\
\hline 13 & 116 & {$[120,5,5,9]$} & 0.068294 & $9.69 \mathrm{E}-06$ & $4.67 \mathrm{E}-07$ & $3.73 \mathrm{E}-05$ & $2.85 \mathrm{E}-05$ & 3.99E-07 & $9.36 \mathrm{E}-06$ \\
\hline 14 & 51 & {$[0,3,3,7]$} & 0.074796 & $1.15 \mathrm{E}-05$ & $6.09 \mathrm{E}-07$ & $2.97 \mathrm{E}-05$ & $3.47 \mathrm{E}-05$ & $5.21 \mathrm{E}-07$ & $1.09 \mathrm{E}-05$ \\
\hline 15 & 95 & {$[150,4,4,7]$} & 0.078031 & $1.22 \mathrm{E}-05$ & $6.09 \mathrm{E}-07$ & $2.96 \mathrm{E}-05$ & $3.52 \mathrm{E}-05$ & $5.21 \mathrm{E}-07$ & $1.09 \mathrm{E}-05$ \\
\hline 16 & 75 & {$[0,4,4,7]$} & 0.078471 & $1.15 \mathrm{E}-05$ & $6.09 \mathrm{E}-07$ & $3.17 \mathrm{E}-05$ & $3.37 \mathrm{E}-05$ & $5.21 \mathrm{E}-07$ & $1.10 \mathrm{E}-05$ \\
\hline 17 & 192 & {$[150,8,4,9]$} & 0.082259 & $8.17 \mathrm{E}-06$ & $4.23 \mathrm{E}-07$ & $2.74 \mathrm{E}-05$ & $4.24 \mathrm{E}-05$ & $3.57 \mathrm{E}-07$ & $1.07 \mathrm{E}-05$ \\
\hline 18 & 144 & {$[150,6,4,9]$} & 0.082992 & $1.14 \mathrm{E}-05$ & 4.74E-07 & $3.26 \mathrm{E}-05$ & $3.45 \mathrm{E}-05$ & $3.90 \mathrm{E}-07$ & $1.08 \mathrm{E}-05$ \\
\hline 19 & 147 & {$[0,5,7,7]$} & 0.083254 & $1.02 \mathrm{E}-05$ & $5.29 \mathrm{E}-07$ & $2.90 \mathrm{E}-05$ & $3.70 \mathrm{E}-05$ & $4.52 \mathrm{E}-07$ & $1.31 \mathrm{E}-05$ \\
\hline 20 & 176 & {$[30,8,8,9]$} & 0.084187 & $9.89 \mathrm{E}-06$ & $4.66 \mathrm{E}-07$ & $3.68 \mathrm{E}-05$ & $2.93 \mathrm{E}-05$ & 3.99E-07 & $1.35 \mathrm{E}-05$ \\
\hline
\end{tabular}

Table 13. Fatigue damage in the six SCR TDZ for the "no vessel relocation" case.

\begin{tabular}{|c|c|c|c|c|c|c|c|c|c|}
\hline \multirow{3}{*}{$\mathrm{S} / \mathrm{N}$} & \multirow{3}{*}{ Index } & $\begin{array}{c}{\left[\alpha, R_{1}, R_{2}, p\right]} \\
{[(-),(\%),(\%),(\mathrm{deg})]}\end{array}$ & \multirow{2}{*}{$F^{\text {nom }}(/ \mathrm{yr})$} & \multicolumn{5}{|c|}{ Fatigue damage for each SCRs' TDZ } \\
\cline { 5 - 10 } & & & SCR-1 & SCR-2 & SCR-3 & SCR-4 & SCR-5 & SCR-6 \\
\hline 1 & NA & NA & NA & $4.96 \mathrm{E}-05$ & $2.63 \mathrm{E}-06$ & $1.21 \mathrm{E}-04$ & $1.39 \mathrm{E}-04$ & $2.26 \mathrm{E}-06$ & $4.68 \mathrm{E}-05$ \\
\hline
\end{tabular}


Table 14. First 20 global optimum solutions obtained by conducting intersections of the index columns for the ideal solutions (method 2).

\begin{tabular}{|c|c|c|c|c|c|c|c|c|c|c|c|c|c|c|c|c|c|c|c|}
\hline \multirow[b]{2}{*}{$q$} & \multicolumn{3}{|c|}{ SCR-1 } & \multicolumn{3}{|c|}{ SCR-2 } & \multicolumn{3}{|c|}{ SCR-3 } & \multicolumn{3}{|c|}{ SCR-4 } & \multicolumn{3}{|c|}{ SCR-5 } & \multicolumn{3}{|c|}{ SCR-6 } & \multirow{2}{*}{$\begin{array}{l}\mathbf{I}_{\text {opt }}=\bigcap_{1}^{q}\left\{\left(I^{\prime}\right)\right\} \\
I^{\prime}=\left[I_{1}^{\prime}, I_{2}^{\prime}, I_{3}^{\prime}, I_{4}^{\prime}, I_{5}^{\prime}, I_{6}^{\prime}\right]\end{array}$} \\
\hline & $\begin{array}{l}\text { Index } \\
\left(l_{1}^{\prime}\right)\end{array}$ & 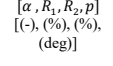 & $D_{e f f}$ & $\begin{array}{l}\text { Index } \\
\left(I_{2}^{\prime}\right)\end{array}$ & 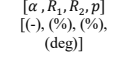 & $D_{\text {eff }}$ & $\begin{array}{l}\text { Index } \\
\left(I^{\prime} 3\right)\end{array}$ & 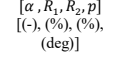 & $D_{\text {eff }}$ & $\begin{array}{l}\text { Index } \\
\left(I_{3}^{\prime}\right)\end{array}$ & 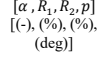 & $D_{e f f}$ & $\begin{array}{l}\text { Index } \\
\left(I_{3}^{\prime}\right)\end{array}$ & 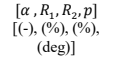 & $D_{\text {eff }}$ & $\begin{array}{l}\text { Index } \\
\left(I_{3}^{\prime}\right)\end{array}$ & 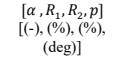 & $D_{e f f}$ & \\
\hline$\frac{1}{26}$ & $\begin{array}{l}356 \\
68\end{array}$ & $\frac{[150,15,4,9]}{[120,3,9]}$ & \begin{tabular}{|l|}
$7.89 E-06$ \\
$8.90 \mathrm{E}-06$
\end{tabular} & \begin{tabular}{|l|}
272 \\
316 \\
\end{tabular} & {$\left[\begin{array}{l}{[30,9,12,9]} \\
{[0.5,1,9]}\end{array}\right.$} & $\begin{array}{l}4.17 \mathrm{E}-07 \\
4.4 \mathrm{E}-07\end{array}$ & $\begin{array}{l}356 \\
416\end{array}$ & $\frac{[150,15,4,9]}{[120.20 .59}$ & $\begin{array}{l}2.26 \mathrm{E}-05 \\
28 \mathrm{E}-05\end{array}$ & $\begin{array}{l}76 \\
280 \\
\end{array}$ & 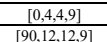 & $\begin{array}{l}2.70 \mathrm{E}-05 \\
3.22 \mathrm{E}-05 \\
\end{array}$ & $\begin{array}{l}404 \\
264\end{array}$ & $\begin{array}{l}{[120,19,5,9]} \\
{[150,11,4,9]}\end{array}$ & $\begin{array}{l}3.56 \mathrm{E}-07 \\
3.00 \mathrm{E}-07 \\
\end{array}$ & \begin{tabular}{|l}
52 \\
119
\end{tabular} & $\begin{array}{c}{[0,3,3,9]} \\
{[150,5,4,7]}\end{array}$ & $\begin{array}{l}8.38 \mathrm{E}-06 \\
1.08 \mathrm{E}-05\end{array}$ & {[]} \\
\hline 32 & 296 & $\begin{array}{c}{[120,0,3,9]} \\
{[30,9,13,9]} \\
\end{array}$ & \begin{tabular}{|l}
$8.006-106$ \\
$9.06-06$ \\
\end{tabular} & \begin{tabular}{|l|}
510 \\
380 \\
\end{tabular} & 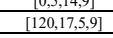 & $\begin{array}{l}4.45 \mathrm{E}-01 \\
4.62 \mathrm{E}-07\end{array}$ & $\begin{array}{l}128 \\
128 \\
\end{array}$ & $\begin{array}{c}1212,0,0,3,9] \\
{[30,6,6,9]}\end{array}$ & $\begin{array}{l}2.30 \mathrm{E}-03 \\
2.93 \mathrm{E}-05 \\
\end{array}$ & $\begin{array}{l}280 \\
159 \\
\end{array}$ & $\begin{array}{l}19,1,1,1,7]\} \\
{[900,7,7]}\end{array}$ & $\begin{array}{l}3.24 \mathrm{E}-05 \\
3.36 \mathrm{E}-05 \\
\end{array}$ & $\begin{array}{l}204 \\
96 \\
\end{array}$ & $\begin{array}{r}[150,1,4,4]] \\
{[150,4,49]} \\
\end{array}$ & $\begin{array}{l}3.305 \mathrm{EE}-07 \\
3.99-07\end{array}$ & 71 & $\begin{array}{c}{[150,0,4,3]} \\
\end{array}$ & $\frac{1.1080-135}{1.092-05}$ & \\
\hline 33 & 184 & {$[90,8,9]$} & 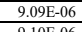 & $\begin{array}{l}360 \\
372 \\
707\end{array}$ & {$[60,16,16,9]$} & $4.66 \mathrm{E}-07$ & $\begin{array}{l}107 \\
\end{array}$ & {$[60,5,5,7]$} & $2.96 \mathrm{E}-05$ & $\begin{array}{l}75 \\
7\end{array}$ & {$[0,4,4,7]$} & $\begin{array}{l}3.37 \mathrm{E}-05 \\
30705\end{array}$ & 116 & {$[120,5,5,9]$} & $\begin{array}{l}3.99 \mathrm{E}-07 \\
\end{array}$ & 95 & {$[150,4,4,7]$} & $\begin{array}{l}1.09 E-05 \\
1.08-0 \varsigma\end{array}$ & \\
\hline 34 & 308 & {$[120,13,5,9]$} & \begin{tabular}{|l|}
$9.10 \mathrm{E}-06$ \\
$910 \mathrm{~F}-06$
\end{tabular} & 372 & {$[60,17,17,9]$} & $4.66 \mathrm{E}-07$ & 95 & {$[150,4,4,7]$} & $\begin{array}{l}2.96 \mathrm{E}-05 \\
\end{array}$ & 71 & {$[150,3,3,7]$} & $3.37 \mathrm{E}-05$ & 76 & {$[0,4,4,9]$} & $3.99 \mathrm{E}-07$ & 148 & {$[0,5,7,9]$} & $\begin{array}{l}1.09 E-05 \\
1.00-05\end{array}$ & {$[148]$} \\
\hline $\begin{array}{l}37 \\
38 \\
\end{array}$ & $\frac{272}{128}$ & $\frac{[33,9,1,2,9]}{[30,6,6,9]}$ & 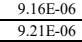 & $\frac{80}{204}$ & $\frac{[30,4,4,9]}{[60,9,9]}$ & $\begin{array}{l}4.66 \mathrm{E}-07 \\
4.66 \mathrm{E}-07\end{array}$ & $\begin{array}{l}240 \\
79 \\
\end{array}$ & $\frac{[150,1,4,4,9]}{[30,4,4,7]}$ & $\frac{2.99 \mathrm{E}-05}{2.99 \mathrm{E}-05}$ & $\begin{array}{l}140 \\
127\end{array}$ & $\frac{[120,6,5,9]}{[30,6,6,7]}$ & $\begin{array}{l}3.44 \mathrm{E}-05 \\
3.4 \mathrm{E}-05\end{array}$ & $\begin{array}{l}104 \\
72\end{array}$ & $\frac{[30,5,5,9]}{[15,0,3,9]}$ & $\begin{array}{l}3.99 \mathrm{E}-07 \\
3.99 \mathrm{E}-07\end{array}$ & $\begin{array}{l}31 \\
75 \\
\end{array}$ & $\frac{[30,2,2,7]}{[0,4,4]}$ & $\begin{array}{l}\frac{1.090-0.05}{1.10-05} \\
\end{array}$ & $\frac{[1488]}{[1448]}$ \\
\hline 39 & 124 & {$[0,5,6,9]$} & \begin{tabular}{|l|}
$9.25 \mathrm{E}-06$ \\
\end{tabular} & \begin{tabular}{|l|l}
207 \\
\end{tabular} & $\begin{array}{l}{[00,9,9,3]} \\
{[60,8,9,}\end{array}$ & $\begin{array}{l}4.60 \mathrm{E}-07 \\
.06 \mathrm{E}\end{array}$ & 55 & $\begin{array}{l}{[30,4,4,4]} \\
\end{array}$ & $3.01 \mathrm{E}-05$ & 112 & $\begin{array}{c}{[30,0,6,7]} \\
{[90,5,9]}\end{array}$ & $\begin{array}{l}.44 \mathrm{E}-03 \\
3.43 \mathrm{E}-05 \\
\end{array}$ & 80 & $\begin{array}{c}{[10,0,3,9]} \\
{[30,4,9]}\end{array}$ & $\begin{array}{l}3.99 \mathrm{E}-07 \\
3.99 \mathrm{E}-07\end{array}$ & 351 & $\frac{[12,4,4,1,5,7]}{[-1}$ & $\frac{1.1010-0.03}{1.10 \mathrm{E}-05}$ & {$\left[\frac{[124,148]}{[140]}\right.$} \\
\hline $\begin{array}{l}40 \\
41\end{array}$ & \begin{tabular}{|l|l|}
208 \\
208
\end{tabular} & $\frac{[150,2,2,9]}{[90,9,9,9}$ & \begin{tabular}{|l|}
$9.27 \mathrm{E}-06$ \\
$9.30 \mathrm{E}-06$
\end{tabular} & \begin{tabular}{|l|}
324 \\
132 \\
\end{tabular} & $\frac{[60,14,14,9]}{[60,6,6,9]}$ & $\begin{array}{l}4.66 \mathrm{E}-07 \\
4.6 \mathrm{E}-07\end{array}$ & $\begin{array}{l}196 \\
404 \\
\end{array}$ & 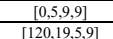 & $\begin{array}{l}3.01 \mathrm{E}-05 \\
3.02 \mathrm{E}-05\end{array}$ & $\begin{array}{l}99 \\
144\end{array}$ & $\begin{array}{c}{[0,5,5,7]} \\
{[15060.96}\end{array}$ & $\begin{array}{l}3.44 \mathrm{E}-05 \\
34 \mathrm{E}-05\end{array}$ & $\begin{array}{l}128 \\
152\end{array}$ & $\begin{array}{c}{[3,0,6,9]} \\
337799]\end{array}$ & $\begin{array}{l}3.99 \mathrm{E}-07 \\
3.9 \mathrm{E}-07\end{array}$ & $\begin{array}{l}115 \\
204 \\
\end{array}$ & {$\left[\begin{array}{lll}02,5,5,7] \\
{[60999]}\end{array}\right.$} & $\begin{array}{l}\frac{1.10 \mathrm{E}-05}{1} \\
10-05-5\end{array}$ & {$\left[\begin{array}{l}{[124,148]} \\
{[124,148]}\end{array}\right.$} \\
\hline $\begin{array}{l}41 \\
42 \\
\end{array}$ & 2088 & $\begin{array}{c}[90,19,9,9], 9] \\
90,10,1\end{array}$ & \begin{tabular}{|l}
$9.30 \mathrm{E}-06$ \\
$9.2 \mathrm{E}-06$
\end{tabular} & \begin{tabular}{|l}
132 \\
300 \\
\end{tabular} & 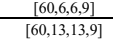 & $\begin{array}{l}4.66 \mathrm{E}-07 \\
4.6 \mathrm{E}-07\end{array}$ & $\frac{404}{72}$ & $\frac{[120,19,5,9]}{[150,3,9]}$ & $\begin{array}{l}3.0 .0 \mathrm{EE}-05 \\
.34 \mathrm{E}-05\end{array}$ & $\frac{144}{271}$ & $\frac{[150,6,4,9]}{[30,912,7]}$ & $\begin{array}{l}3.44 \mathrm{E}-05 \\
3.6 \mathrm{E}-05\end{array}$ & $\frac{152}{92}$ & $\frac{[31,7,7,9]}{[120,4,4,9]}$ & $\begin{array}{l}3.39 \mathrm{E}-07 \\
.99 \mathrm{E}-07\end{array}$ & $\begin{array}{l}204 \\
236\end{array}$ & 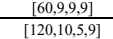 & $\frac{1.1010-\mathrm{E}-5}{1.111-05}$ & 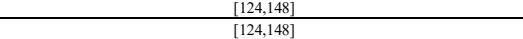 \\
\hline 43 & 248 & {$[30,9,11,9]$} & \begin{tabular}{|c|}
$9.36 \mathrm{E}-06$ \\
.606
\end{tabular} & 52 & {$[0,3,3]$} & $4.66 \mathrm{E}-07$ & 123 & {$[0,5,6,7]$} & $\begin{array}{l}3.04 \mathrm{E}-05 \\
.05\end{array}$ & 175 & {$[30,8,8,7]$} & $\begin{array}{l}3.46 \mathrm{E}-05 \\
.4505\end{array}$ & $\begin{array}{l}176 \\
728\end{array}$ & {$[30,8,8,9]$} & $3.99 \mathrm{E}-07$ & 131 & {$[60,6,6,7]$} & $1.111 \mathrm{E}-05$ & 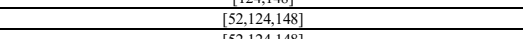 \\
\hline & 116 & {$[120,5,5,9]$} & \begin{tabular}{|l|}
$9.69 \mathrm{E}-06$ \\
\end{tabular} & 252 & {$[60,11,11,9]$} & $4.66 \mathrm{E}-07$ & 171 & {$[0,5,8,7]$} & 3.14E-05 & 348 & {$[90,15,11,9]$} & 3.48E-05 & 228 & {$[60,10,10,9]$} & 3.99E- 07 & 143 & {$[[150,6,4,7]$} & $1.12 \mathrm{E}-05$ & 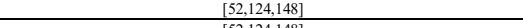 \\
\hline $\begin{array}{l}47 \\
48 \\
\end{array}$ & 152 & {$[30,7,7,9]$} & $\begin{array}{l}9.74 \mathrm{E}-06 \\
075 \mathrm{E}-06\end{array}$ & 200 & {$[30,9,9,9]$} & $\begin{array}{l}4.66 \mathrm{E}-07 \\
46 \mathrm{~F}-07\end{array}$ & 312 & {$[150,13,4,9]$} & $\begin{array}{r}3.14 \mathrm{E}-05 \\
3.14-05\end{array}$ & $\begin{array}{l}115 \\
207 \\
\end{array}$ & {$[120,5,5,7]$} & $\begin{array}{l}3.49 \mathrm{E}-05 \\
3.9 \mathrm{E}-05\end{array}$ & 252 & {$[60,11,1,9]$} & $\begin{array}{l}3.99 \mathrm{E}-07 \\
309 \mathrm{E}-07\end{array}$ & $\begin{array}{l}47 \\
36\end{array}$ & {$[150,2,2,7]$} & $\frac{1.12 E-05}{1+305}$ & {$[52,124,148]$} \\
\hline 48 & $\frac{364}{96}$ & $\frac{[90,10,4,1,9]}{[150,4,9]}$ & \begin{tabular}{|l|}
$9.1 / 8 \mathrm{E}-06$ \\
$9.98 \mathrm{E}-06$ \\
\end{tabular} & $\begin{array}{l}106 \\
104\end{array}$ & $\frac{[0,4,4,9]}{[30,5,9]}$ & $\begin{array}{l}4.66 \mathrm{E}-07 \\
4.67 \mathrm{E}-07\end{array}$ & $\frac{316}{120}$ & $\frac{[0,5,1,9,9]}{[150,4,9]}$ & $\frac{3.14 \mathrm{E}-03}{3.16 \mathrm{E}-05}$ & 207 & $\frac{[91,99,9,7]}{[150,4,7]}$ & $\begin{array}{l}3.4 .4 \mathrm{E}-05 \\
3.25 \mathrm{E}-05\end{array}$ & $\begin{array}{l}180 \\
276\end{array}$ & $\frac{[60,8,8,9]}{[-60,12,12,9]}$ & $\begin{array}{l}3.99 \mathrm{E}-07 \\
.399 \mathrm{E}-07\end{array}$ & $\begin{array}{l}36 \\
128\end{array}$ & 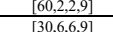 & $\frac{1.13 \mathrm{E}-0.5}{1.133-05}$ & $\frac{[52,76,124,148]}{52,76,104,120,124,148]}$ \\
\hline 50 & 176 & {$[30,8,8,9]$} & $9.89 \mathrm{E}-06$ & 56 & {$[30,3,3,9]$} & $4.66 \mathrm{E}-07$ & 83 & $\frac{[60,4,4,7]}{[60,4}$ & $3.16 \mathrm{E}-05$ & 103 & {$[30,5,5,7]$} & $3.56 \mathrm{E}-05$ & 300 & $\frac{[0,1,1,1,3]}{[60,13,13,9]}$ & $3.99 \mathrm{E}$ & 79 & $\frac{d P, 0,0,9]}{[30,4,7]}$ & 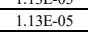 & 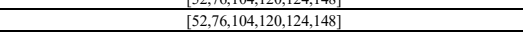 \\
\hline 51 & 291 & {$[0,5,13,7]$} & $\begin{array}{l}9.97 \mathrm{E}-06 \\
\end{array}$ & 96 & {$[150,4,4,9]$} & $4.66 \mathrm{E}-07$ & 75 & {$[0,4,4,7]$} & $3.17 \mathrm{E}-05$ & 111 & {$[90,5,5,7]$} & $3.57 \mathrm{E}-05$ & 324 & {$[60,14,14,9]$} & $3.99 \mathrm{E}-07$ & 380 & {$[120,17,5,9]$} & $0.1 .14 \mathrm{E}-05$ & {$[52,76,96,104,120,124,148]$} \\
\hline 52 & 263 & {$[150,11,4,7]$} & $\begin{array}{l}9.97 \mathrm{E}-06 \\
\end{array}$ & 128 & {$[30,6,6,9]$} & $4.66 \mathrm{E}-07$ & 103 & {$[30,5,5,7]$} & $\begin{array}{ll}3.20 \mathrm{E}-05 \\
.05\end{array}$ & 320 & {$[30,9,14,9]$} & $3.60 \mathrm{E}-05$ & 56 & {$[30,3,3,9]$} & $3.99 \mathrm{E}-07$ & 210 & {$[150,9,4,9]$} & $1.14 E-05$ & 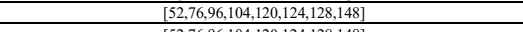 \\
\hline$\frac{53}{54}$ & $\frac{355}{2087}$ & $\frac{[150,15,4,7]}{[150,12,4]}$ & \begin{tabular}{|l|l}
$9.97 \mathrm{E}-06$ \\
$0.95-06$
\end{tabular} & $\begin{array}{l}176 \\
152 \\
\end{array}$ & $\begin{array}{l}{[30,8,8,9]} \\
{[30707}\end{array}$ & $\begin{array}{l}4.66 \mathrm{E}-07 \\
4.6 \mathrm{E}-07\end{array}$ & 228 & $\begin{array}{l}{[60,10,10,9]} \\
{[150,15,47}\end{array}$ & $3.21 \mathrm{E}-05$ & 199 & $\frac{[30,9,9,7]}{900,10,107}$ & $3.61 \mathrm{E}-05$ & $\begin{array}{l}344 \\
156 \\
\end{array}$ & {$[60,15,15,9]$} & 3.991 & 367 & {$[120,16,5,7]$} & $\frac{1.15 E-05}{1.505}$ & $2,76,96,104,120,124,128,148]$ \\
\hline$\frac{34}{55}$ & 287 & $\frac{[150,512,4,7]}{[0,5,14,7]}$ & \begin{tabular}{|l|l|}
$9.98 \mathrm{E}-06$ \\
$9.86 \mathrm{E}$
\end{tabular} & $\frac{152}{72}$ & $\frac{[30,7,7,9]}{[150,3,3,9]}$ & $\begin{array}{l}4.66 \mathrm{E}-07 \\
.66 \mathrm{E}-07\end{array}$ & $\begin{array}{l}355 \\
392 \\
\end{array}$ & $\frac{[150,15,4,7]}{[120,18,5]}$ & $\frac{3.2 \mathrm{E}-05}{3.22 \mathrm{E}-05}$ & 231 & $\frac{[90,1,1,1,0,7]}{[150,2,2,9]}$ & $\begin{array}{l}3.66 \mathrm{E}-05 \\
3.65 \mathrm{E}-05\end{array}$ & $\begin{array}{l}156 \\
372 \\
\end{array}$ & $\frac{[60,7,7,9]}{[60,17,17,9]}$ & $\begin{array}{l}3.99 \mathrm{E}-07 \\
.399 \mathrm{E}-07\end{array}$ & $\begin{array}{l}404 \\
155 \\
\end{array}$ & $\frac{[120,1,5,5,9]}{[60,7,7]}$ & $\frac{1.15 \mathrm{E}-0.5}{1.155-05}$ & 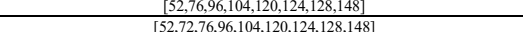 \\
\hline 56 & 335 & {$[150,14,4,4]$} & $9.98 \mathrm{E}-06$ & 100 & {$[0,5,5,9]$} & $4.66 \mathrm{E}-07$ & 264 & {$[150,11,4,4,9]$} & $3.25 \mathrm{E}-05$ & 80 & {$[30,4,4,9]$} & $3.66 \mathrm{E}-05$ & 360 & {$[60,16,16,9]$} & $3.99 \mathrm{E}$ & 328 & {$[90,14,11,9]$} & $\frac{1.16 \mathrm{E}-05}{1.15}$ & $128,148]$ \\
\hline 86 & 347 & {$[90,15,11,7]$} & $1.05 \mathrm{E}-05$ & & {$[60,17,19,7]$} & $5.30 \mathrm{E}-07$ & & {$[120,15,5,7]$} & $3.50 \mathrm{E}-\mathrm{C}$ & 44 & {$[120,2,2,9]$} & $4.13 \mathrm{E}-05$ & & {$[30,9,11,7]$} & $4.52 \mathrm{E}$ & 327 & {$[90,14,11,7]$} & $1.24 \mathrm{I}$ & {$\left[\begin{array}{l}60,96,104,120,124,128,148] \\
0\end{array}\right.$} \\
\hline 87 & 327 & {$[90,14,11,7]$} & $1.05 E-05$ & 239 & {$[150,10,4,7]$} & $5.30 \mathrm{E}-07$ & 272 & {$[30,9,12,9]$} & $3.50 \mathrm{E}-05$ & 87 & {$[90,4,4,7]$} & $4.14 E-05$ & 171 & {$[0,5,8,7]$} & 4.521 & 388 & {$[90,18,11,9]$} & $1.25 \mathrm{E}-05$ & $6,80,96,104,120,124,128,148]$ \\
\hline$\frac{88}{80}$ & $\frac{139}{139}$ & {$[120,4$} & $1.05 E-05$ & 367 & & $5.31 \mathrm{E}-07$ & 368 & {$[120,16,5,9]$} & $3.50 \mathrm{E}$ & $\frac{18}{18}$ & & 4.14E & 143 & {$[150$} & 4.52 & 363 & & $\frac{1.25 \mathrm{E}-05}{105}$ & 1.128,148] \\
\hline$\frac{89}{90}$ & $\frac{303}{200}$ & $\frac{1[0,1,1,1,1]}{[309]}$ & 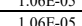 & $\frac{123}{331}$ & $\frac{10,0,1,7}{[120,57]}$ & $\frac{5.33 \mathrm{E}-07}{53 \mathrm{E}-07}$ & $\frac{179}{143}$ & $\frac{100}{105}$ & 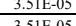 & $\frac{123}{192}$ & $\frac{10.5}{0.03}$ & 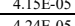 & $\frac{163}{123}$ & {$[120,5,7,7]$} & $\frac{3.52 \mathrm{E}}{4.5 \mathrm{E}}$ & $\frac{103}{4515}$ & $\frac{100,3,1,1}{402020}$ & $\frac{1.232-053}{1.2505}$ & 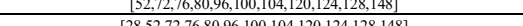 \\
\hline 92 & 310 & $\frac{[3,9,1,4]}{[30,9]}$ & $1007 \mathrm{~F}-05$ & 331 & $\frac{1.120,1}{[1120.1}$ & $\frac{531 \mathrm{E}-07}{5}$ & 276 & $\frac{160,12}{[60.12}$ & $3.35 \mathrm{E}$ & 139 & & $\frac{4.47}{4277}>0$ & 283 & & $\frac{2.32}{452}$ & $\frac{413}{172}$ & & $\frac{1.25}{1.25}$ & 48] \\
\hline 93 & 339 & {$[30,915,7]$} & $1.08 \mathrm{E}-05$ & 391 & {$[120,18,5,7]$} & $5.31 \mathrm{E}-07$ & 319 & {$[30,9,14,7]$} & $3.5 \mathrm{E}-05$ & 412 & $\frac{[0,2,0,1,9]}{[90,201,19]}$ & $4.36 \mathrm{E}-05$ & 415 & $\frac{1[120,20,5,7]}{[120.57}$ & $4.52 \mathrm{E}$ & 252 & $\frac{[60,1,1,1,9]}{[60,11,1}$ & $\frac{1.291}{1.291}$ & \\
\hline 94 & 295 & {$[30,9,13,7$,} & $1.08 \mathrm{E}-05$ & 163 & {$[120,7,5,7]$} & $5.32 \mathrm{E}-0$ & 243 & & 3.55E- & 27 & & 4.3 & 40 & & & 386 & & & \\
\hline 101 & 399 & {$[90,19,11,7]$} & 1.14E-05 & 44 & {$[120,2,2,9]$} & $5.35 \mathrm{E}-07$ & 27 & {$[0,2,2,7]$} & 3.65E-05 & 236 & {$[120,10,5,9]$} & 4.46E-05 & 24 & {$[150,1,1,9]$} & 4.59 & 410 & {$[90,20,11,5]$} & 1.31. & $8,80,96,10$ \\
\hline 102 & & {$[120,9,5,9]$} & $1.14 \mathrm{E}-05$ & 187 & & 5.35E- & 59 & {$[00$.} & $3.67 \mathrm{E}-05$ & 294 & & 4.46 & 368 & & & 20. & & & $0,9,100,114,100,124,12$ \\
\hline$\frac{103}{10 .}$ & $\frac{75}{713}$ & {$[0,4,4,1]$} & $\begin{array}{l}1.1 .15 E-05 \\
1.1505\end{array}$ & $\frac{4}{383}$ & $\frac{10,1,1,1]}{-[0,1,1]}$ & 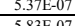 & $\frac{176}{364}$ & 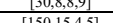 & $\frac{3.86 \mathrm{E}-05}{3.05}$ & $\frac{375}{323}$ & $\frac{190,1,1,1}{5301}$ & 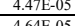 & $\frac{21}{26}+2$ & {$[110,2,3$} & $\begin{array}{l}4.62 \\
4.37\end{array}$ & $\frac{362}{376}+2$ & $\frac{100,16,}{16012}$ & $\frac{1.32}{1.32}$ & 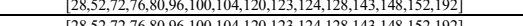 \\
\hline$\frac{111}{111}$ & 183 & $\frac{100,0.81}{[90,8]}$ & \begin{tabular}{|l|l|l|l|l|l|}
$1.15-05$ \\
\end{tabular} & $\frac{24}{24}$ & 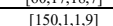 & $\frac{3.5 \mathrm{~B}-07}{5.87}$ & 215 & 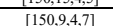 & $\frac{3.79 \mathrm{E}-05}{3}$ & 346 & $\frac{100,1,1,5]}{[90,1,1,1]}$ & $\frac{4.64 \mathrm{E}-05}{4.05}$ & 295 & $\frac{1.3 .9}{[30.93}$ & $\frac{4.76}{4.76}$ & 231 & $\frac{10,1}{90,11}$ & $\frac{1.35}{1.35}$ & \\
\hline 112 & 135 & {$[90,6,6,7]$} & $\begin{array}{l}1.15 \mathrm{E}-05 \\
\end{array}$ & 8 & {$[30,1,1,9]$} & $5.84 \mathrm{E}-07$ & 300 & {$[60,13$} & $3.80 \mathrm{E}-05$ & 195 & {$[0,5$} & $4.65 \mathrm{E}-05$ & 355 & & & 255 & {$[90,1]$} & 1. & 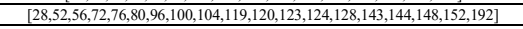 \\
\hline 113 & 159 & $[90,7,7,7]]$ & $1.15 \mathrm{E}-05$ & 212 & [1120. & $6.00 \mathrm{E}-07$ & 195 & & $3.81 \mathrm{E}-05$ & 338 & & 4.671 & 319 & {$[30,9,9$,} & 4.91 & 176 & & & \\
\hline 118 & 55 & [30,3,3,7] & $1.17 \mathrm{E}-05$ & 55 & {$[30,3,3,7]$} & $6.09 \mathrm{E}-07$ & 227 & {$[60,10,10,7]$} & 3.89E- -05 & 230 & {$[90.11$} & $4.74 \mathrm{E}-05$ & 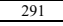 & {$[0,5,1]$} & 409 & 27 & {$[30,4$,} & $1.37 \mathrm{E}-05$ & 44,147,3, \\
\hline & 87 & $[90,4,4,7]]$ & 1.17E- -05 & 79 & {$[30,4,4,7]$} & $6.09 \mathrm{E}-07$ & 48 & $0,2,2,9]]$ & $3.92 \mathrm{E}-05$ & 399 & {$[1,7]$} & $4.75 \mathrm{E}-05$ & 280 & $\frac{112,12,9]}{0.12}$ & $06 \mathrm{E}-07$ & 208 & $9,9]$ & $1.38 \mathrm{E}-05$ & $104,119,120,123,124,128,143,144,147,148$, \\
\hline
\end{tabular}

Note:

- The texts size in the table have been scaled down to fit into one page.

- For brevity, there are jumps in $q$ column to avoid repetitions of a set of intersected indices in the $\mathbf{I}_{\mathbf{o p t}}$ column.

- $q=119$ provides 20 global optimums in the $\mathbf{I}_{\mathbf{o p t}}$ column. 


\subsubsection{Comparison of global optimum solutions for method-1 and method-2}

For multi-objective optimisation engineering problems, there is no unique best solution for the problem, but a family of optimum solutions that the engineer can choose from, based on the design requirements. A matching comparison for the first 20 members of the family of optimum vessel relocation programs from method-1 and method-2 are compared through a matching plot shown in Figure 21. This matching plot shows which of the optimum relocation program are common for the family of solutions obtained by method- 1 and method- 2 . Note that only the first 20 members are considered here and that the order in which these relocation program indices occur from the two methods is not considered. As the number of members considered increases (beyond 20), more matches will be obtained, but we believe that the list of these first 20 members is sufficient for demonstration. As observed from Figure 22, there are 15 matches out of the 20 first optimum relocation programs from method-1 and method-2. This indicates that the two methods sufficiently capture a good number of optimum relocation programs for the problem.
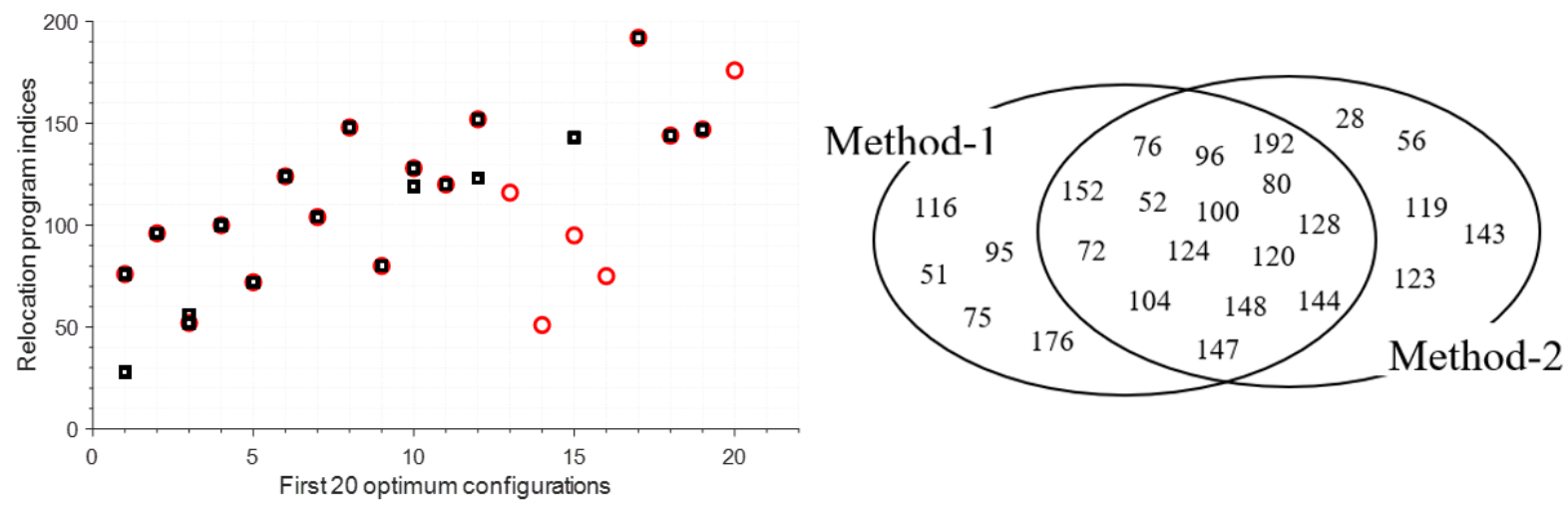

Figure 22. Matching plot for the first 20 global optimum relocation programs from method-1 and method-2.

Considering the 15 common optimum relocation programs between method- 1 and method-2, the fatigue performance measured as percentage reductions in fatigue damage relative to the "no relocation case" are presented in Table 15. A bar chart representation of these percentage reductions is presented in Figure 23. It is observed from Table 15 and Figure 23 that the overall improvements in fatigue damage across all SCR are quite close to each other, indicating that in the solution process, we achieved a balanced interest to reduce the fatigue in the six SCR TDZ. Among these 15 global optimum programs, the relocation program index-76 provides the largest combined reduction in fatigue damage of $486.5 \%$ for all SCRs, while index-147 provide the least reduction in fatigue damage of $460.7 \%$. However, the contributions to the damage reduction of the programs considering individual SCR may be slightly different. This is measured in terms of the standard deviation $(\sigma)$ from the mean percentage fatigue damage reduction for each SCR as presented in Table 15. From Table 15, it could be seen that index76 has the smallest $\sigma$ indicating that this relocation program provides a more equally distributed fatigue damage reduction across all SCRs. For this reason, we select the index-76 relocation program for further results discussions. A general observation of the performance of these optimum relocation programs from Table 15 and Figure 23 indicate the significance of the vessel relocation strategy to achieve longer lives for new SCRs and extend the lives of existing SCRs. Including vessel relocation programs for existing SCRs can result in significant life extension. For new risers, apart from higher fatigue lives, the design requirements such as the pipe wall thickness, internal cladding of pipe to mitigate corrosion, etc., can be reduced, 
resulting in significant improvement in the design cost of the risers. However, these benefits must be compared with the cost incurred for the vessel relocation operation, to make appropriate, cost-effective decisions during the SCR design and relocation plan. It should be noted that out of these 15 -relocation programs, 5 of them are non-symmetric $\left(R 1 \neq R_{2}\right)$. This emphasises the importance of the screening methodology presented in section 4.1 and the modification/conversion of unfeasible symmetric relocation programs to feasible nonsymmetric programs. If only symmetric relocation programs were considered, these good nonsymmetric vessel relocations programs would not be captured.

Table 15. Percentage reduction in SCR TDZ $D_{\text {eff }}$ compared with the no relocation fatigue damage.

\begin{tabular}{ccccccccc}
\hline & {$\left[\alpha, R_{1}, R_{2}, p\right]$} & \multicolumn{6}{c}{ Reduction in Fatigue damage (\%) } & \multicolumn{1}{c}{$\sigma$} \\
\cline { 3 - 7 } Index & {$[(-),(\%),(\%),($ deg) $]$} & SCR-1 & SCR-2 & SCR-3 & SCR-4 & SCR-5 & SCR-6 & \\
\hline 52 & {$[0,3,3,9]$} & 82.1 & 82.3 & 77.9 & 76.9 & 82.3 & 82.1 & 2.5 \\
72 & {$[150,3,3,9]$} & 82.2 & 82.3 & 74.9 & 78.9 & 82.3 & 81.9 & 3.0 \\
76 & {$[0,4,4,9]$} & 81.8 & 82.3 & 78.3 & 80.6 & 82.3 & 81.2 & 1.5 \\
80 & {$[30,4,4,9]$} & 81.9 & 82.3 & 79.5 & 73.7 & 82.3 & 80.5 & 3.3 \\
96 & {$[150,4,4,9]$} & 80.1 & 82.3 & 78.3 & 79.2 & 82.3 & 82.1 & 1.8 \\
100 & {$[0,5,5,9]$} & 79.5 & 82.3 & 76.2 & 79.6 & 82.3 & 78.9 & 2.3 \\
104 & {$[30,5,5,9]$} & 81.8 & 82.3 & 78.1 & 76.4 & 82.3 & 78.4 & 2.6 \\
120 & {$[150,5,4,9]$} & 82.5 & 84.0 & 73.9 & 77.1 & 84.2 & 81.5 & 4.1 \\
124 & {$[0,5,6,9]$} & 81.3 & 84.1 & 78.9 & 76.2 & 84.2 & 79.1 & 3.2 \\
128 & {$[30,6,6,9]$} & 81.4 & 82.3 & 75.7 & 78.4 & 82.3 & 75.9 & 3.1 \\
144 & {$[150,6,4,9]$} & 77.0 & 82.0 & 73.0 & 75.2 & 82.7 & 76.8 & 3.8 \\
147 & {$[0,5,7,7]$} & 79.5 & 79.9 & 76.0 & 73.4 & 80.0 & 72.0 & 3.5 \\
148 & {$[0,5,7,9]$} & 82.6 & 84.1 & 76.9 & 77.2 & 84.1 & 76.7 & 3.7 \\
152 & {$[30,7,7,9]$} & 80.4 & 82.3 & 73.0 & 78.9 & 82.3 & 73.7 & 4.1 \\
192 & {$[150,8,4,9]$} & 83.5 & 83.9 & 77.3 & 69.5 & 84.2 & 77.1 & 5.8 \\
\hline
\end{tabular}

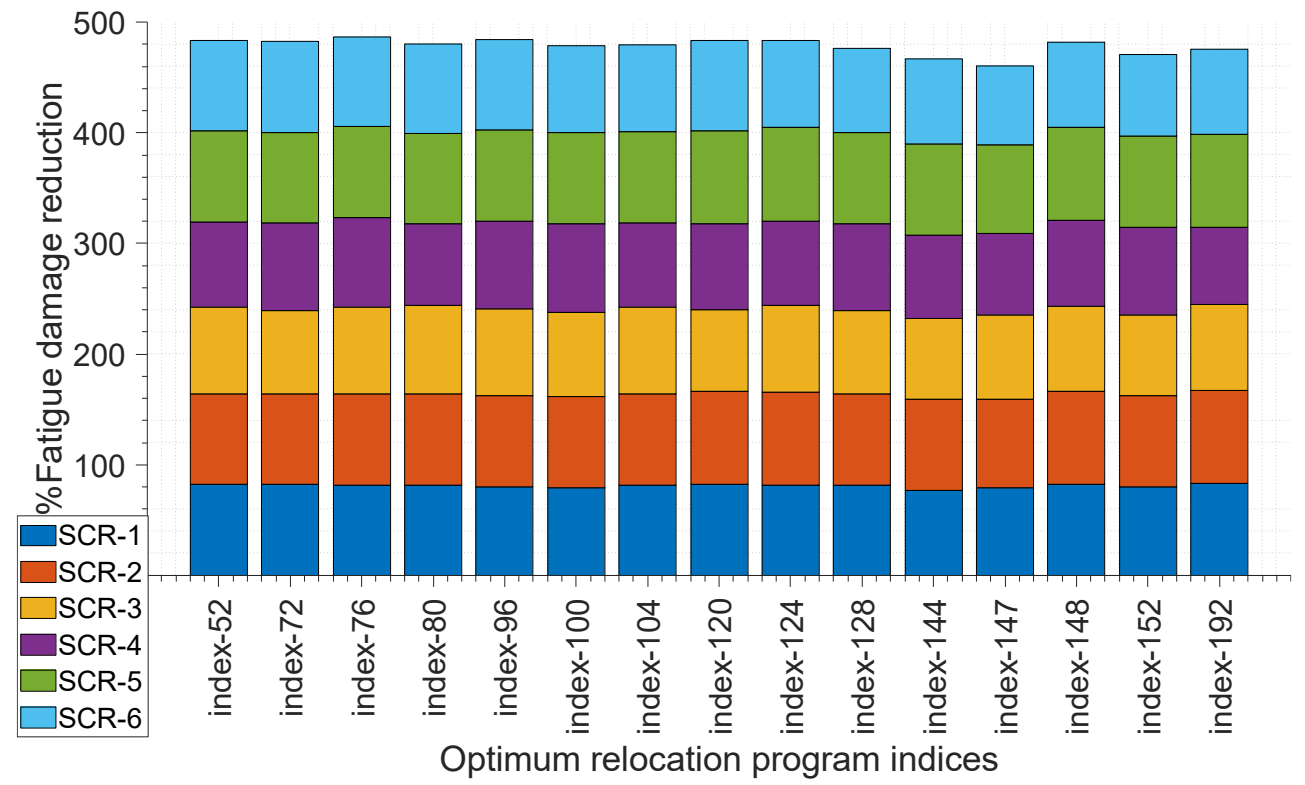

Figure 23. Bar chart representation of the percentage reduction in SCR TDZ $D_{\text {eff }}$ compared with the no relocation fatigue damage 


\subsection{Result discussions for the selected global optimum configuration (index-76)}

\subsubsection{Comparison of the index-76 program with the ideal optimum relocation program.}

Table 16 compares the selected global optimum relocation program (index-76) with the ideal optimum relocation programs for the $6 \mathrm{SCRs}$, obtained from method-2. These comparisons are conducted with respect to the no relocation case, also included in Table 16. Recall from Table 14 that the ideal solutions for the individual SCRs (if each objective function is considered exclusively) are : index-356 for SCR-1, index-272 for SCR-2, index-356 for SCR-3, index-76 for SCR-4, index-404 for SCR-5 and index-52 for SCR-6 respectively. Consider the best optimal relocation program for a given SCR; that relocation program will provide the least value of its objective function and have associated objective functions' values for the other 5 SCRs, which are not necessarily minimum for them. Each best ideal solution and its associated relocation programs for other SCRs are presented in Table 16. Note that index-76, which is the selected global optimum relocation program happens to be the best relocation program for SCR-4, and hence appears two times in Table 16. Each ideal optimum relocation program is greyed, and the associated values of the other five objective functions are presented on the same row with it. From the computed percentages of fatigue damage reduction with respect to the no vessel relocation case, it could be observed that the ideal relocation programs (except index-76 and index-52) do not provide a balanced reduction of fatigue damage across all SCRs. A more intuitive view of the percentage fatigue damage reduction potentials of the relocation programs is presented in Figure 24 (a). The orientations of the SCRs and the axes of relocations have been included in Figure 24 (b) to provide the reader with the sense of configuration change of the SCRs for the different relocation programs. Note that the directions of the relocation programs presented in Figure 24 (a) are also provided as $\alpha$ in the fourth column of Table 16. It could be seen easily from Figure 24 (a) that index-76 (also ideal solution for SCR-4) and index-52 (ideal solution for SCR-6) both provide a good level of balance of fatigue damage reduction in all SCRs compared with the no vessel relocation case. Both are seen in Table 16 to have the least standard deviations from the mean of the percentage fatigue reduction. It should be noted that these two relocation programs (index-76 and index-52) are also in the list of top members of the global optimum relocation programs obtained from both method- 1 and method-2 (see Figure 22).

The relevance of comparing the global performances and the ideal solutions may be obvious from a scenario where there are a large number of SCRs hosted by the vessel. Consider, for example, a vessel hosting 30 or more SCRs, vessel relocation optimisation for such configuration with all SCRs included in each simulation model can be prohibitive numerically, especially when thousands of models need to be simulated to evaluate the objective functions. However, this example analysis shows that some ideal solutions can provide good fatigue reduction across other SCRs, like index-76 and index-52. A recommended approach for such a scenario will be to conduct an exclusive optimisation analysis for carefully selected SCR(s). The ideal solutions obtained are then investigated to determine their balanced contributions to fatigue damage reduction across other SCRs. Perhaps a good global optimum solution may be detected that will effectively reduce fatigue damage across all SCRs. The number of design variables can also be reduced for the problem, such as selecting the likely best axis of relocation. As could be seen in this example, index -76 has an axis of relocation of $0^{\circ}$, which is close to a line of symmetry for all the azimuths of the SCRs (see Figure 6). The number of relocation stations can also be reduced for the problem, below the number at which no significant fatigue reduction benefits to relocation cost ratios are achieved. This will be discussed shortly. 
Table 16. Comparison of the selected global optimum program, the first ideal optimum programs for the respective SCRs and the no vessel relocation case

\begin{tabular}{|c|c|c|c|c|c|c|c|c|c|c|c|c|c|c|c|c|}
\hline \multirow[t]{2}{*}{ Result Type } & \multirow[t]{2}{*}{ SCRs } & \multirow[t]{2}{*}{ Index } & \multirow{2}{*}{$\begin{array}{c}{\left[\alpha, R_{1}, R_{2}, p\right]} \\
{[(-),(\%),(\%),(\operatorname{deg})]}\end{array}$} & \multicolumn{6}{|c|}{$\left(D_{e f f}\right)_{j}, j=1$ to 6} & \multicolumn{6}{|c|}{$\begin{array}{l}\text { Percentage reduction in fatigue damage (\%) } \\
\text { (Relative to fatigue damage for no-relocation) }\end{array}$} & \multirow[t]{2}{*}{$\sigma$} \\
\hline & & & & SCR-1 & SCR-2 & SCR-3 & SCR-4 & SCR-5 & SCR-6 & SCR-1 & SCR-2 & SCR-3 & SCR-4 & SCR-5 & SCR-6 & \\
\hline No relocation & NA & - & {$[\mathrm{NA}, \mathrm{NA}, \mathrm{NA}]$} & $4.96 \mathrm{E}-05$ & $2.63 \mathrm{E}-06$ & $1.21 \mathrm{E}-04$ & $1.39 \mathrm{E}-04$ & $2.26 \mathrm{E}-06$ & $4.68 \mathrm{E}-05$ & - & 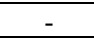 & - & - & - & - & - \\
\hline Selected optimum & All & Index-76 & {$[0,4,4,9]$} & $9.01 \mathrm{E}-06$ & $4.66 \mathrm{E}-07$ & $2.62 \mathrm{E}-05$ & $2.70 \mathrm{E}-05$ & $3.99 \mathrm{E}-07$ & $8.81 \mathrm{E}-06$ & 81.8 & 82.3 & 78.3 & 80.6 & 82.3 & 81.2 & 1.5 \\
\hline \multirow{6}{*}{ Ideal optimum } & SCR-1 & Index-356 & {$[150,15,4,9]$} & $7.89 \mathrm{E}-06$ & $4.19 \mathrm{E}-07$ & $2.26 \mathrm{E}-05$ & $8.16 \mathrm{E}-05$ & $3.89 \mathrm{E}-07$ & $1.91 \mathrm{E}-05$ & 84.1 & 84.1 & 81.3 & 41.3 & 82.8 & 59.1 & 17.9 \\
\hline & SCR-2 & Index-272 & {$[30,9,12,9]$} & $9.16 \mathrm{E}-06$ & $4.17 \mathrm{E}-07$ & $3.50 \mathrm{E}-05$ & $3.19 \mathrm{E}-05$ & $3.93 \mathrm{E}-07$ & $1.71 \mathrm{E}-05$ & 81.5 & 84.2 & 71.0 & 77.1 & 82.6 & 63.5 & 8.0 \\
\hline & SCR-3 & Index-356 & {$[150,15,4,9]$} & $7.89 \mathrm{E}-06$ & $4.19 \mathrm{E}-07$ & $2.26 \mathrm{E}-05$ & $8.16 \mathrm{E}-05$ & $3.89 \mathrm{E}-07$ & $1.91 \mathrm{E}-05$ & 84.1 & 84.1 & 81.3 & 41.3 & 82.8 & 59.1 & 17.9 \\
\hline & SCR-4 & Index-76 & {$[0,4,4,9]$} & $9.01 \mathrm{E}-06$ & $4.66 \mathrm{E}-07$ & $2.62 \mathrm{E}-05$ & $2.70 \mathrm{E}-05$ & $3.99 \mathrm{E}-07$ & $8.81 \mathrm{E}-06$ & 81.8 & 82.3 & 78.3 & 80.6 & 82.3 & 81.2 & 1.5 \\
\hline & SCR-5 & Index-404 & {$[120,19,5,9]$} & $7.90 \mathrm{E}-06$ & $4.22 \mathrm{E}-07$ & $3.02 \mathrm{E}-05$ & $8.07 \mathrm{E}-05$ & $3.56 \mathrm{E}-07$ & $1.15 \mathrm{E}-05$ & 84.1 & 84.0 & 75.0 & 42.0 & 84.2 & 75.4 & 16.3 \\
\hline & SCR-6 & Index-52 & {$[0,3,3,9]$} & $8.86 \mathrm{E}-06$ & $4.66 \mathrm{E}-07$ & $2.67 \mathrm{E}-05$ & $3.21 \mathrm{E}-05$ & $3.99 \mathrm{E}-07$ & $8.38 \mathrm{E}-06$ & 82.1 & 82.3 & 77.9 & 76.9 & 82.3 & 82.1 & 2.5 \\
\hline
\end{tabular}
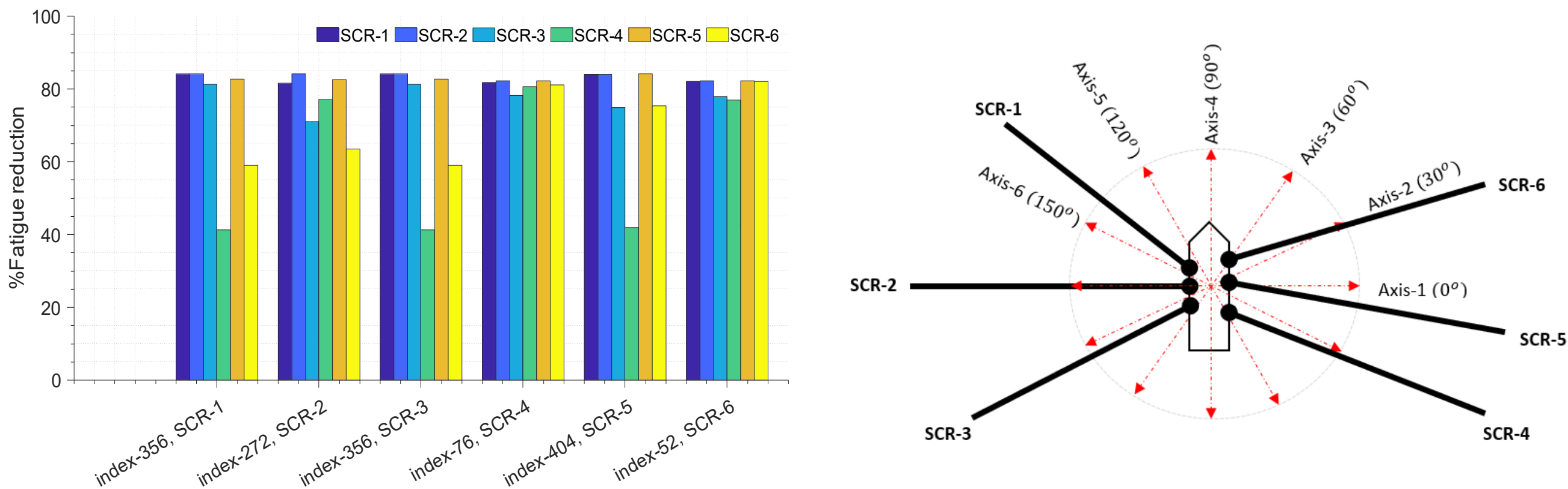

Ideal optimums with associated objective function values

Figure 24. (a) Percentage fatigue damage reduction for individual SCR's ideal optimum relocation program, with associated percentage fatigue damage reduction for other SCRs, (b) Vessel-SCR layout showing the risers' orientations (azimuth) and the relocation axes, $\alpha$ 


\subsubsection{Further discussion on relocation program (index-76)}

The optimisation design variables for index-76 are $\left[\alpha, R_{1}, R_{2}, p\right]=[0,4,4,9]$, as seen in Table 15. The values of the span radii $\left(R_{1}=R_{2}=4 \%\right)$ indicate that this relocation program is symmetric with the axis of relocation, $\alpha=0^{\circ}$, the number of stations, $p=9$. For this relocation program, the vessel span limit stations are at $60 \mathrm{~m}(4 \%$ of water depth $(1500 \mathrm{~m}))$ equidistance from the nominal stations along the relocation axis. Since there are 9 stations, the relocation offsets calculated from equation (2), $\Delta h$, will be $15 \mathrm{~m}$. This means the vessel is relocated 15 $\mathrm{m}$ at each relocation step from one station to another, which is also the distance between neighbouring stations. The fatigue damage fraction computed using equation (3) is presented in Figure 25. It could be seen that the nominal station, which received the highest number of vessel presence (exposure) during the vessel relocation, has the highest damage fraction. The span limit stations received the vessel presence once per relocation cycle, while the other 6 stations received the vessel presence twice per relocation cycle.

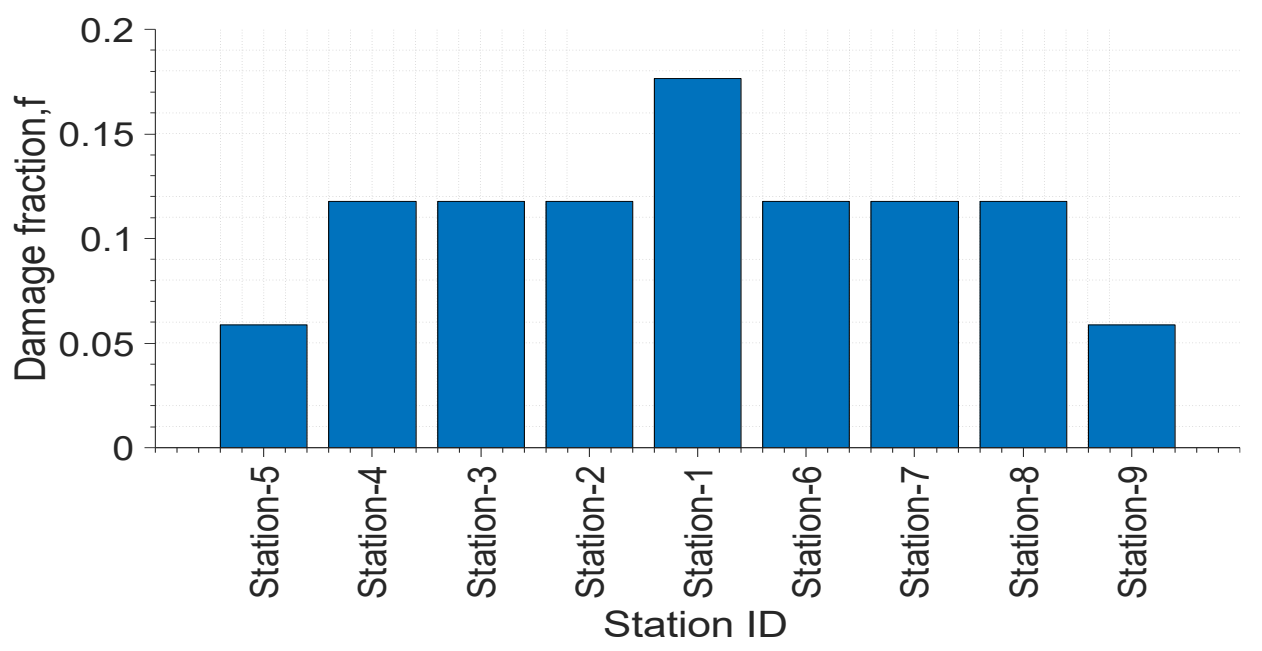

Figure 25. Damage fraction, $f$, for index-76 relocation program.

For illustration purposes, Figure 26 presents the unfactored fatigue damage for the 6 SCRs for the vessel at stations 1 to 9 in index-76 relocation program. The unfactored fatigue damage plots are made on a y-logarithm scale. The maximum fatigue damage values and the point in the SCR TDZ where they occur (critical arc lengths) are presented in Table 17. It could be seen from Figure 26 and Table 17 that the maximum fatigue damages are concentrated around a short section of each SCR TDZ but with different critical arc lengths along the TDZ sections of the 6 SCRs due to different vessel locations. When the unfactored fatigue damages across the nine stations of the index-76 relocation program are factored by the fatigue damage fraction in Figure 25, the resulting effective fatigue damage $\left(D_{\text {eff }}\right)$ along the SCRs are presented in Figure 27. It could be seen by comparing Figure 26 and Figure 27 that the relocation program is effective in spreading the fatigue damage over more extended sections of each of the SCR TDZ, as well as reducing the peak fatigue damage response by a large percentage as discussed in previous results. These underline the relevance of the vessel relocation and the need to optimally conduct such operation to maximise fatigue damage reduction across multiple SCRs hosted by a floating production platform. 

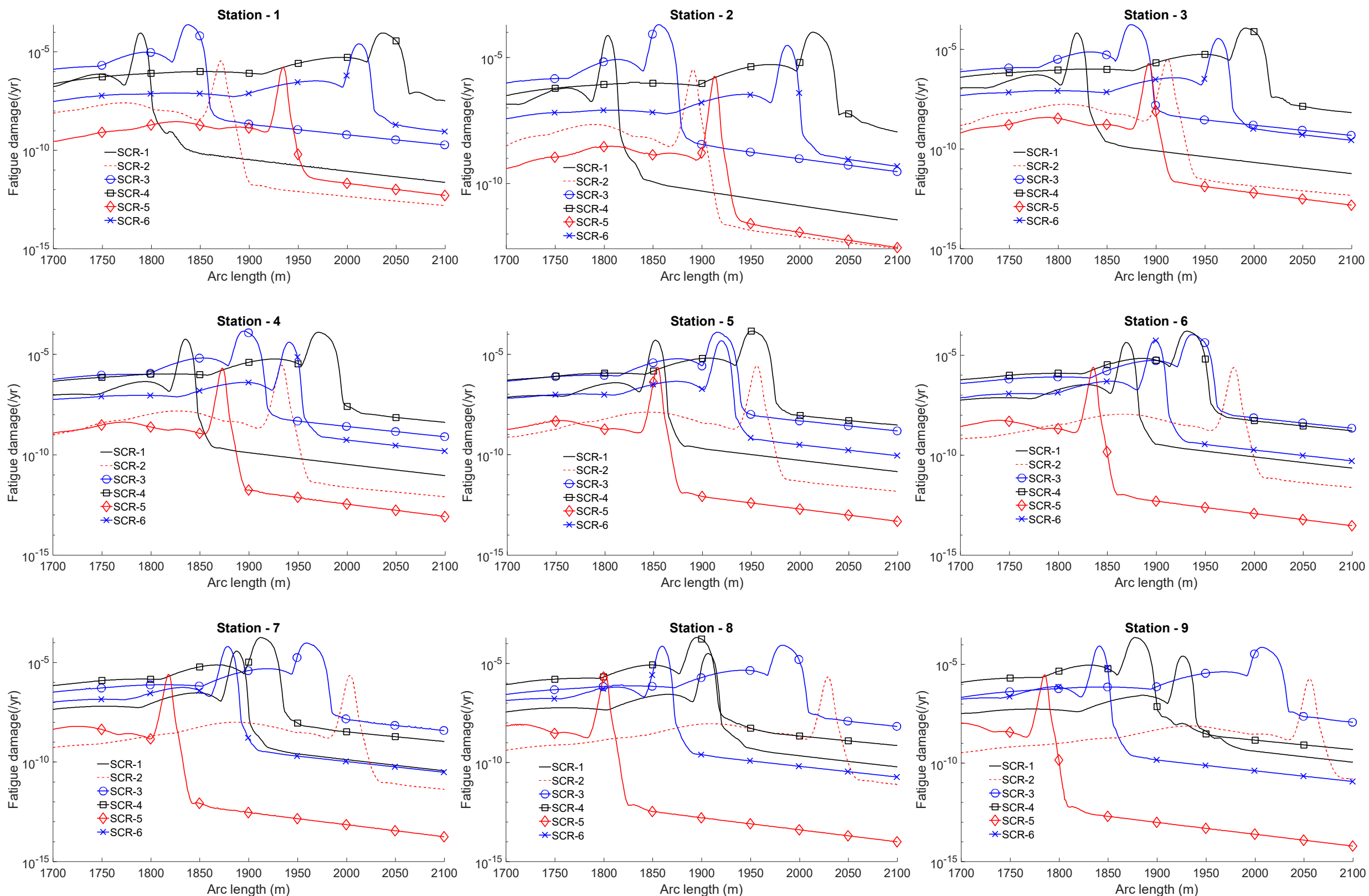

Figure 26. Unfactored SCR TDZ fatigue damage at station 1 to 9 for the index 76 relocation program.

Page | 44 
Table 17. Unfactored maximum fatigue damage and points where they occur (critical points) in the SCR TDZ across the relocation stations in index-76 relocation program.

\begin{tabular}{|c|c|c|c|c|c|c|c|c|c|c|c|c|c|c|c|c|c|c|}
\hline \multirow[b]{2}{*}{ SCRs } & \multicolumn{2}{|c|}{ Station-1 } & \multicolumn{2}{|c|}{ Station-2 } & \multicolumn{2}{|c|}{ Station-3 } & \multicolumn{2}{|c|}{ Station-4 } & \multicolumn{2}{|c|}{ Station-5 (nominal) } & \multicolumn{2}{|c|}{ Station-6 } & \multicolumn{2}{|c|}{ Station-7 } & \multicolumn{2}{|c|}{ Station-8 } & \multicolumn{2}{|c|}{ Station-9 } \\
\hline & 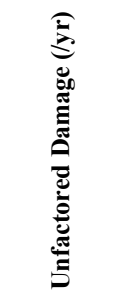 & 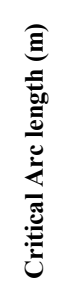 & 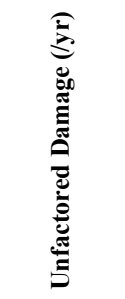 & 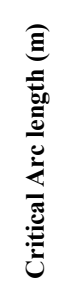 & 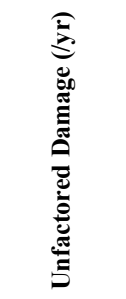 & 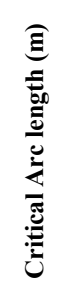 & 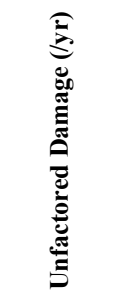 & 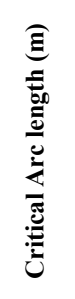 & 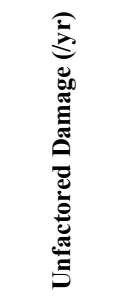 & 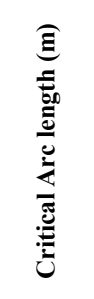 & 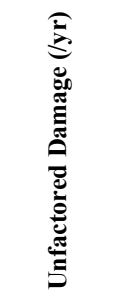 & 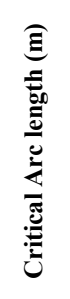 & 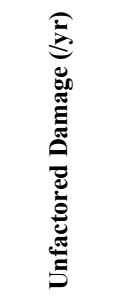 & 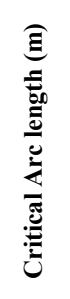 & 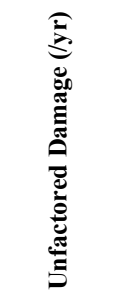 & 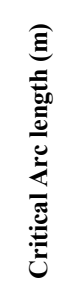 & 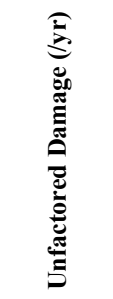 & 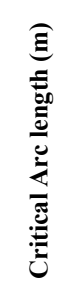 \\
\hline SCR-1 & $8.94 \mathrm{E}-05$ & 1789 & $51 \mathrm{E}-05$ & 1804 & $43 \mathrm{E}-05$ & 1819 & $5.68 \mathrm{E}-05$ & 1836 & $4.96 \mathrm{E}-05$ & 1851.7 & $28 \mathrm{E}-05$ & 870 & $.68 \mathrm{E}-05$ & 1888 & $.15 \mathrm{E}-05$ & 1907 & $.62 \mathrm{E}-05$ & 1927 \\
\hline SCR-2 & $3.47 \mathrm{E}-06$ & 1871 & $3.35 \mathrm{E}-06$ & 1891 & $3.10 \mathrm{E}-06$ & 1912 & $2.88 \mathrm{E}-06$ & 1933 & $2.63 \mathrm{E}-06$ & 1956 & $2.40 \mathrm{E}-06$ & 1979 & $2.23 \mathrm{E}-06$ & 2004 & $.06 \mathrm{E}-06$ & 2029 & $.84 \mathrm{E}-06$ & 2056 \\
\hline SCR-3 & $2.38 \mathrm{E}-04$ & 1837 & $2.00 \mathrm{E}-04$ & 1855 & $1.69 \mathrm{E}-04$ & 1874 & $1.43 \mathrm{E}-04$ & 1894 & $1.21 \mathrm{E}-04$ & 1914.4 & $1.05 \mathrm{E}-04$ & 1936 & $9.38 \mathrm{E}-05$ & 1959 & $8.12 \mathrm{E}-05$ & 1982 & $7.21 \mathrm{E}-05$ & 2007 \\
\hline SCR-4 & $9.03 \mathrm{E}-05$ & 2036 & $1.01 \mathrm{E}-04$ & 2014 & $1.14 \mathrm{E}-04$ & 1992 & $1.25 \mathrm{E}-04$ & 1971 & $1.39 \mathrm{E}-04$ & 1951 & $1.57 \mathrm{E}-04$ & 1932 & $1.77 \mathrm{E}-04$ & 1912 & $1.98 \mathrm{E}-04$ & 1895 & $2.28 \mathrm{E}-04$ & 1878 \\
\hline SCR-5 & $1.66 \mathrm{E}-06$ & 1935 & $1.78 \mathrm{E}-06$ & 1913 & $1.95 \mathrm{E}-06$ & 1893 & $2.08 \mathrm{E}-06$ & 1873 & $2.26 \mathrm{E}-06$ & 1853.7 & $2.45 \mathrm{E}-06$ & 1836 & $2.47 \mathrm{E}-06$ & 1818 & $2.77 \mathrm{E}-06$ & 1802 & $2.91 \mathrm{E}-06$ & 1786 \\
\hline SCR-6 & $2.54 \mathrm{E}-05$ & 2012 & $3.05 \mathrm{E}-05$ & 1987 & $3.40 \mathrm{E}-05$ & 1963 & $3.99 \mathrm{E}-05$ & 1941 & $4.68 \mathrm{E}-05$ & 1919.4 & $5.47 \mathrm{E}-05$ & 1898 & $6.36 \mathrm{E}-05$ & 1878 & 7.32E-05 & 1859 & $8.48 \mathrm{E}-05$ & 1841 \\
\hline
\end{tabular}

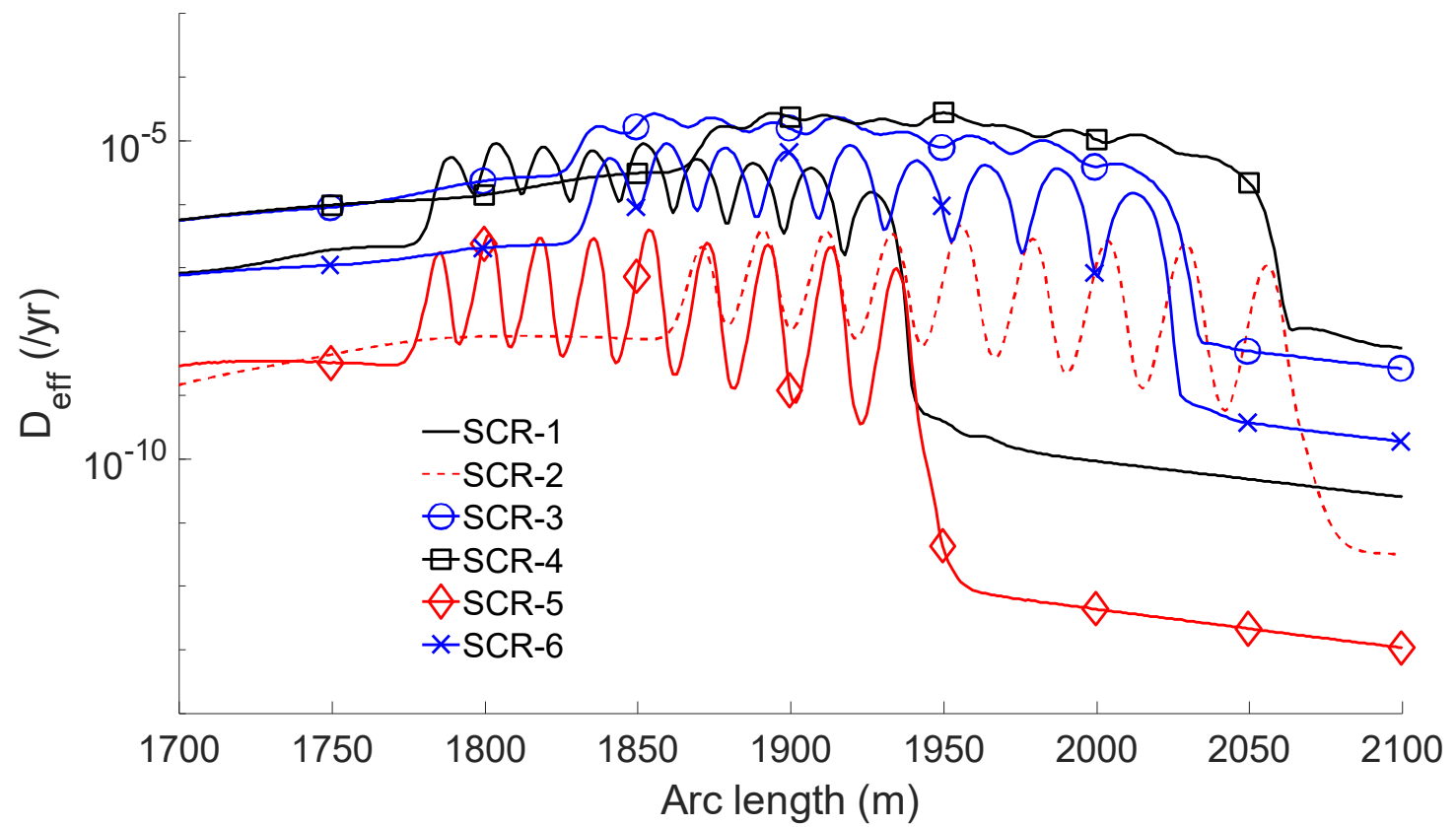

Figure 27. SCR TDZ effective fatigue damage obtained from the sum of factored fatigue damages across the 9 stations of the index-76 relocation program. 
One cycle of relocation is considered for the analyses in this study, as multiple cycles of relocations do not further reduce the fatigue damage of the SCR [31]. The number of times the vessel is moved from one station to another per relocation cycle is the number of relocations $(n)$. The number of relocations, $n$, depends on the number of relocation station, $p$, as follows:

$$
n=2(p-1)
$$

When $p=1, n=0$ meaning which is the no vessel relocation case. The cost associated with the relocation program over the life span of the SCRs depends on $n$. The $D_{\text {eff }}$ presented in Figure 27 were obtained for the $p=9$ station relocation program (index-76). We can investigate the resulting $D_{\text {eff }}$ if the number of stations is reduced from $p=9$. This will demonstrate if the choice of maximum $p=9$ (see Figure 8) for this example was sufficient to achieve the best reduction in the fatigue damage without a significant increase in the associated cost of relocation. The investigation will also tell if $p=9$ was an optimum limiting number of stations for the analysis considering the balance between the fatigue damage reduction and associated cost of vessel relocation operations. For this demonstration, we acquire relocation programs with the same $\alpha, R_{1}, R_{2}$ with index-76 relocation program, but with different values of $p$ i.e $p=3,5,7$. The effective fatigue damage of these programs, including index-76, are presented in Table 18. The percentage fatigue reductions relative to the no vessel relocation case are shown in Figure 28.

Table 18. Influence of varying $p$ on the effective fatigue damage of the SCRs.

\begin{tabular}{lccccccc}
\hline & & \multicolumn{6}{c}{ Effective fatigue damage $\left(D_{\text {eff }}\right)$} \\
\cline { 3 - 8 } Index & {$\left[\alpha, R_{1}, R_{2}, p\right]$} & & & \\
& & SCR-1 & SCR-2 & SCR-3 & SCR-4 & \multirow{2}{*}{ SCR-5 } & \multirow{2}{*}{ SCR-6 } \\
\hline 76 & {$[0,4,4,9]$} & $2.98 \mathrm{E}-05$ & $1.58 \mathrm{E}-06$ & $7.27 \mathrm{E}-05$ & $8.40 \mathrm{E}-05$ & $1.35 \mathrm{E}-06$ & $2.81 \mathrm{E}-05$ \\
75 & {$[0,4,4,7]$} & $1.66 \mathrm{E}-05$ & $8.79 \mathrm{E}-07$ & $4.15 \mathrm{E}-05$ & $4.79 \mathrm{E}-05$ & $7.52 \mathrm{E}-07$ & $1.57 \mathrm{E}-05$ \\
74 & {$[0,4,4,5]$} & $1.15 \mathrm{E}-05$ & $6.09 \mathrm{E}-07$ & $3.17 \mathrm{E}-05$ & $3.37 \mathrm{E}-05$ & $5.21 \mathrm{E}-07$ & $1.10 \mathrm{E}-05$ \\
73 & {$[0,4,4,3]$} & $9.01 \mathrm{E}-06$ & $4.66 \mathrm{E}-07$ & $2.62 \mathrm{E}-05$ & $2.70 \mathrm{E}-05$ & $3.99 \mathrm{E}-07$ & $8.81 \mathrm{E}-06$ \\
\hline
\end{tabular}

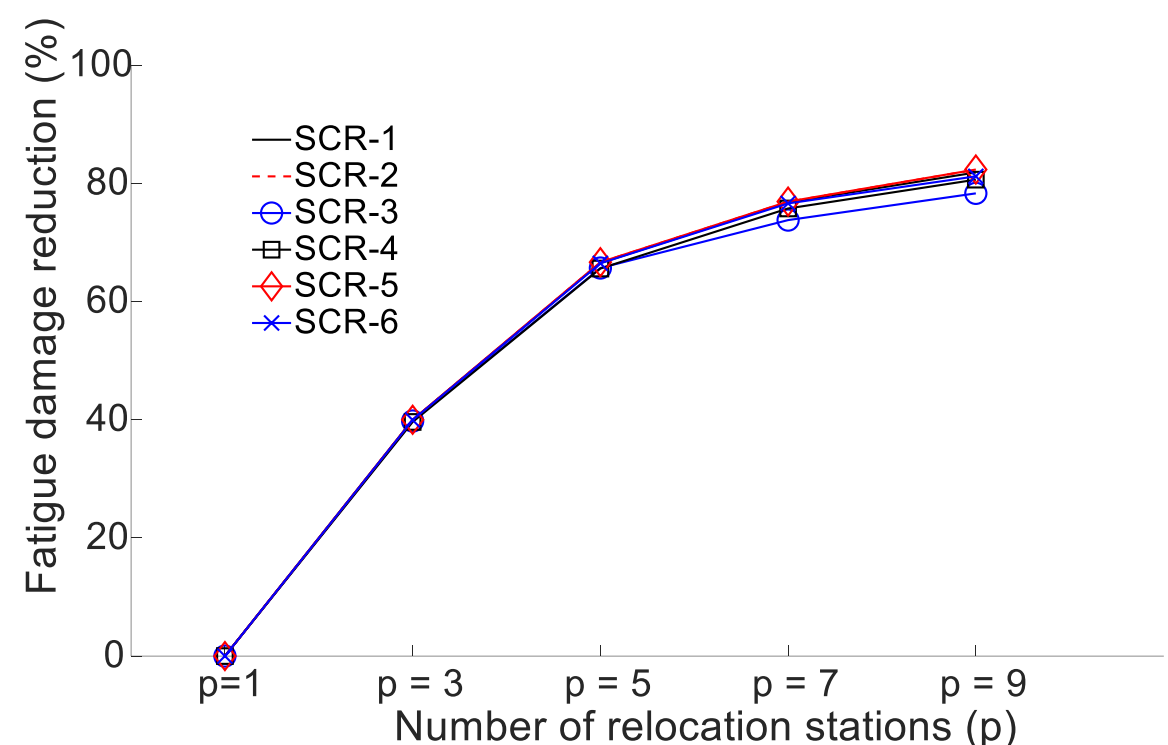

Figure 28. (a) Variation of fatigue damage reduction (\%) with number of location stations, $p$

From Figure 28, it could be observed that significant reductions in fatigue damage can be achieved for all SCRs when the number of stations of the relocation program ranges from 1 to 5. The slope of each line segment drops quickly after $p=5$ implying that additional stations 
beyond 9 will only slightly reduce fatigue damage for the SCRs with cost implications for the relocation operations. The significance of this variation of fatigue damage reduction with $p$ is that if the vessel relocation optimisation analyses are conducted without the operation cost included, these curves will help determine an appropriate cut-off point for $p$. .

\section{CONCLUSION}

The vessel relocation program involves the management, engineering, and operations required to move a floating production platform from one location or station to another. Vessel relocation operation can be conducted to enhance the spreading and consequent reduction in fatigue damage over a longer section of the SCR TDZ. The previous work [51] developed a vessel relocation optimisation technique for a single SCR system to access the best relocation program. However, since the riser vessel system consists of multiple risers, there is the need to extend the previous method to solve the multiple SCR vessel relocation problems. The multiple SCR vessel relocation optimization technique is developed based on four optimization design variables, which are the axis of relocation $(\alpha)$, the span radii of relocation $\left(R_{1}\right.$ and $\left.R_{2}\right)$ and the number of relocation stations $(p)$. The effective fatigue damages, $D_{e f f}$, for the SCR are the objective functions. The limiting values on the SCR design storm responses, which are the stress utilization around TDZ $\left(U_{T D Z}\right)$, the top tension $\left(T_{\text {top }}\right)$ and the TDZ compression $\left(T_{T D Z}\right)$ are the imposed constraints on the optimisation design space. The span limits of any relocation program are defined by the distances of the extreme stations (span limit stations) from the nominal station $\left(R_{1}\right.$ and $\left.R_{2}\right)$. The relocation patterns are symmetrical if $R_{1}=R_{2}$ and are not symmetrical if $R_{1} \neq R_{2}$. Two optimisation methods based on the index matching optimisation technique are presented to solve the resulting multi-objective optimisation problem. The methods are either developing a normalised joint objective function or conducting direct intersections of the sorted columns of indices representing the families of ideal optimum solutions to the six objective functions. The methods provided good results with up to $75 \%$ match considering the first 20 family members of the global optimum relocation programs obtained from both methods.

To reduce the huge computation resource in the study, a screening analysis process is developed. The SCRs strength feasibilities based on the satisfaction of the constraint functions are evaluated only at the two-span limit stations. The initial consideration of the screening analyses were relocation programs with symmetric relocation patterns $\left(R_{1}=R_{2}\right)$. If at least one of the constraint functions is not satisfied at any of the span limit stations, the non-feasible symmetric relocation pattern degenerates to a feasible non-symmetric relocation pattern $\left(R_{1} \neq\right.$ $R_{2}$ ) instead of it being eliminated. This screening analysis stage reduced the computation need by up to $47 \%$ (in this work) and expanded the solution space by including non-symmetric relocation programs. The feasible relocation programs are then modelled and simulated to evaluate the objective functions for the fatigue wave load. The approach is demonstrated using a vessel hosting 6 SCRs, which are characterized by different cross-sections, azimuths and configurations. For demonstration purposes, a single representative regular storm wave load is simulated during the screening stage, while the single regular fatigue wave load is simulated for the evaluation of the objective function, $D_{e f f}$. The performances of the optimum global relocation programs are compared with the no-vessel relocation case and the ideal optimum relocation programs for the SCRs. The following can be deduced from the analyses:

- The vessel relocation technique, if optimally implemented, can significantly reduce the fatigue damage of newly designed SCRs, and provide good life extension for existing 
SCRs. These benefits can reduce the costs associated with the required additional material strength and wall thickness for fatigue mitigation.

- For a single SCR vessel relocation problem, the objective could be to minimise fatigue damage, i.e., to increase the reduction in the SCR TDZ fatigue response compared with the no vessel relocation case. For multiple SCRs, while minimisation of the fatigue damage across all SCRs is crucial, it is also essential to search for a relocation program that will provide balanced contributions to all SCR TDZ fatigue damage reduction. This can be measured (as in this study) in terms of the standard deviations of the percentage damage reductions relative to the fatigue damage of the no vessel relocation case.

- The reduction in the SCR TDZ fatigue damage increases with an increasing number of relocation stations, $p$ for any relocation program. As $p$ goes beyond specific values, the fatigue reduction contributions may not sufficiently justify the cost implications associated with the number of relocations of the vessel $(n=2(p-1))$. Hence, fatigue reduction performance should be considered along with the associated cost incurred during the vessel relocation operation.

- It is possible for some ideal optimum relocation programs, exclusive to individual SCR, to provide a good fatigue reduction performance across all SCRs. For example, in this study, index-76 and index-52 relocation programs are ideal optimum programs for SCR-4 and SCR-6, respectively. However, they are also members of the best 20 global optimum relocation programs. Exploring this possibility may significantly reduce the computation that would have been conducted if all SCRs were included in the models and simulated for the design points.

- It is observed from this study that the best relocation axes are those which are close or equal to the line of symmetry for all SCR azimuths, which in this study was $\alpha=0^{\circ}$. With this information, fewer relocation axes can be selected for the optimisation analysis process. Also, a preliminary analysis of a single SCR effective fatigue damage response variation with $p$ can provide a good idea of what suitably low number of $p$ to apply for the problem. In addition, with the screening analyses conducted before the evaluation of the objective function, simulation for unfeasible relocation stations can be avoided. With these observations carefully incorporated into the vessel relocation optimisation process, enormous computational resources can be saved, especially when many SCRs are involved.

\section{RECOMMENDATION}

In this study, we have used a single design storm and a single fatigue wave load representative of the sea state conditions. However, a large wave database will require constructing better representative wave loads for the strength and fatigue analysis. The technique presented in this study can be scaled up to accommodate such wider load cases. However, a balance between accuracy in computation and computational resource requirement will play an imperative role in deciding the number of representative wave loads to apply. Also, in this study, the coupled interactions between the fatigue damages during the vessel transition period and the period spent at each station are not considered. This is an interesting problem to consider for future work. 


\section{ACKNOWLEDGEMENTS}

The authors acknowledge the support of the University of Strathclyde and McDermott International for this research. Results in this work were obtained using the ARCHIE-WeST High-Performance Computer (www.archie-west.ac.uk) based at the University of Strathclyde.

\section{REFERENCES}

[1] C. M. Larsen and T. Hanson, "Optimization of catenary risers," 1999.

[2] B. A. Carter and B. F. Ronalds, "Deepwater Riser Technology," in SPE Asia Pacific Oil and Gas Conference and Exhibition, 1998, vol. All Days, SPE-50140-MS, doi: 10.2118/50140-ms. [Online]. Available: https://doi.org/10.2118/50140-MS

[3] S. A. Hatton, "Update on the design of steel catenary riser systems," TRANSACTIONSINSTITUTE OF MARINE ENGINEERS-SERIES C-, vol. 111, pp. 127-138, 1999.

[4] R. Song and P. Stanton, "Advances in Deepwater Steel Catenary Riser Technology State-of-the-Art: Part II-Analysis," in ASME 2009 28th International Conference on Ocean, Offshore and Arctic Engineering, 2009: American Society of Mechanical Engineers Digital Collection, pp. 285-296.

[5] E. Clukey, R. Ghosh, P. Mokarala, and M. Dixon, "Steel catenary riser (SCR) design issues at touch down area," 2007: International Society of Offshore and Polar Engineers.

[6] R. Song and P. Stanton, "Advances in Deepwater Steel Catenary Riser Technology State-of-the-Art: Part I-Design," in International Conference on Offshore Mechanics and Arctic Engineering, 2007, vol. 42673, pp. 331-344.

[7] H. Quintin, J.-L. Legras, K. Huang, and M. Wu, "Steel catenary riser challenges and solutions for deepwater applications," in Offshore technology conference, 2007: Offshore Technology Conference.

[8] J. R. Maison and J. F. Lea, "Sensitivity Analysis Of Parameters Affecting Riser Performance," presented at the Offshore Technology Conference, Houston, Texas, 1977/1/1/, 1977.

[9] L. M. Quéau, M. Kimiaei, and M. F. Randolph, "Sensitivity studies of SCR fatigue damage in the touchdown zone using an efficient simplified framework for stress range evaluation," Ocean Engineering, vol. 96, pp. 295-311, 2015.

[10] P. Cao and J. Cheng, "Design of Steel Lazy Wave Riser for Disconnectable FPSO," in Offshore Technology Conference, 2013, vol. All Days, OTC-24166-MS, doi: 10.4043/24166-ms. [Online]. Available: https://doi.org/10.4043/24166-MS

[11] B. P. Jacob, M. C. Reyes, B. S. de Lima, A. L. Torres, M. M. Mourelle, and R. Silva, "Alternative configurations for steel catenary risers for turret-moored FPSOs," in The Ninth International Offshore and Polar Engineering Conference, 1999: International Society of Offshore and Polar Engineers.

[12] E. Q. De Andrade, L. L. de Aguiar, S. F. Senra, E. F. N. Siqueira, A. L. F. L. Torres, and M. M. Mourelle, "Optimization Procedure of Steel Lazy Wave Riser Configuration for Spread Moored FPSOs in Deepwater Offshore Brazil," in Offshore Technology Conference, 2010, vol. All Days, OTC-20777-MS, doi: 10.4043/20777-ms. [Online]. Available: https://doi.org/10.4043/20777-MS

[13] R. Franciss and E. Ribeiro, "Analyses of a Large Diameter Steel Lazy Wave Riser for Ultra Deepwater in Campos Basin," in ASME 2004 23rd International Conference on Offshore Mechanics and Arctic Engineering, 2004, vol. 23rd International Conference on Offshore Mechanics and Arctic Engineering, Volume 1, Parts A and B, pp. 355-361, 
doi:

10.1115/omae2004-51176.

[Online].

Available:

https://doi.org/10.1115/OMAE2004-51176

[14] A. L. c. F. Lima Torres, E. C. Gonzalez, M. Q. de Siqueira, C. M. Silva Dantas, M. M. Mourelle, and R. M. Correia da Silva, "Lazy-Wave Steel Rigid Risers for TurretMoored FPSO," in ASME 2002 21st International Conference on Offshore Mechanics and Arctic Engineering, 2002, vol. 21st International Conference on Offshore Mechanics and Arctic Engineering, Volume 1, pp. 203-209, doi: 10.1115/omae200228124. [Online]. Available: https://doi.org/10.1115/OMAE2002-28124

[15] L. V. Sudati Sagrilo, E. Castro Prates de Lima, F. J. Mendes de Sousa, C. M. Silva Dantas, M. Q. de Siqueira, and A. L. c. Fernandes Lima Torres, "Steel Lazy Wave Riser Design: API-RP-2RD and DNV-OS-F201 Criteria," in ASME 2005 24th International Conference on Offshore Mechanics and Arctic Engineering, 2005, vol. 24th International Conference on Offshore Mechanics and Arctic Engineering: Volume 1, Parts A and B, pp. 107-113, doi: 10.1115/omae2005-67040. [Online]. Available: https://doi.org/10.1115/OMAE2005-67040

[16] R. Brito, L. Aguiar, and V. Prado, "Technical Feasibility Study of Steel Catenary Risers for Pre-Salt Field Developments," presented at the OTC Brasil, Rio de Janeiro, Brazil, 2017/10/24/, 2017.

[17] J. Murali and M. W. Joosten, "Titanium Drilling Risers-Application and Qualification," 2000.

[18] C. F. Baxter, R. W. Schutz, and C. S. Caldwell, "Experience and Guidance in the Use of Titanium Components in Steel Catenary Riser Systems," in Offshore Technology Conference, 2007, vol. All Days, OTC-18624-MS, doi: 10.4043/18624-ms. [Online]. Available: https://doi.org/10.4043/18624-MS

[19] R. K. Aggarwal et al., "Development and Qualification of Alternative Solutions for Improved Fatigue Performance of Deepwater Steel Catenary Risers," in ASME 2007 26th International Conference on Offshore Mechanics and Arctic Engineering, 2007, vol. Volume 1: Offshore Technology; Special Symposium on Ocean Measurements and Their Influence on Design, pp. 315-329, doi: 10.1115/omae2007-29325. [Online]. Available: https://doi.org/10.1115/OMAE2007-29325

[20] M. Nygård, A. Sele, and K. Lund, "Design of a 25.5-in Titanium Catenary Riser for the Åsgard B Platform," in Offshore Technology Conference, 2000: Offshore Technology Conference.

[21] M. Randolph and P. Quiggin, "Non-linear hysteretic seabed model for catenary pipeline contact," in ASME 2009 28th International Conference on Ocean, Offshore and Arctic Engineering, 2009: American Society of Mechanical Engineers, pp. 145154.

[22] E. Zargar, M. Kimiaei, and M. Randolph, "A new hysteretic seabed model for riser-soil interaction," Marine Structures, vol. 64, pp. 360-378, 2019.

[23] C. P. Aubeny and G. Biscontin, "Seafloor-riser interaction model," International Journal of Geomechanics, vol. 9, no. 3, pp. 133-141, 2009.

[24] F. Jamaludin and J. Koto, "Catenary Offset Buoyant Riser Assembly for Malaysian Deepwater," Science and Engineering, vol. 12, 2017.

[25] D. Karunakaran, H. Aasen, and R. Baarholm, "New Un-coupled Deepwater Riser Concept for Harsh Environment-Catenary Offset Buoyant Riser Assembly (COBRA)," in Deepwater Offshore Technology Conference. New Orleans, USA, 2011, pp. 11-13.

[26] A. Izquierdo et al., "Qualification of Weldable X65 Grade Riser Sections with Upset Ends to Improve Fatigue Performance of Deepwater Steel Catenary Risers," in The Eighteenth International Offshore and Polar Engineering Conference, 2008: International Society of Offshore and Polar Engineers. 
[27] C. E. Haveman, A. R. Cribbs, and J. D. Miller, "Global Benefits and Operational Challenges of Vessel Relocation," in ASME 2015 34th International Conference on Ocean, Offshore and Arctic Engineering: American Society of Mechanical Engineers Digital Collection.

[28] S. Bhat, A. Dutta, J. Wu, and I. Sarkar, "Pragmatic Solutions to Touch-Down Zone Fatigue Challenges in Steel Catenary Risers," in Offshore Technology Conference, 2004: Offshore Technology Conference.

[29] B. Yue, M. Campbell, D. Walters, H. Thompson, and K. Raghavan, "Improved SCR design for dynamic vessel applications," in International Conference on Offshore Mechanics and Arctic Engineering, 2010, vol. 49132, pp. 495-504.

[30] V. Vijayaraghavan et al., "Large diameter steel catenary riser solutions for semisubmersible platforms in offshore Northwest Australia," in Offshore Technology Conference, 2015: Offshore Technology Conference.

[31] A. M. Ogbeifun et al., "Vessel relocation solution for steel catenary riser touch down fatigue management," Ocean Engineering, vol. 237, p. 109632, 2021.

[32] D.-O. Standard, "F201, 2010," Dynamic Risers. DNV: Norway.

[33] D. N. Veritas, "Recommended practice DNV-C203: Fatigue design of offshore steel structures," ed: DNV Oslo, 2010.

[34] D. Heffernan, "An introduction to the Python interface to OrcaFlex," Orcina, Tech. Rep2016, 2016.

[35] D. N. Veritas, "Offshore standard dnv-os-f101," Submarine pipeline systems, 2010.

[36] M. Matsuishi and T. Endo, "Fatigue of metals subjected to varying stress," Japan Society of Mechanical Engineers, Fukuoka, Japan, vol. 68, no. 2, pp. 37-40, 1968. 